Aus der Abteilung Zelluläre und Molekulare Immunologie

(Prof. Dr. rer. nat. J. Wienands)

im Zentrum Hygiene und Humangenetik

der Medizinischen Fakultät der Universität Göttingen

\title{
Untersuchung zur Funktion von Cathepsin B in der durch zytotoxische T-Zellen vermittelten Lyse von Tumorzellen
}

\author{
INAUGURAL-DISSERTATION \\ zur \\ Erlangung des Doktorgrades \\ der Medizinischen Fakultät der \\ Georg-August-Universität zu Göttingen
}

vorgelegt von

Miriam Ensslen

aus

Offenbach am Main

Göttingen 2009 
Dekan: Prof. Dr. med. C. Frömmel

I. Berichterstatter: PD Dr. med. R. Dressel

II. Berichterstatter/in:

III. Berichterstatter/in:

Tag der mündlichen Prüfung: 


\section{Abkürzungsverzeichnis}

aa

Aminosäure

APC

antigenpräsentierende Zelle

APS

Ammoniumpersulfat

BAGE

B-Antigen

BSA

bovines Serumalbumin

ca.

CA-074

circa

[L-3-trans-(Propylcarbamoyl)oxirane-2carbonyl]-L-isoleucyl-L-proline

CA-074 Me

[L-3-trans-(Propylcarbamoyl)oxirane-2carbonyl]-L-isoleucyl-L-proline-MethylEster

CathB -/-

Cathepsin B knock-out

CathB Wt

Cathepsin-B-Wildtyp

CD

cluster of differentiation

$\mathrm{cm}$

Zentimeter

$\mathrm{CO}_{2}$

Kohlendioxid

Con A

Concanavalin A

cpm

counts per minute

CTL

zytotoxische T-Lymphozyten

DAB

Diaminobenzidin

dest.

destilliert

DMEM

Dulbecco`s modifiziertes Eagle

Medium

DMSO

Dimethylsulfoxid

EDTA

Ethylendiamintetraessigsäure

EGTA

Ethylenglycol bis(2-aminoethylether)-

N,N,N',N'-tetraessigsäure

FACS

Fluorescence activated cell sorting

FasL

Fas-Ligand

FCS

fetales Kälberserum

FGF-2

Fibroblasten-Wachstumsfaktor 2 
g

GAGE

gp

Gy

h

Hepes

Her-2/neu

HRP

IFN- $\gamma$

$\lg$

IL

$\mathrm{Kb}$

$\mathrm{kDa}$

I

M

$\mathrm{mA}$

MAGE

MEF

$\mu \mathrm{g}$

$\mathrm{mg}$

MHC

$\mathrm{mlg}_{2 a}$

$\min$

$\mu l$

$\mathrm{ml}$

$\mu \mathrm{M}$

$\mathrm{mM}$

$\mathrm{mm}$

MPR
Gramm

G-Antigen

Glykoprotein

Gray

Stunde

2-(4-(2-Hydroxyethyl)- 1-piperazinyl)-

ethansulfonsäure

Human epidermal growth factor

receptor-2

Meerrettichperoxidase

Interferon-gamma

Immunglobulin

Interleukin

Kilobasenpaar

Kilodalton

Liter

Molar

Milliampere

Melanozyten-Antigen

embryonale Mäusefibroblasten

Mikrogramm

Milligramm

Haupthistokompatibilitätskomplex

Maus-Immunglobulin $\mathrm{G}_{2 a}$

Minute

Mikroliter

Milliliter

Mikromolar

Millimolar

Millimeter

Mannose-6-Phosphat-Rezeptor 
mRNA

$\mathrm{ng}$

$\mathrm{nM}$

PBS

PDGF

$\mathrm{pH}$

RAG-2

rm IFN- $\gamma$

rm IL-2

RNA

RPE

SDA

STAT-1

TCR

TEMED

TGF- $\beta$

TNF

TNF-R

TNF- $\alpha$

Tris

Tween

U

$\times g$

z. B.

Z-Phe-Arg-AMC messenger RNA

Nanogramm

Nanomolar

Phosphat-gepufferte Salzlösung

platelet-derived growth factor

(pondus oder) potentia Hydrogenii

Recombination activating gene 2

rekombinantes murines IFN- $\gamma$

rekombinantes murines IL-2

Ribonukleinsäure

rotes Phycoerythrin

Natriumdodecylsulfat

Signal transducers and activators of transcription 1

T-Zell-Rezeptor

$\mathrm{N}, \mathrm{N}, \mathrm{N}^{\prime}, \mathrm{N}^{\prime}$-Tetramethylethylendiamin

transforming growth factor-beta

Tumor-Nekrose-Faktor

Tumor-Nekrose-Faktor-Rezeptor

Tumor-Nekrose-Faktor-alpha

Tris(hydroxymethyl)-aminomethan

Polyoxyethylen(20)-sorbitan-

monolaurat

Units

Erdbeschleunigung

zum Beispiel

Benzyloxycarbonyl-phenylalanyl-

Arginin-7-amido-4-methyl-coumarin 


\section{Inhaltsverzeichnis}

1. Einleitung

S. 1

1.1. Zytotoxische T-Lymphozyten und ihre Effektormechanismen

S. 1

1.1.1 Zytotoxische T-Lymphozyten

S. 1

1.1.2 Die MHC-Moleküle

S. 2

1.1.3 Aktivierung der zytotoxischen T-Lymphozyten

S. 2

1.1.4 Effektormechanismen der zytotoxischen T-Lymphozyten

S. 4

1.2 Protektionsmechanismen der zytotoxischen T-Lymphozyten

S. 5

1.3 Lysosomale Cystein-Proteasen und Cathepsin B

S. 6

1.3.1 Lysosomale Cystein-Proteasen

S. 6

1.3.2 Cathepsine

S. 7

1.3.3 Cathepsin B

S. 7

1.3.4 Cathepsin B und Krebs

S. 8

1.4 Tumore und das Immunsystem

S. 11

1.5 "Immune escape"-Mechanismen

S. 12

$1.6 \quad$ Fragestellung

S. 14

2. Materialien und Methoden

S. 15

$2.1 \quad$ Materialien

S. 15

2.1.1 Chemikalien und Reagenzien

S. 15

2.1.2 Nährmedien

S. 16

2.1.3 Puffer und Stammlösungen

S. 17

2.1.4 Gele

S. 19

2.1.5 Verwendete Geräte

S. 20

2.1.6 Antikörper

S. 21

2.1.6.1 Primäre Antikörper

S. 21

2.1.6.2 Sekundäre Anitkörper und Isotypenkontrolle

S. 21

2.1.7 Proteinmarker

S. 22 
2.1.8 Inhibitoren

S. 22

2.1.9 Zytokine

S. 22

2.1.10 Einwegartikel

S. 22

2.1.11 Zelllinien

S. 23

2.1.12 Versuchstiere

S. 23

2.1.13 Computeranalyse

S. 24

2.1.14 Herstellerliste

S. 25

$2.2 \quad$ Methoden

S. 26

2.2.1 Zellkulturmethoden

S. 26

2.2.1.1 Allgemeines zu der Arbeit mit Zellkulturen

S. 26

2.2.1.2 Kultivierung adhärenter Zellen

S. 26

2.2.1.3 Kultivierung nicht-adhärenter Zellen

S. 27

2.2.1.4 Einfrieren und Auftauen von Zellen

S. 27

2.2.1.5 Bestimmung der Zellzahl

S. 28

2.2.1.6 Isolation von Lymphozyten aus Mäusemilzen

S. 28

2.2.1.7 Gewinnung von Concanavalin-A-Überstand

S. 29

2.2.1.8 Stimulation zytotoxischer T-Lymphozyten

S. 30

2.2.1.9 Restimulation zytotoxischer T-Lymphozyten

S. 30

2.2.2 Zytotoxizitätstest

S. 31

2.2.2.1 Allgemeines zu der Arbeit mit radioaktiven Stoffen

S. 31

2.2.2.2 Der ${ }^{51}$ Chrom-Freisetzungs-Test

S. 31

2.2.2.3 Durchführung des ${ }^{51}$ Chrom-Freisetzungs-Tests

S. 31

2.2.2.4 ${ }^{51}$ Chrom-Freisetzungs-Test mit Inhibitor

S. 35

2.2.2.5 ${ }^{51}$ Chrom-Freisetzungs-Test mit Zugabe von Cathepsin-B-

S. 36 Inhibitoren zu den Zielzellen

2.2.2.6 ${ }^{51}$ Chrom-Freisetzungs-Test mit Zugabe von Inhibitor zu den

S. 36 Effektorzellen

2.2.2.7 ${ }^{51}$ Chrom-Freisetzungs-Test mit MEF

S. 37

2.2.3 Durchflusszytometrie

S. $\quad 37$

2.2.3.1 Allgemeines zur Durchflusszytometrie

S. $\quad 37$ 
2.2.3.2 Bestimmung der MHC-Klasse-I-Expression auf MEF-

S. $\quad 38$

Zellen mittels Durchflusszytometrie

2.2.4 Westernblot-Analyse

S. $\quad 39$

2.2.4.1 Allgemeines zur Westernblot-Analyse

S. 39

2.2.4.2 Erstellen von Zell-Lysaten für den Westernblot

S. 39

2.2.4.3 SDS-Polyacrylamid-Gelelektrophorese

S. 40

2.2.4.4 Der Westernblot

S. 41

2.2.4.5 Immunfärbung der transferierten Proteine

S. 41

2.2.5 Statistische Analyse

S. 42

3. Ergebnisse

S. 44

3.1 Einfluss des zellmembranimpermeablen Cathepsin-B-

S. 44 Inhibitors CA-074 auf die Lyse von Tumorzellen durch CTL

3.1.1 Signifikante Verbesserung der durch CTL induzierten Lyse

S. 44 von Tumorzellen durch den zellmembranimpermeablen Cathepsin-B-Inhibitor CA-074

3.1.2 Bestimmung der relativen Lyse

S. 47

3.2 Einfluss des zellmembranpermeablen Cathepsin-B-Inhibitors CA-074 Me auf die Lyse von Tumorzellen durch CTL

S. 48

3.2.1 Tendenziell verbesserte Lyse von RMA-Tumorzellen durch

S. 49 den zellmembranpermeablen Cathepsin-B-Inhibitor CA-074 Me

3.2.2 Bestimmung der relativen Lyse

S. 51

3.3. Einfluss der ausschließlichen Inhibition des Tumorzell-

S. 52 assoziierten Cathepsin B auf die Lyse durch CTL

3.3.1 Bei ausschließlicher Inhibition des Tumorzell-assoziierten Cathepsin B wird die Lysibilität durch CTL nicht wesentlich verbessert

3.3.2 Bestimmung der relativen Lyse

S. 55

3.4 Vergleich der Lyse von Cathepsin-B-defizienten und WildtypZielzellen durch CTL

S. 56

3.4.1 Cathepsin-B- knock-out- und Cathepsin-B-Wildtyp-MEF

S. 56 
3.4.3 Erhöhung der MHC-Klasse-I-Expression auf MEF nach Stimulation mit Interferon- $\gamma$

S. $\quad 57$

3.4.4 Signifikant verbesserte Lyse von Cathepsin-B-defizienten

S. 59 Zellen im Vergleich zu Wildtyp-Zellen

3.5 Einfluss der Cathepsin-B-Inhibition in CTL auf die Lyse von Tumorzellen

S. 61

3.5.1 Inhibition des Cathepsin B von CTL beeinflusst die Lyse von Tumorzellen nicht

S. 61

4. Diskussion

S. 64

5. Zusammenfassung

S. $\quad 76$

6. Literaturverzeichnis

S. $\quad 78$ 


\section{Einleitung}

\subsection{Zytotoxische T-Lymphozyten und ihre Effektormechanismen}

\subsubsection{Zytotoxische T-Lymphozyten}

Zytotoxische T-Lymphozyten (CTL) sind wichtige Effektorzellen bei der Immunabwehr von Viren, intrazellulären Bakterien und Tumoren (Russell and Ley 2002). Nach antigenspezifischer Erkennung der Zielzelle sezernieren sie ihre zytotoxischen Granula in die so genannte immunologische Synapse und induzieren so den Tod der Zielzelle (Grakoui et al. 1999).

Wie bei anderen T-Lymphozyten findet die Differenzierung der CTL im Thymus statt. Dort erwerben sie ihren spezifischen T-Zell-Rezeptor (TCR). Bei 95\% der T-Lymphozyten ist der TCR aus einer $\alpha$ - und einer $\beta$-Kette zusammengesetzt. Bei den restlichen T-Zellen besteht er aus einer $\gamma$ - und einer $\delta$-Kette. Die $\alpha \beta$-TZellen sind für die meisten T-Zell-vermittelten Immunantworten verantwortlich. Über die Funktion der $\gamma \delta$-T-Zellen ist sehr viel weniger bekannt. Sie befinden sich vor allem in den Epithelien der Epidermis und des Dünndarms (Marrack and Kappler 1987).

Der TCR ist mit dem Proteinkomplex CD3 assoziiert, welcher für die Signaltransduktion verantwortlich ist. Die CTL tragen das CD8-Molekül auf der Oberfläche, welches als Co-Rezeptor an den MHC-Klasse-I-Komplex bindet. Andere Oberflächenmoleküle der CTL (z.B. CD2, CD28) spielen eine wichtige Rolle bei der Aktivierung der CTL nach Antigenerkennung durch den TCR. CTL sind außerstande, freie Antigene zu erkennen, diese müssen innen von MHCMolekülen auf anderen Zellen präsentiert werden (Groscurth and Filgueira 1998). 


\subsubsection{Die MHC-Moleküle}

Die MHC-Moleküle binden fremde oder zelleigene Peptide und präsentieren sie den T-Lymphozyten (Maffei et al. 1997). Man unterscheidet zwei Klassen von MHC-Molekülen: MHC-Klasse-I-Moleküle und MHC-Klasse-II-Moleküle. Beides sind Transmembran-Moleküle, welche von Ribosomen am rauen endoplasmatischen Retikulum synthetisiert werden (Kvist et al. 1982). MHCKlasse-I-Moleküle werden von praktisch allen Zellen exprimiert. Sie präsentieren zelleigene Peptide. Dies ermöglicht den CTL zu überprüfen, ob die Zellen mit Viren infiziert sind oder ob sie veränderte Proteine exprimieren, wie es zum Beispiel in Tumorzellen der Fall sein kann. Die MHC-Klasse-II-Moleküle befinden sich an der Oberfläche von professionellen antigenpräsentierenden Zellen (APC), zu diesen zählen zum Beispiel die dendritischen Zellen. Die APC präsentieren den CTL ursprünglich extrazelluläre Peptide, die zum Beispiel über Endozytose in die Zelle aufgenommen worden sind (Ackerman and Cresswell 2004).

\subsubsection{Aktivierung der zytotoxischen T-Lymphozyten}

Die Zerstörung von Zielzellen setzt eine antigenspezifische Aktivierung der CTL voraus. Dies geschieht durch Interaktionen der CTL mit dem MHC-Klasse-IKomplex auf der das Antigen präsentierenden Zelle. Für die Aktivierung ist zunächst eine antigenspezifische Interaktion zwischen peptidbeladenem MHCKlasse-I-Molekül und dem TCR notwendig. Diese Interaktion wird durch den CD8-Co-Rezeptor stabilisiert (Jones et al. 1998). Für die Aktivierung sind noch co-stimulatorische Signale nötig. Diese werden zum Beispiel durch die Interaktion des CD28 auf den T-Zellen mit einem Molekül der B7-Familie auf den antigenpräsentierenden Zellen ausgelöst (Lenschow et al. 1996).

Auch Tumorzellen präsentieren veränderte Proteine, die als Antigen fungieren können. Diese so genannten Tumorantigene werden in den Tumorzellen vermehrt oder ausschließlich exprimiert und den CTL auch auf den MHC- 
Klasse-I-Molekülen präsentiert. Diese Tumorantigene können in verschiedene Gruppen eingeteilt werden. Dies sind:

1. Tumorspezifische Antigene, wie Melanozyten-Antigen (MAGE), GAntigen (GAGE) und B-Antigen (BAGE). Dies sind Antigene, die von vielen verschiedenen Tumoren exprimiert werden. Sie werden sonst im gesunden Gewebe nur in Zellen des Hodens und der Plazenta exprimiert.

2. Differenzierungsantigene sind nur in bestimmten Zelltypen exprimiert. Für Melanomzellen wurden verschiedene Differenzierungsantigene beschrieben, wie zum Beispiel Melan-A/Mart-1, gp100 und gp75.

3. Tumorspezifische Antigene, welche durch Punktmutationen in den einzelnen Tumoren entstehen.

4. Überexpression ubiquitärer Antigene, wie zum Beispiel Her-2/neu.

5. Virale Antigene, bei virusinduzierten Tumoren, wie zum Beispiel das humane Pappilomavirus.

(Boon and van der Bruggen 1996; Boon et al. 1994).

Den CTL müssen diese Antigene präsentiert werden, damit sie aktiviert werden. Ein Weg ist, dass die Tumorzelle in die sekundären lymphatischen Organe migriert und dort den CTL direkt das Antigen über die MHC-Klasse-I-Moleküle präsentiert (Ochsenbein 2005). Dies ist jedoch eher sehr selten der Fall, da die meisten Tumorzellen nicht die notwendigen co-stimulatorischen Moleküle haben.

Antigenpräsentierende Zellen nehmen in der Peripherie Tumorzellbestandteile von zugrunde gegangenen Tumorzellen auf und prozessieren diese. Die APC wandern dann zu den Lymphknoten und präsentieren dort über ihre MHCKlasse-II-Moleküle diese Antigene und aktivieren so T-Helferzellen, welche dann durch Sekretion von Zytokinen zur Aktivierung von CTL beitragen können (Schirrmacher et al. 1993).

Eine Möglichkeit, wie den CTL Tumor-Antigene präsentiert werden, ist die so genannte Kreuzpräsentation. Dies erlaubt den dendritischen Zellen, exogene 
Antigene, die normalerweise über MHC-Klasse-II-Moleküle präsentiert werden, über MHC-Klasse-I-Moleküle zu präsentieren und so die CTL zu aktivieren (Ackerman and Cresswell 2004).

\subsubsection{Effektormechanismen der zytotoxischen T-Lymphozyten}

CTL können infizierte oder transformierte Zellen über mindestens zwei unterschiedliche Mechanismen töten. Zum einen durch Exozytose von zytotoxischen Granula, zum anderen über die Aktivierung von so genannten Todesrezeptoren (Henkart 1994; Lowin et al. 1994).

Im letzteren Fall führt die Aktivierung des TCR zur Expression von Todesrezeptorliganden der Tumor-Nekrose-Faktor (TNF) Superfamilie (wie zum Beispiel dem Fas-Liganden (FasL)), welche zu einer Quervernetzung der Todesrezeptoren auf den Zielzellen führt und dadurch den Zelltod einleitet (Hanabuchi et al. 1994; Henkart 1994). Die Aktivierung von so genannten Todesrezeptoren aktiviert in den Zellen Caspasen und leitet so die Apoptose ein (Nagata and Golstein 1995). Der andere Weg ist der Granula-ExozytoseWeg. Dabei werden zytotoxische Granula durch die Effektorzellen sezerniert, welche Perforin und Granzyme enthalten. Von den Granzymen ist Granzym B das bekannteste. Es führt in der Zelle zu einer Aktivierung von Caspasen, welche dann zur Apoptose der Zelle führen (Lord et al. 2003).

Es wird aber auch auf eine von Caspasen unabhängige Weise der Zelltod eingeleitet (Sarin et al. 1997).

Auch dem Perforin wird eine entscheidende Rolle bei dem durch Granula vermittelten Zelltod durch CTL zugeschrieben. Perforin-defiziente Mäuse sind in vitro nicht fähig, virusinfizierte Zellen zu lysieren oder transformierte Zellen zu zerstören (Kagi et al. 1994). Außerdem entwickeln diese Mäuse häufiger spontane Lymphome (Smyth et al. 2000). Trotz intensiver Forschungen ist der genaue Wirkmechanismus des Perforins immer noch nicht bekannt. Nach der Aktivierung der CTL durch die Zielzelle kommt es zu einer Degranulation, bei der Perforin und die anderen Komponenten der zytotoxischen Granula 
freigesetzt werden. In der Zielzelle können dann Transmembrankanäle durch Perforin gebildet werden und dadurch kommt es zu einem Verlust der Plasmamembranstabilität und osmotischer Lyse (Trapani 1998). Lange nahm man an, dass die durch das Perforin geformten Poren dem Granzym als Eintrittspforte in die Zelle dienen (Young et al. 1986). Diese Hypothese wird aber kontrovers diskutiert. Perforin kann Granzym B auch dann in Zielzellen einschleusen, wenn es in sublytischen Konzentrationen vorliegt, die nicht ausreichen, um Poren zu bilden. Eine aktuelle Hypothese ist, dass Granzym über einen spezifischen Rezeptor in die Zelle eingeschleust wird und Perforin dann für die Freisetzung des Granzyms aus dem Endosom in das Cytosol dient (Froelich et al. 1996). Zunächst gab es Hinweise dafür, dass der Mannose-6Phosphat-Rezeptor 300 (MPR 300) auf den Zielzellen an der Aufnahme des Granzym B beteiligt ist (Motyka et al. 2000). Versuche mit Zellen, die defizient für den MPR 300 waren, zeigten, dass der MPR 300 nicht für die Granzym-Binduzierte Apoptose in Zielzellen notwendig ist (Dressel et al. 2004).

\subsection{Protektionsmechanismen der zytotoxischen T-Lymphozyten}

Wie sich die CTL vor ihren eigenen zytotoxischen Mechanismen schützen, war schon länger Gegenstand der Forschung. Zunächst nahm man an, dass die CTL eine angeborene Resistenz gegenüber den zytotoxischen Mediatoren hätten, vor allem gegenüber Perforin. Diese These wurde unter anderem durch Experimente mit CTL gestützt, die Oberflächenantigene hatten, die von anderen CTL erkannt wurden. Diese wurden, verglichen mit einer Tumorzellpopulation, von den CTL wesentlich weniger lysiert (Blakely et al. 1987; Kranz and Eisen 1987; Luciani et al. 1986). Ebenso wurde gezeigt, dass CTL relativ resistent sowohl gegenüber Lyse durch Granula als auch gegen gereinigtes Perforin waren (Blakely et al. 1987; Liu CC et al. 1989; Muller and Tschopp 1994; Verret et al. 1987). Die genaue molekulare Basis für diese Resistenz blieb aber noch ungeklärt. 
Eine Studie von Jiang et al. (1990) deutete an, dass die Ursache dafür, dass Perforin nicht die CTL selbst lysiert, einem Molekül auf der Oberfläche der CTL zu verdanken ist, welches die Bindungsfähigkeit des Perforin an die Oberfläche verringert und somit die Porenbildung durch Perforin verhindert. Eine andere Studie zeigte dagegen, dass das Perforin zwar von den CTL in gleichem Maße gebunden wird wie von den Tumorzellen, aber das membrangebundene Perforin der CTL eine andere Konformation hat, was zu einer verminderten Lysibilität führt (Muller and Tschopp 1994).

Im Jahr 2002 sprach eine Arbeitsgruppe um Henkart (Balaji et al. 2002) der Protease Cathepsin B eine entscheidende Rolle bei der Selbstprotektion von CTL vor ihren eigenen Perforinen zu. Sie zeigten, dass es durch eine Inhibition von Cathepsin B zu einer erhöhten Lyse von CTL kam, wenn diese zur Degranulation angeregt wurden. Dies wurde aber nicht bei T-Zellen beobachtet, die den Granula-Exozytose-Weg nicht aufwiesen oder defizient für Perforin waren. Weiterhin konnte gezeigt werden, dass Cathepsin B auf den CTL nur in sehr geringem Maße exprimiert wird, wenn sich diese Zellen im Ruhezustand befinden. Nach der Aktivierung des TCR konnte aber ein starker Anstieg des messbaren Cathepsin B auf der Oberfläche der CTL nachgewiesen werden.

\subsection{Lysosomale Cystein-Proteasen und Cathepsin B}

\subsubsection{Lysosomale Cystein-Proteasen}

Proteasen katalysieren die Spaltung von Peptidbindungen zwischen einzelnen Aminosäuren. Cathepsin B gehört zu der Gruppe der lysosomalen CysteinProteasen und innerhalb dieser zu der Papain-Familie (Kirschke et al. 1995). Cystein-Proteasen werden in 59 Familien mit vielen Subfamilien unterteilt, zu denen auch die Papain-Superfamilie gehört. Papain, der Namensgeber dieser Gruppe, wurde aus dem Latex des Melonenbaums isoliert (McGrath 1999). Ursprünglich wurde den lysosomalen Cystein-Proteasen als Hauptfunktion die Degradation von Proteinen im lysosomalen System zugesprochen (Kirschke et al. 1995; Mort and Buttle 1997). 


\subsubsection{Cathepsine}

Der Begriff Cathepsine steht für "lysosomale proteolytische Enzyme“, egal welcher Enzymklasse sie angehören. Cathepsin A und $G$ sind zum Beispiel Serin-Proteasen, während Cathepsin D und E den Aspartat-Proteasen zugeordnet werden (Buhling et al. 2004). Heute weiß man, dass die lysosomalen Cystein-Proteasen neben dem intrazellulären Proteinumsatz an einer Reihe weiterer wichtiger zellulärer Funktionen beteiligt sind, wie zum Beispiel dem Abbau von Komponenten der extrazellulären Matrix, der Aktivierung von Vorläuferproteinen, der Verarbeitung der invarianten Ketten der MHC-Klasse-II-Moleküle und bei der Knochenresorption durch Osteoklasten (Reinheckel et al. 2001; Turk BE et al. 2001).

\subsubsection{Cathepsin B}

Cathepsin B wird bei Säugern in den meisten Geweben und Organen exprimiert. Es ist überwiegend in den lysosomalen/endosomalen Kompartimenten lokalisiert (Werle et al. 1994). Das Gen des Cathepsin B liegt in einer einzigen Kopie im Genom vor. Es wurde auf dem kurzen Arm des Chromosoms 8 lokalisiert (8p22) (Fong et al. 1992). Es umfasst mehr als 27 Kilobasen im humanen Genom (Berquin et al. 1995).

Cathepsin B wird als Präproenzym am rauen Endoplasmatischen Retikulum synthetisiert. Dort wird die Signalsequenz co-translational abgespalten und das dann so genannte Procathepsin B zum Golgi-Apparat transportiert, dort weiter modifiziert und an den Mannose-6-Phosphat-Rezeptor gebunden. Durch diesen wird das Enzym zum prälysosomalen Kompartiment (z.B. späte Endosome) weitergeleitet, in dem es zu der Abspaltung der Pro-Region und des Rezeptors kommt. Daraufhin wird das Enzym zu den Lysosomen transportiert (Mort and Buttle 1997). Durch die Abspaltung der Pro-Region des Cathepsin B konvertiert das Enzym zu seiner einkettigen aktiven Form mit einer Molekülmasse von 31$\mathrm{kDa}$ und wird sodann zu den Lysosomen transportiert. In den Lysosomen wird 
das Cathepsin B weiter zu seiner doppelkettigen Form prozessiert, welche aus einer 25- bis 26-kDa schweren Kette und einer 5-kDa leichten Kette besteht (Nishimura et al. 1988; Rowan et al. 1992).

Unter normalen Bedingungen sind die Cathepsin-B-haltigen Lysosomen in der perinukleären Region lokalisiert. Für humane Hautfibroblasten und humane Leberzellen wurde nachgewiesen, dass sie $5-10 \%$ des Procathepsin B sezernieren (Hanewinkel et al. 1987; Mach et al. 1992). Reguliert wird die Aktivität des Cathepsin B vor allem durch ihre endogenen Inhibitoren, die Cystatine (Turk V and Bode 1991).

Ursprünglich nahm man an, dass die Hauptfunktion des Cathepsin B in der Degradation von Proteinen liegt, die entweder von extrazellulär oder aus einem anderen Zellkompartiment in die Lysosomen eingedrungen sind (Mort and Buttle 1997). In den letzten Jahren wurde immer deutlicher, dass Cathepsin B noch in viele weitere Prozesse involviert ist, wie zum Beispiel an der Proteolyse des Thyreoglobulins im Rahmen der Freisetzung der Schilddrüsenhormone (Brix et al. 2001). Aber auch in vielen pathologischen Prozessen spielt Cathepsin B eine Rolle. So scheint Cathepsin B an der Gelenkzerstörung im Rahmen der Rheumatoiden Arthritis beteiligt zu sein. Es wurde gezeigt, dass besonders in Bereichen, in denen die Gelenksynovia dem geschädigten Knorpel und Knochen anliegen, die Cathepsin-B-Transkription in den Synoviazellen, verglichen mit normalen Fibroblasten, erhöht ist (Trabandt et al. 1991). Auch beim Abbau des Gelenkknorpels im Rahmen der Osteoarthritis scheint Cathepsin B mitbeteiligt zu sein (Lang et al. 2000). Weiterhin wird Cathepsin B in Zusammenhang mit entzündlichen Atemwegserkrankungen (Burnett et al. 1995) und der Alzheimer Krankheit gebracht, bei der es eine der entscheidenden Beta-Sekretasen zu sein scheint (Hook et al. 2008).

\subsubsection{Cathepsin B und Krebs}

Immer deutlicher wird die Rolle von Cathepsin B bei der Tumorentwicklung und Invasivität von malignen Zellen. Zahlreiche Studien haben eine Assoziation von 
Cathepsin B mit bösartigen Tumoren gezeigt (Poole et al. 1978; Sloane et al. 1981):

1. Eine erhöhte Menge an Cathepsin B mRNA wurde in kolorektalen Karzinomen (Murnane et al. 1991), Prostata-Tumoren (Sinha et al. 1993), Gliomen (Rempel et al. 1994; Sivaparvathi et al. 1995) und Melanomen (Frohlich et al. 2001) nachgewiesen.

2. Ein erhöhte Menge des Cathepsin-B-Proteins und eine erhöhte EnzymAktivität wurde für Brust- (Krepela et al. 1989), Kolon- (Campo et al. 1994; Emmert-Buck et al. 1994), Ösophagus- (Hughes et al. 1998) und Magentumore (Liu Y et al. 1998) beschrieben.

3. Ein Zusammenhang zwischen Cathepsin B und Invasivität von Tumorzellen wurde für humane Osteosarkomzellen gezeigt. Eine Inhibition von Cathepsin B führte zu einer verminderten Invasivität der Tumorzellen (Krueger et al. 1999).

4. Es wurde für murine Melanome eine positive Korrelation zwischen Metastasierungspotenzial und Cathepsin-B-Aktivität gezeigt (Qian et al. 1989; Sloane et al. 1981).

5. Ein Zusammenhang zwischen erhöhter Cathepsin-B-Expression und einer verkürzten Lebenszeit konnte für Kolon- (Campo et al. 1994) und Ovarialkarzinome (Scorilas et al. 2002) gezeigt werden.

Dabei ist das Cathepsin B nicht immer in allen Zellen des malignen Tumors in gleichem Maße erhöht, sondern besonders in den invasiven Abschnitten des Tumors, in denen der Tumor Kontakt mit der extrazellulären Matrix hat (Demchik et al. 1999; Sinha et al. 1993).

Die Expression von Cathepsin B wird über verschiedene Mechanismen reguliert: angefangen bei der Gen-Amplifikation, beim Einsatz alternativer Promotoren, bei erhöhter Transkription, alternativem Splicen, bis zur erhöhten Stabilität der mRNA und des Proteins. Während des Übergangs zur Malignität ereignet sich ein Wechsel der Lokalisation des Cathepsin B. Im Gegensatz zu den nicht transformierten Zellen, bei denen Cathepsin B vor allem im 
perinukleären Raum lokalisiert ist, findet sich bei Tumorzellen Cathepsin B zusätzlich sowohl in Vesikeln, die sich im peripheren Zytoplasma befinden, als auch auf der Membran der Tumorzellen (Roshy et al. 2003).

Studien an Melanomzellen haben gezeigt, dass ein leicht saures Milieu $(\mathrm{pH}-$ Wert 6,5) dazu führt, dass Cathepsin-B-haltige Vesikel zur Zellperipherie migrieren und es zu einer erhöhten Sekretion von Cathepsin B kommt (Rozhin et al. 1994). Zudem führt eine Reduktion des zytoplasmatischen pH-Wertes zu einer Migration von Lysosomen zur Zelloberfläche (Heuser 1989).

Außerdem wurde die Sekretion von Procathepsin B (Achkar et al. 1990; Recklies et al. 1982) und reifem Cathepsin B (Linebaugh et al. 1999) nachgewiesen. Der genaue Mechanismus, wie das Cathepsin B sezerniert wird, ist noch immer nicht bekannt. Procathepsin B wird über einen konstitutiven Weg sezerniert, aktives Cathepsin B dagegen über einen induzierbaren Weg. Ursächlich für die Sekretion von Procathepsin B könnte ein Defekt im normalen Zielweg der Lysosomen sein. Der normale Weg, wie Enzyme zu den Lysosomen geleitet werden, invovlviert den MPR, entweder den 300-kDaKationen-unabhängigen MPR oder den 46-kDa-Kationen-abhängigen MPR (Roshy et al. 2003). So sezerniert zum Beispiel eine hoch invasive Form des Plattenepithelkarzinoms, welche defizient für den 300-kDa-MPR ist, eine große Menge an neu synthetisiertem Procathepsin B (Lorenzo et al. 2000).

Für das reife Cathepsin B nimmt man an, dass es zwei verschiedene Mechanismen gibt:

1. Cathepsin B wird intrazellulär prozessiert, zu den Lysosomen transportiert und dann in seiner aktiven Form sezerniert.

2. Cathepsin B wird an der Zelloberfläche prozessiert und aktiviert und dann freigesetzt (Cavallo-Medved and Sloane 2003).

Die Sekretion von aktivem Cathepsin B kann selektiv und nicht-selektiv induziert werden. Wie es genau zu einer selektiven Erhöhung der Cathepsin-BSekretion kommt, ist bisher nicht verstanden. Verschiedene Zytokine können selektiv die Sekretion von lysosomalen Proteasen in Fibroblasten induzieren. Tumor-Nekrose-Faktor-alpha (TNF- $\alpha)$ und der Blutplättchen-Wachstumsfaktor 
PDGF erhöhen die Sekretion von Cathepsin B, während der Fibroblastenwachstumsfaktor 2 (FGF-2) die Sekretion von Cathepsin L erhöht. Interferon-gamma (IFN- $\gamma$ ) erhöht die Sekretion von Cathepsin B und Cathepsin L (Lemaire et al. 1997).

Auch wie Cathepsin B an die Oberfläche von Zellen bindet, ist noch nicht vollständig verstanden. Durch Isolation und Charakterisierung von membranassoziiertem Cathepsin B hat man gezeigt, dass es keine Transmembrandomäne hat und somit kein integrales Membranprotein ist (Cao et al. 1994; Moin et al. 1992). Es wurden mehrere mögliche Bindungspartner für Cathepsin B entdeckt. Es wurde gezeigt, dass Cathepsin B alpha-2Makroglobulin und seinen Rezeptor auf Tumorzellen bindet (Arkona and Wiederanders 1996). Auch das Annexin-II-Tetramer wird als möglicher Bindungspartner für Procathepsin B auf der Tumorzelloberfläche in Betracht gezogen (Mai et al. 2000).

\subsection{Tumore und das Immunsystem}

Burnet (1970) und Thomas (1982) befassten sich mit der Kontrolle von Tumoren durch das Immunsystem und postulierten die KrebsImmunüberwachungs-Hypothese ("Immunosurveillance“-Hypothese). Sie nahmen an, dass im Körper während des Lebens immer wieder Zellen transformieren und entarten, diese Zellen aber eine Immunantwort hervorrufen, die in der Regel zu einer Regression des Tumors führen. Beide sahen die Lymphozyten als die entscheidenden Effektorzellen bei der Wiedererkennung und Elimination der ständig entstehenden transformierten Zellen.

Unterstützung fand diese Hypothese durch Experimente mit Mäusen, die an einem Immundefekt leiden. So zeigten zum Beispiel immundefiziente Mäuse, bei denen RAG-2 (defizient für T-, B- und Natürliche Killerzellen (NK)) oder STAT-1 (insensitiv für IFN- $\gamma$ und IFN- $\alpha / \beta$ ) ausgeschaltet waren, eine erhöhte Rate an durch Karzinogene induzierten Sarkomen und spontanen Tumoren (Shankaran et al. 2001). 
Dunn et al. (2002) prägten den Begriff des "Immunoediting". Es wurde beobachtet, dass Tumore, die in immunsupprimierten Mäusen entstanden waren und in immunkompetente Mäuse transplantiert wurden, besser von diesen Mäusen abgewehrt wurden als Tumore, die in immunkompetenten Mäusen entstanden waren und auf andere immunkompetente Mäuse transplantiert wurden. Daraus schloss man, dass das Immunsystem nicht nur die Tumorzellen abwehrt, sondern diese auch beeinflusst, indem die Angriffe des Immunsystems die Tumorzellen dazu bringen, Mechanismen zu entwickeln, um diesen Angriffen zu entgehen. Die Autoren teilen diesen Prozess in 3 Phasen ein:

1. Die Eliminierung: Diese erfolgt nach dem zuvor beschriebenen System der Immunüberwachung (Immunosurveillance). Die Tumorzellen führen zu einer Aktivierung des Immunsystems und können zunächst durch dieses kontrolliert werden.

2. Das Gleichgewicht: Das Immunsystem und die Tumorzellen, die in der Phase der Eliminierung überlebt haben, treten in ein Gleichgewicht. Dadurch entsteht ein starker Selektionsdruck auf die Tumorzellen. Da die meisten Tumorzellen genetisch instabil sind, entstehen neue Varianten mit verschiedenen Mutationen, die diese Tumorzellen durch erhöhte Resistenz vor dem Immunsystem des Wirts schützen. Diese Phase kann mehrere Jahre dauern.

3. Das Entkommen: Die überlebenden Tumorzellen, die durch genetische oder epigenetische Veränderungen für das Immunsystem nicht mehr sichtbar sind, beginnen unkontrolliert zu wachsen.

\section{5 „Immune escape“-Mechanismen}

Obwohl das Immunsystem an der Kontrolle von Tumorzellen beteiligt ist, kommt es dennoch nur in seltenen Fällen zu einer effektiven Kontrolle eines bereits etablierten Tumors durch das Immunsystem. Dafür sind auch die so genannten "Immune escape"-Mechanismen der Tumorzellen verantwortlich. Diese führen 
dazu, dass die Tumorzellen eine verminderte Immunogenität haben, oder aber auch, dass die Tumorzellen das Immunsystem supprimieren (Marincola et al. 2000).

Zu diesen Mechanismen zählen:

1. Herabregulation der Tumorantigene, der MHC-Moleküle oder der Moleküle, welche an der Antigenprozessierung beteiligt sind. So können die Tumorzellen von den CTL nicht mehr erkannt werden (Kageshita et al. 1999; Marincola et al. 2000).

2. Sekretion immunsuppressiver Substanzen, wie zum Beispiel Interleukin (IL) -10 oder der Transformierende Wachstumsfaktor-beta (TGFß) (Chen et al. 1994; Gorelik and Flavell 2001).

3. Expression Apoptose-induzierender Todesrezeptorliganden, wie FasL, auf den Tumorzellen und so Induktion der Apoptose der CTL, da diese den Fas-Rezeptor exprimieren (Andreola et al. 2002).

4. Induktion regulatorischer T-Zellen des Immunsystems, wie zum Beispiel $\mathrm{CD}^{+} 5^{+}, \mathrm{CD}^{+}$(Morse et al. 2002; Sakaguchi et al. 2001).

5. Es gibt Hinweise dafür, dass eine starke Immunantwort des Wirtes das Tumorwachstum fördern kann. Dafür werden vor allem die Zytokine, die von den T-Zellen produziert werden, verantwortlich gemacht. Für einige Interleukine, z. B. IL-4 und IL-10, konnte gezeigt werden, dass sie in manchen Tumoren das Wachstum fördern (Dancescu et al. 1992; Yue et al. 1997).

Zusammenfassend kann man sagen, dass die Tumorzellen antigen und häufig auch immunogen sind. Sie entgehen aber dem Immunsystem durch viele verschiedene Mechanismen wie Unsichtbarkeit und aktive Unterdrückung der Immunantwort (Pawelec 2004). 


\subsection{Fragestellung}

Ziel dieser Arbeit war es, die Bedeutung des Cathepsin B als eines möglichen "Immune escape"-Mechanismus zu untersuchen.

Gesteigerte Expression, Membranassoziation und Sekretion von Cathepsin B konnte für viele Arten von Tumoren gezeigt werden, ebenso auch eine positive Korrelation der Menge des Cathepsin B mit Invasivität und Metastasierungspotenzial der Tumorzellen (Frosch et al. 1999). Da CTL das Cathepsin B als Protektionsmechnismus nutzen, um sich vor ihren eigenen Perforinen zu schützen (Balaji et al. 2002), haben wir untersucht, ob Tumorzellen Cathepsin B ebenso als Schutzmechanismus vor den Perforinen der CTL einsetzen.

Für diesen Zweck nutzen wir den ${ }^{51}$ Chrom-Freisetzungs-Test, um die Lyse von chromierten Tumorzellen durch antigenspezifische CTL zu messen. Die Funktion des Cathepsin B untersuchten wir durch den Einsatz verschiedener Inhibitoren und durch Versuche mit Fibroblasten von Mäuseembryonen (MEF). Diese Fibroblasten stammten zum einen aus Cathepsin-B-knock-out-Mäusen (CathB -/-) und zum anderen aus Cathepsin-B-Wildtyp-Mäusen (CathB Wt). 


\section{Material und Methoden}

\subsection{Materialien}

\subsubsection{Chemikalien und Reagenzien}

\begin{tabular}{|c|c|}
\hline Chemikalie & Hersteller \\
\hline $\begin{array}{l}\text { Acrylamid 40\% (Rotiphorese Gel } 40 \\
(29: 1))\end{array}$ & Roth GmbH \& Co. \\
\hline APS (Ammoniumpersulfat) & Sigma-Aldrich Chemie GmbH \\
\hline Bromphenolblau & Merck Bioscience GmbH \\
\hline BSA (bovines Serumalbumin) FraktionV & Merck Bioscience GmbH \\
\hline Concanavalin A & Sigma-Aldrich Chemie GmbH \\
\hline DAB (Diaminobenzidin) & Sigma-Aldrich Chemie $\mathrm{GmbH}$ \\
\hline $\begin{array}{l}\text { DMEM (Dulbecco`s modifiziertes Eagle } \\
\text { Medium ) }\end{array}$ & Biochrom AG \\
\hline DMSO (Dimethylsulfoxid) & Merck Bioscience GmbH \\
\hline EDTA (Ethylendiamintetraessigsäure) & Roth $\mathrm{GmbH} \& \mathrm{Co}$. \\
\hline $\begin{array}{l}\text { EGTA (Ethylenglycol bis(2- } \\
\text { aminoethylether)-N,N,N',N'- } \\
\text { tetraessigsäure) }\end{array}$ & Roth GmbH \& Co. \\
\hline Essigsäure $100 \%$ & Merck Bioscience GmbH \\
\hline Ethanol $99 \%$ & GeReSo GmbH \\
\hline FCS (fetales Kälberserum) & Biochrom AG \\
\hline Glycerin & Merck Bioscience GmBH \\
\hline Glycin & Roth GmbH \& Co. \\
\hline $\mathrm{HCl}$ (Salzsäure) & Merck Bioscience GmBH \\
\hline $\begin{array}{l}\text { Hepes (2-(4-(2-Hydroxyethyl)- 1- } \\
\text { piperazinyl)-ethansulfonsäure) }\end{array}$ & Sigma-Aldrich Chemie GmbH \\
\hline Isopropanol & Merck Bioscience GmbH \\
\hline \multicolumn{2}{|l|}{$\mathrm{KHCO}_{3}$ (Kaliumhydrogencarbonat) } \\
\hline Methanol & Merck Bioscience GmbH \\
\hline $\mathrm{MgCl}_{2}$ (Magnesiumchlorid) Hexahydrat & Merck Bioscience GmbH \\
\hline $\begin{array}{l}\mathrm{Na}_{2}{ }^{51} \mathrm{CrO}_{4} \text { (radioaktives } \\
\text { Natriumchromat) }\end{array}$ & Hartmann Analytic GmbH \\
\hline
\end{tabular}




\begin{tabular}{|c|c|}
\hline $\mathrm{NaCl}$ (Natriumchlorid) & Merck Bioscience GmbH \\
\hline $\mathrm{NaHCO}_{3}$ (Natriumhydrogencarbonat) & Merck Bioscience $\mathrm{GmbH}$ \\
\hline $\mathrm{NaOH}$ (Natronlauge) & Merck Bioscience GmbH \\
\hline $\mathrm{NH}_{4} \mathrm{Cl}$ (Ammoniumchlorid) & Merck Bioscience $\mathrm{GmbH}$ \\
\hline Optiphase "Supermix" & PerkinElmer LAS GmbH \\
\hline PBS (Phosphat-gepufferte Salzlösung) & Biochrom AG \\
\hline Penicillin G & Sigma-Aldrich Chemie GmbH \\
\hline Perhydrol $30 \% \mathrm{H}_{2} \mathrm{O}_{2}$ & Merck Bioscience $\mathrm{GmbH}$ \\
\hline Ponceau S & Sigma-Aldrich Chemie GmbH \\
\hline Pyruvat & Sigma-Aldrich Chemie GmbH \\
\hline SDS (Natriumdodecylsulfat) & Roth $\mathrm{GmbH} \&$ Co. \\
\hline SIINFEKL (Ovalbumin aa 257-264) & Bachem Distribution Services $\mathrm{GmbH}$ \\
\hline Streptomycin Sulfat & Sigma-Aldrich Chemie GmbH \\
\hline $\begin{array}{l}\text { TEMED } \\
\text { (N,N,N',N'-Tetramethylethylendiamin) }\end{array}$ & AppliChem \\
\hline $\begin{array}{l}\text { Tris (Tris-(hydroxymethyl)- } \\
\text { aminomethan) }\end{array}$ & Roth GmbH \& Co. \\
\hline Triton X-100 & Sigma-Aldrich Chemie GmbH \\
\hline Trypanblau & Sigma-Aldrich Chemie GmbH \\
\hline Trypsin & Biochrom AG \\
\hline $\begin{array}{l}\text { Tween-20 (Polyoxyethylen(20)- } \\
\text { sorbitan-monolaurat) }\end{array}$ & Sigma-Aldrich GmbH \\
\hline$\beta$ - Mercaptoethanol & Sigma-Aldrich Chemie GmbH \\
\hline
\end{tabular}

\subsubsection{Nährmedien}

\begin{tabular}{ll}
\hline Name & Zusammensetzung \\
\hline DMEM-Medium & $13,54 \mathrm{~g} / \mathrm{DMEM}$ \\
\hline & $3.7 \mathrm{~g} \mathrm{NaHCO}_{3}$ \\
\hline & dest. $\mathrm{H}_{2} \mathrm{O}$ \\
\hline & $\mathrm{pH}$ auf 7,0 mit konzentrierter HCl einstellen \\
\hline DMEM-Komplett-Medium & \\
\hline & $440 \mathrm{ml}$ DMEM Medium \\
\hline
\end{tabular}


$5 \mathrm{ml}$ 100x Pyruvat

$50 \mathrm{ml}$ FCS

\begin{tabular}{ll}
\hline Hepes-gepuffertes DMEM & 13,54 g/l DMEM \\
\hline & $4.77 \mathrm{~g} / \mathrm{l} \mathrm{Hepes}$ \\
\hline & dest. $\mathrm{H}_{2} \mathrm{O}$ \\
\hline pH auf $7.2 \mathrm{mit} \mathrm{NaOH}$ einstellen \\
\hline Hepes-gepuffertes DMEM mit 10\% FCS & $10 \%$ FCS \\
\hline & Hepes-gepuffertes DMEM \\
\hline
\end{tabular}

\subsubsection{Puffer und Stammlösungen}

\begin{tabular}{|c|c|}
\hline Name & Zusammensetzung \\
\hline \multirow[t]{3}{*}{ DAB-Lösung } & 50 ml PBS/Tween \\
\hline & $25 \mathrm{mg}$ DAB \\
\hline & $50 \mu \mathrm{H} \mathrm{H}_{2} \mathrm{O}_{2}$ \\
\hline \multirow[t]{3}{*}{ EDTA /Trypsin } & $0.05 \%$ Trypsin \\
\hline & $0.02 \%$ EDTA \\
\hline & in PBS \\
\hline \multirow[t]{5}{*}{ EGTA/MgCl 2} & 4 mM EGTA \\
\hline & $8 \mathrm{mM} \mathrm{MgCl} 2$ \\
\hline & $10 \%$ FCS \\
\hline & Hepes gepuffertes DMEM hinzu \\
\hline & $\mathrm{pH}$ auf 7.2 mit $0,5 \mathrm{M} \mathrm{NaOH}$ einstellen \\
\hline \multirow[t]{2}{*}{ Einfriermedium } & $80 \%$ FCS \\
\hline & $20 \%$ DMSO \\
\hline \multirow[t]{4}{*}{ Erythrozytenlyse-Puffer } & $155 \mathrm{mM} \mathrm{NH}_{4} \mathrm{Cl}$ \\
\hline & $10 \mathrm{mM} \mathrm{KHCO}_{3}$ \\
\hline & $0,1 \mathrm{mM}$ EDTA \\
\hline & dest. $\mathrm{H}_{2} \mathrm{O}$ \\
\hline
\end{tabular}


$\mathrm{pH} 7,2-7,4$

9,55 g/l PBS

dest. $\mathrm{H}_{2} \mathrm{O}$

\begin{tabular}{|c|c|}
\hline PBS/Tween & $0,05 \%$ Tween -20 \\
\hline & in PBS \\
\hline \multirow[t]{4}{*}{ Penicillin-Streptomycin 100x } & Penicillin $1 \times 10^{5}$ Einheiten/l \\
\hline & Streptomycin $100 \mathrm{mg} / \mathrm{l}$ \\
\hline & in PBS \\
\hline & steril filtrieren \\
\hline \multirow[t]{7}{*}{ Probenpuffer (reduzierend) } & $0,02 \mathrm{M}$ Tris/HCl pH 8,0 \\
\hline & 20\% Glycerin \\
\hline & $2 \%$ SDS \\
\hline & 2 mM EDTA \\
\hline & $10 \% \beta$-Mercaptoethanol \\
\hline & 0,1\% Bromphenolblau \\
\hline & in dest. $\mathrm{H}_{2} \mathrm{O}$ \\
\hline \multirow[t]{3}{*}{ Pyruvat 100x } & $11 \mathrm{~g} / \mathrm{l}$ Pyruvat \\
\hline & in PBS \\
\hline & steril filtrieren \\
\hline \multirow[t]{3}{*}{ Sammelgelpuffer } & $0,5 \mathrm{M}$ Tris/HCl pH 6,8 \\
\hline & $0,4 \%$ SDS \\
\hline & in dest. $\mathrm{H}_{2} \mathrm{O}$ \\
\hline \multirow[t]{4}{*}{ SDS-Laufpuffer } & $25 \mathrm{mM}$ Tris \\
\hline & 192 mM Glycin pH 8,8 \\
\hline & $0,1 \%$ SDS (hitzeinaktiviert, für $1 \mathrm{~h}$ bei $65^{\circ} \mathrm{C}$ ) \\
\hline & in dest. $\mathrm{H}_{2} \mathrm{O}$ \\
\hline \multirow[t]{2}{*}{ Triton-Lyse-Puffer } & $10 \%$ Triton $\mathrm{X}-100$ \\
\hline & in PBS \\
\hline
\end{tabular}




\begin{tabular}{ll}
\hline Transferpuffer & $25 \mathrm{mM}$ Tris \\
\hline & $192 \mathrm{mM}$ Glycin $\mathrm{pH} 8,8$ \\
\hline & $20 \%$ Methanol \\
\hline Trenngelpuffer & \\
\hline & $1,5 \mathrm{M} \mathrm{Tris} / \mathrm{HCl} \mathrm{pH} \mathrm{8,8}$ \\
\hline & $0,4 \% \mathrm{SDS}$ \\
\hline Trypanblau & dest. $\mathrm{H}_{2} \mathrm{O}$ \\
\hline & \\
\hline & $0.2 \% \mathrm{Trypanblau}$ \\
\hline & in dest. $\mathrm{H}_{2} \mathrm{O}$ \\
\hline & $4.25 \% \mathrm{NaCl}^{\circ}$ \\
\hline & in dest. $\mathrm{H}_{2} \mathrm{O}$ \\
\hline & Trypanblau mit $\mathrm{NaCl}$ in einem Verhältnis von \\
\hline
\end{tabular}

\subsubsection{Gele}

\begin{tabular}{ll}
\hline Name & Zusammensetzung \\
\hline Sammelgel & 1 ml Acrylamid $40 \%$ \\
\hline & $2,5 \mathrm{ml}$ Sammelgelpuffer \\
\hline & $6,4 \mathrm{ml}$ dest. $\mathrm{H}_{2} \mathrm{O}$ \\
\hline & unmittelbar vor dem Gießen zufügen: \\
\hline & $100 \mu \mathrm{APS} 10 \%$ \\
\hline Trenngel & $10 \mu \mathrm{l}$ TEMED \\
\hline & 5 ml Acrylamid $40 \%$ \\
\hline & $5 \mathrm{ml}$ Trenngelpuffer \\
\hline 9,8 ml dest. $\mathrm{H}_{2} \mathrm{O}$ \\
\hline unmittelbar vor dem Gießen zufügen: \\
\hline $200 \mu l$ APS $10 \%$ \\
\hline $200 \mu l$ TEMED
\end{tabular}




\subsubsection{Verwendete Geräte}

\begin{tabular}{|c|c|c|}
\hline Gerät & Typ & Firma \\
\hline Autoklav & A 40 & Webeco GmbH \& Co.KG \\
\hline Blotkammer & & Biotec Fisher GmbH \\
\hline Durchflusszytometer & FACScan & Becton Dickinson $\mathrm{GmbH}$ \\
\hline \multicolumn{3}{|l|}{ Zubehör } \\
\hline Glaspipetten & $10 \mathrm{ml}$ und $5 \mathrm{ml}$ & Brand GmbH + CoKG \\
\hline Hamiltonspritze & Hamilton Mikroliter Spritze & Hamilton Bonaduz AG \\
\hline Homogenisator & Tenbroek & $\begin{array}{l}\text { über Schütt Labortechnik } \\
\mathrm{GmbH}\end{array}$ \\
\hline \multirow[t]{2}{*}{ Inkubatoren } & Hera Cell 150 & Heraeus Holding GmbH \\
\hline & B $5060 \mathrm{EK}$ & Heraeus Holding GmbH \\
\hline Flüssigszintillationszähler & 1450 MicroBeta Trilux & Wallac \\
\hline Magnetrührer & IKAMAG RET & IKA Werke GmbH \& Co.KG \\
\hline \multirow[t]{2}{*}{ Mikroskop } & No. 471202-9901 & $\begin{array}{l}\text { Carl Zeiss Microlmaging } \\
\text { GmbH }\end{array}$ \\
\hline & No. 491220 & $\begin{array}{l}\text { Carl Zeiss Microlmaging } \\
\text { GmbH }\end{array}$ \\
\hline \multirow[t]{2}{*}{ Netzteile } & $\begin{array}{l}\text { LKB Bromma } 2197 \text { Power } \\
\text { Supply }\end{array}$ & $\begin{array}{l}\text { LKB Instruments, jetzt } \\
\text { Amersham Biosence }\end{array}$ \\
\hline & Power Pack 25 & Biometra GmbH \\
\hline Neubauer-Zählkammer & & über Omnilab \\
\hline $\mathrm{pH}$ Meter & CG-837 & Schott AG \\
\hline Pipetten & $\begin{array}{l}20 \mu \mathrm{l}, 200 \mu \mathrm{l}, 1000 \mu \mathrm{l}, 300 \mu \mathrm{l} \\
\text { 8-Kanal }\end{array}$ & Eppendorf AG \\
\hline Pipettierhilfe & $\begin{array}{l}\text { pipette boy: Automatic } \\
\text { Sarpette }\end{array}$ & Desaga (Sarstedt-Gruppe) \\
\hline Scanner & Hp office jet 7110 & $\mathrm{HP}$ \\
\hline Schüttler & IKA-Schüttler MTS-4 & IKA Werke GmbH \& Co KG \\
\hline Sterile Werkbank & Lamin Air HLB 2448 & Heraeus Holding GmbH \\
\hline Trockenschrank & 5000 & Heraeus Holding GmbH \\
\hline Vortexer & MS1 Minishaker & IKA Werke GmbH \& Co.KG \\
\hline Waagen & Vicon & Sartorius AG \\
\hline & BP 61 & Sartorius AG \\
\hline
\end{tabular}




\begin{tabular}{lll}
\hline Wasserbad & Julabo U3 & Krannich GmbH \& Co.KG \\
\cline { 2 - 3 } & TC 60/2 & Bio-med \\
\hline Zentrifugen & Multifuge 1 L & Heraeus Holding GmbH \\
\cline { 2 - 3 } & Multifuge 3 S-R & Heraeus Holding GmbH \\
\cline { 2 - 3 } & Mikro 22 & Hettich GmbH \& Co.KG \\
\cline { 2 - 3 } & Labofuge GL & Heraeus Holding GmbH \\
\cline { 2 - 3 } & Minifuge GL & Heraeus Holding GmbH \\
\hline
\end{tabular}

\subsubsection{Antikörper}

\subsubsection{Primäre Antikörper}

Im folgenden Abschnitt werden die primären und sekundären Antikörper sowie die Isotypenkontrolle aufgelistet. Die Antikörper wurden für die Durchflusszytometrie und für den Westernblot eingesetzt. Die Antikörper waren teilweise mit RPE (rotes-Phycoerythrin) oder mit HRP (horseradish peroxidase) konjugiert.

\begin{tabular}{|c|c|c|}
\hline Antikörper & Clon/Isotyp & Hersteller \\
\hline Anti-Cathepsin B & Isotyp: Ziege IgG & R \& D Systems GmbH \\
\hline \multirow[t]{2}{*}{ Anti- $\beta$-Aktin } & Klon: AC-15 & Sigma-Aldrich Chemie \\
\hline & Isotyp: Maus $\operatorname{lgG}_{1}$ & $\mathrm{GmbH}$ \\
\hline \multirow[t]{2}{*}{ Anti-H2K ; RPE-konjugiert } & Klon : CTK $^{b}$ & Caltag Laboratories \\
\hline & Isotyp: Maus $\lg _{2 a}$ & \\
\hline
\end{tabular}

\subsubsection{Sekundäre Antikörper und Isotypenkontrolle}

\begin{tabular}{ll}
\hline Name & Hersteller \\
\hline Kaninchen anti-Ziege IgG; & Dianova \\
HRP-konjugiert & \\
\hline Ziege anti-Maus IgG; HRP-konjugiert & Dianova \\
\hline Maus IgG2a; RPE-konjugiert & Caltag Laboratories \\
\hline
\end{tabular}




\subsubsection{Proteinmarker}

\begin{tabular}{lll}
\hline Proteinmarker & Beschreibung & Hersteller \\
\hline SDS-6H & Molekulargewicht: 30,000- & Sigma-Aldrich-Chemie GmbH \\
& 200,000 & \\
\hline
\end{tabular}

\subsubsection{Inhibitoren}

\begin{tabular}{lll}
\hline Inhibitor & Eigenschaften & Hersteller \\
\hline CA-074 & Zellmembranimpermeabler & Merck Bioscience GmbH \\
& Cathepsin-B-Inhbitor & \\
\hline CA-074 Me & Zellmembranpermeabler & Merck Bioscience GmbH \\
& Cathepsin-B-Inhibitor & \\
\hline
\end{tabular}

\subsubsection{Zytokine}

\begin{tabular}{ll}
\hline Zytokin & Hersteller \\
\hline Rekombinantes murines Interferon-Gamma & ImmunoTools GmbH \\
$(\mathrm{rm}$ IFN- $\gamma)$ & \\
\hline Rekombinantes murines Interleukin-2 (rm IL-2) & R\&D Systems GmbH \\
\hline
\end{tabular}

\subsubsection{Einwegartikel}

\begin{tabular}{lll}
\hline Artikel & Typ & Firma \\
\hline Eppendorfgefäß & $1,5 \mathrm{ml}$ & Sarstedt AG \& Co. \\
\hline FACS-Röhrchen & $2 \mathrm{ml}$ & Sarstedt AG \& Co. \\
\hline Gefrierröhrchen & BD Falcon 5 ml & Becton Dickinson GmbH \\
\hline Gewebekultur-Petrischale & Cryo Tube Vialis 1,8 ml & Nunc A/S \\
\hline & beschichtet 100x20mm & Sarstedt AG \& Co. \\
\hline & unbeschichtet 100x20mm & Sarstedt AG \& Co. \\
\hline
\end{tabular}




\begin{tabular}{lll}
\hline Klebefolie & Top Seal-A 96 & PerkinElmer LAS GmbH \\
\hline Mikrotiterplatte & 96 -Loch-Rundboden & Sarstedt AG \& Co. \\
\hline Nitrozellulosemembran & $200 \times 200 \mathrm{~mm}$ & Schleicher\&Schuell \\
& $0,45 \mathrm{~mm}$ Porengröße & \\
\hline Pipetten & $10 \mathrm{ml}$ & Sarstedt AG \& Co. \\
\hline Pipettenspitzen & $200 \mu \mathrm{l}$ gelb & Sarstedt AG \& Co. \\
\hline & $1000 \mu \mathrm{l} \mathrm{blau}$ & Sarstedt AG \& Co. \\
\hline Sterilfilter & $0,2 \mu \mathrm{M}$ Porengröße & Sarstedt AG \& Co. \\
\hline Wallac Messplatte & $96-$-Loch & PerkinElmer LAS GmbH \\
\hline Whatmanpapier & GB 003 & Schleicher\&Schuell \\
\hline Zellkulturflaschen & Beschichtet T-75, belüftete & Sarstedt AG \& Co. \\
\hline Zentrifugationsröhrchen & Klappe (250 ml) & \\
\hline & $13 \mathrm{ml} \mathrm{Röhrchen}$ & Sarstedt AG \& Co. \\
\hline
\end{tabular}

\subsubsection{Zelllinien}

\begin{tabular}{lll}
\hline Name & Art & Beschreibung \\
\hline CathB -I- & Embryonale Fibroblasten & $\begin{array}{l}\text { Knock-out des Cathepsin-B- } \\
\text { Gens }\end{array}$ \\
& & Wildtyp \\
\hline CathB Wt & Embryonale Fibroblasten & \\
\hline RMA & Maus T-Zell-Lymphom-Linie & \\
\hline
\end{tabular}

Diese Zellen dienten als Zielzellen für den ${ }^{51}$ Chrom-Freisetzungstest. RMA sind Suspensionszellen. Fibroblasten sind Bindegewebszellen, sie wachsen adhärent. Die Fibroblasten von Mäuseembryonen (MEF) wurden freundlicherweise von Prof. C. Peters, Institut für Molekulare Medizin und Zellforschung, Universität Freiburg, zur Verfügung gestellt.

\subsubsection{Versuchstiere}

Die Versuchstiere wurden in der zentralen Tierexperimentellen Einrichtung der Universitätsmedizin der Georg-August-Universität Göttingen gehalten. 


\begin{tabular}{|c|c|c|}
\hline Name & Art & Beschreibung \\
\hline \multirow[t]{2}{*}{ OT-I } & Maus & Transgen für einen $\mathrm{V} \alpha 2 \mathrm{~V} \beta 5$ \\
\hline & & TCR \\
\hline C57BL/6 & Maus & Haplotyp: $\mathrm{H}^{\mathrm{b}}$ \\
\hline $129 / \mathrm{Sv}$ & Maus & Haplotyp: $\mathrm{H}^{\mathrm{b}}$ \\
\hline BUF & Ratte & Haplotyp: RT1 ${ }^{b}$ \\
\hline LOU & Ratte & Hapoltyp: RT1 ${ }^{u}$ \\
\hline
\end{tabular}

OT-I-Mäuse sind transgen für einen V $\alpha 2$ V $\beta 5$-T-Zell-Rezeptor (Hogquist et al. 1994), welcher spezifisch für das $H 2 K^{b}$-präsentierte, vom Ovalbumin abgeleitete Peptid SIINFEKL ist. Auch Ratten verschiedener Stämme wurden verwendet, um aus ihren Milzen Zellen zur Produktion von Concanavalin-AÜberstand zu gewinnen. Weiterhin wurden die Milzen von C57BL/6- oder 129/Sv-Mäusen für die Gewinnung von Stimulatorzellen für die Restimulation der OT-I-Zellen genutzt. Diese Zellen wurden zuvor für 15 Minuten bei $30 \mathrm{~Gy}$ bestrahlt.

\subsubsection{Computeranalyse}

Die Computeranalyse des ${ }^{51}$ Chrom-Freisetzungs-Tests erfolgte mit der MicroBeta Software für den Wallac MicroBeta Trilux Flüssigszintillationszähler und Excel 2003 (Microsoft).

Die Analyse der FACS-Daten wurde mit Cell Quest (BD Biosciences) und die mathematische und visuelle Analyse wurde mit Excel 2003 durchgeführt.

Die statistische Analyse der Ergebnisse wurde mit WinSTAT für Excel oder SAS Version 9.1 durchgeführt. 


\subsubsection{Herstellerliste}

\begin{tabular}{|c|c|}
\hline Amersham Biosence & Munziger Str. 9, 79111 Freiburg \\
\hline AppliChem GmbH & Ottoweg 10b, 64291 Darmstadt \\
\hline Bachem Distribution Services $\mathrm{GmbH}$ & Hegenheimer Str. 5, 79576 Weil am Rhein \\
\hline Becton Dickinson $\mathrm{GmbH}$ & Tullastr. 8-12, 69126 Heidelberg \\
\hline Biochrom AG & Leonorenstr. 2-6, 12247 Berlin \\
\hline Bio-med GmbH & Bruckmannring 32, 85764 Oberschleißheim \\
\hline Biometra GmbH & Rudolf-Wissel-Straße 30, 37079 Göttingen \\
\hline Biotec-Fischer GmbH & Daimlerstraße 6, 35447 Reiskirchen \\
\hline Brand GmbH + Co. KG & Otto-Schott-Straße 25, 97877 Wertheim \\
\hline Caltag Laboratories & Brauhausstieg 15-17, 22041 Hamburg \\
\hline Carl Zeiss Microlmaging GmbH & Königsallee 9-21, 37081 Göttingen \\
\hline Desaga (Sarstedt-Group) & In den Ziegelwiesen 1-7, 69168 Wiesloch \\
\hline Dianova & Warburgstr. 45, 20354 Hamburg \\
\hline Eppendorf AG & Barkhausenweg 1, 22339 Hamburg \\
\hline GeReSo GmbH & Carl-Orff-Str. 33, 37574 Einbeck \\
\hline Hamilton Bonaduz AG & Via Crush 8, 7402 Bonadiz, Schweiz \\
\hline Hartmann Analytic GmbH & Inhoffenstr. 7, 38124 Braunschweig \\
\hline Hettich GmbH \& Co.KG & Föhrenstraße 12, 78532 Tuttlingen \\
\hline Heraeus Holding GmbH & Heraeusstraße 12-14, 63450 Hanau \\
\hline Hewlett-Packard & Herrenbergerstraße 140, 71034 Böblingen \\
\hline ICN/MP Biomedicals & Thüringer Str. 15, 37269 Eschwege \\
\hline IKA Werke GmbH \& Co. KG & Janke \& Kunkel-Str. 10, 79219 Staufen \\
\hline ImmunoTools GmbH & Altenoyther Str. 10, 26169 Friesoythe \\
\hline Krannich GmbH \& Co. KG & Elliehäuser Weg 17, 37079 Göttingen \\
\hline LKB Instruments & Jetzt: Amersham Biosience \\
\hline Merck Biosciences GmbH & Ober der Roeth 4, 65824 Schwalbach/Ts \\
\hline Microsoft Deutschland GmbH & Konrad-Zuse-Straße 1, 85716 Unterschleißheim \\
\hline Nunc A/S & Kamstrupvej 90, 4000 Roskilde, Denmark \\
\hline Omnilab (Krannich) & Elliehäuserweg 17, 37079 Göttingen \\
\hline PerkinElmer LAS GmbH & $\begin{array}{l}\text { Ferdinand-Porsche-Ring } 17,63110 \text { Rodgau- } \\
\text { Jügesheim }\end{array}$ \\
\hline Phase GmbH & Blücherstraße 2, 23564 Lübeck \\
\hline R \& D Systems GmbH & Borsigstr. 7, 65205 Wiesbaden-Nordenstadt \\
\hline Roth GmbH \& Co. & Schoemperlenstr. 1-5, 76185 Karlsruhe \\
\hline
\end{tabular}




\begin{tabular}{ll}
\hline Sarstedt AG \& Co. & Postfach 1220, 51582 Nümbrecht \\
\hline Sartorius AG & Weender Landstraße 94-108, 37075 Göttingen \\
\hline Schleicher \& Schuell GmbH & Hahnestrasse 3, 37586 Dassel \\
\hline Schott AG & Hattenbergstr. 10, 55122 Mainz \\
\hline Schütt Labortechnik GmbH & Rudolf-Wissell-Str. 11, 37079 Göttingen \\
\hline Sigma-Aldrich Chemie GmbH & Eschenstrasse 5, 82024 Taufkirchen \\
\hline SPSS GmbH Software & Rosenheimer Str. 30, 81669 München \\
\hline Wallac & Jetzt: PerkinElmer LAS GmbH \\
\hline Webeco GmbH \& Co.KG & An der Trave 14, 23923 Selmsdorf \\
\hline
\end{tabular}

\subsection{Methoden}

\subsubsection{Zellkulturmethoden}

\subsubsection{Allgemeines zu der Arbeit mit Zellkulturen}

Alle Arbeiten an Zellkulturen wurden unter sterilen Bedingungen mit sterilen Medien und Materialien an einer Werkbank vorgenommen, um eine Kontamination mit Bakterien oder Pilzen zu vermeiden. Die Zellkulturen wurden bei $37^{\circ} \mathrm{C}$ und $10 \% \mathrm{CO}_{2}$ im Wärmeschrank inkubiert. Als Kultivierungsmedium diente DMEM-Komplett-Medium.

\subsubsection{Kultivierung adhärenter Zellen}

Die adhärent wachsenden Zellen, wie die MEF, wurden in beschichteten Gewebekultur-Petrischalen in 5-ml- oder 10-ml-Kulturen gehalten. Je nach Wachstumsgeschwindigkeit musste alle 4 - 5 Tage das Medium gewechselt werden oder die Zellen mussten aufgeteilt werden. Der Wechsel des Mediums erfolgte, indem das alte Medium mit einer Pipette abgesaugt und neues Medium hinzu gegeben wurde. Zum Splitten der Zellen wurde zunächst das Kulturmedium abgesaugt. Anschließend wurde die Schale mit Hepesgepuffertem DMEM-Medium gespült, um FCS zu entfernen. Der Überstand wurde abgesaugt und verworfen. Dann wurden ca. $3 \mathrm{ml}$ einer EDTA/Trypsin- 
Lösung hinzu gegeben, bevor die Platten für ca. 4-5 Minuten im Wärmeschrank bei $37^{\circ} \mathrm{C}$ inkubiert wurden. Wenn sich die Zellen bei mikroskopischer Kontrolle abgerundet zeigten, wurden sie resuspendiert und in ein Röhrchen mit $5 \mathrm{ml}$ Hepes-gepuffertem DMEM-Medium mit 10\% FCS überführt. Im Anschluss wurden die Zellen 10 Minuten bei $300 \mathrm{xg}$ zentrifugiert und der Überstand wurde verworfen. Die Zellen wurden in 2-3 neue Petrischalen mit DMEM-KomplettMedium überführt.

\subsubsection{Kultivierung nicht-adhärenter Zellen}

Die nicht-adhärent wachsenden Zellen, wie die RMA-Zellen, wurden in unbeschichteten Gewebekultur-Petrischalen in 10-ml-Kulturen gehalten. Sie wurden alle 2-3 Tage geteilt, indem ein Teil der Zellen in neue Petrischalen überführt und mit DMEM-Komplett-Medium auf das Volumen von $10 \mathrm{ml}$ aufgefüllt wurde.

\subsubsection{Einfrieren und Auftauen von Zellen}

Zellen, die eingefroren werden sollten (ca. $5 \times 10^{6}$ Zellen pro Portion), wurden in ein 13-ml-Röhrchen überführt und bei $300 \times \mathrm{g} 10$ Minuten zentrifugiert. Der Überstand wurde verworfen. Das Zellpellet wurde in 0,5 $\mathrm{ml}$ Hepes-gepuffertem DMEM-Medium resuspendiert. Dann gab man die gleiche Menge an Einfriermedium hinzu. Da das Einfriermedium DMSO enthält, welches stoffwechselaktive Zellen schädigt, wurden die Zellen nach Zugabe des Einfriermediums schnell in Einfrierröhrchen überführt und in einer Styroporbox bei $-80^{\circ} \mathrm{C}$ langsam eingefroren.

Das Auftauen der Zellen erfolgte unter fließendem warmem Wasser, bis der Inhalt der Einfrierröhrchen fast ganz flüssig war. Dann wurde der Inhalt in ein 13-ml-Röhrchen mit $10 \mathrm{ml}$ Hepes-gepuffertem DMEM-Medium überführt und 10 Minuten bei $300 \times \mathrm{g}$ zentrifugiert. Der Überstand wurde verworfen und die Zellen wurden anschließend in Kulturmedium aufgenommen. 


\subsubsection{Bestimmung der Zellzahl}

Zur Bestimmung der Zellzahl der Zielzellen wurde aus der Zellsuspension $10 \mu \mathrm{l}$ entnommen und in eine Neubauer-Zählkammer pipettiert. Die unter dem Mikroskop bestimmte Zellzahl konnte dann auf das Gesamtvolumen der Zellsuspension umgerechnet werden. Dazu wurden zunächst alle 4 Großquadrate der Neubauer-Zählkammer ausgezählt und dann der Mittelwert gebildet. Anhand der gezählten Zellzahl in dem Volumen von $10 \mu$ l konnte dann die Zellzahl pro Milliliter errechnet werden. Die Zellzahl pro Suspensionslösung ergibt sich aus der Formel:

mittlere Zellzahl x Verdünnungsfaktor x $10^{4}$

Bei der Bestimmung der Effektor-Zellzahl wurden die Zellen zunächst im Verhältnis 1:10 mit Trypanblau verdünnt und angefärbt. Es wurden dann nur die lebenden, das heißt die nicht mit Trypanblau gefärbten Zellen gezählt.

\subsubsection{Isolation von Lymphozyten aus Mäusemilzen}

Zur Isolation von Lymphozyten wurde zunächst die Milz aus OT-I-Mäusen präpariert. Die Mäuse wurden durch Inhalation von $\mathrm{CO}_{2}$ oder durch Genickbruch getötet. Danach erfolgte die Explantation der Milz mit autoklavierten chirurgischen Instrumenten. Nach alkoholischer Desinfektion des Fells wurde ein medianer Bauchschnitt durchgeführt, die Haut wurde seitlich abpräpariert und das Peritoneum dargestellt. Das Abdomen wurde eröffnet und die Milz durch Lösen der bindegewebigen Strukturen entnommen. Die Milz wurde in ein Röhrchen mit 10 ml Hepes-gepuffertem DMEM-Medium überführt.

Der weitere Teil der Isolation erfolgte unter der Werkbank. Die Milz wurde mit dem Medium in einem Tenbroek-Homogenisator vorsichtig homogenisiert, so dass Einzelzellen aus dem Gewebeverband gelöst wurden. Der Überstand mit den Zellen wurde dann in ein Röhrchen überführt. Anschließend wurde dieses 
bei 300 x g für 5 Minuten zentrifugiert und der Überstand daraus verworfen. Die Erythrozyten wurden durch Zugabe von $5 \mathrm{ml}$ Erythrozytenlyse-Puffer für 3-5 Minuten lysiert; anschließend wurden nach Zugabe von 5 ml Hepes-gepuffertem DMEM-Medium die Zellen erneut zentrifugiert und der Überstand verworfen. Die so gewonnenen Lymphozyten wurden dann zur Aktivierung der CTL antigenspezifisch stimuliert.

\subsubsection{Gewinnung von Concanavalin-A-Überstand}

Concanavalin-A-Überstand wurde zur Stimulation der CTL benötigt. Con A hat auf Lymphozyten eine mitogene Aktivität.

Die Milz wurde den Ratten nach dem gleichen Verfahren wie unter 2.2.1.6 für die Mäusemilz beschrieben entnommen. Die Milzen wurden unter einer sterilen Werkbank in Hepes-gepuffertem DMEM-Medium in einem TenbroekHomogenisator homogenisiert und anschließend in einem Röhrchen für 10 Minuten bei $300 \times \mathrm{g}$ zentrifugiert. Der Überstand wurde verworfen und die Zellen wurden pro Milz in $40 \mathrm{ml}$ Hepes-gepuffertem DMEM-Medium mit 10\% FCS und $200 \mu \mathrm{l}$ Con $\mathrm{A}(1 \mathrm{mg} / \mathrm{ml})$ resuspendiert und für 4 Stunden bei $37^{\circ} \mathrm{C} \mathrm{im}$ Wasserbad in einer Zellkulturflasche inkubiert. Nach Ablauf der Inkubationszeit wurden die Zellen in ein 50-ml-Röhrchen überführt und bei 300 x g 10 Minuten zentrifugiert. Der Überstand wurde verworfen und die Zellen wurden in $20 \mathrm{ml}$ MilzDMEM-Komplett-Medium resuspendiert und in eine Zellkulturflasche überführt. In dieser wurden sie dann 20 bis $24 \mathrm{~h}$ bei $37^{\circ} \mathrm{C}$ und $10 \% \mathrm{CO}_{2}$ inkubiert. Nach der Inkubation wurden die Zellen wieder in ein 50-ml-Röhrchen überführt und für 10 Minuten bei 1100 x g zentrifugiert. Der Überstand wurde abgenommen und je $8 \mathrm{ml}$ in 13-ml-Röhrchen überführt und bei $-20^{\circ} \mathrm{C}$ eingefroren. 


\subsubsection{Stimulation zytotoxischer T-Lymphozyten}

Die peptidspezifische Stimulation erfolgte durch Zugabe von $8 \mathrm{ml}$ Con AÜberstand, $32 \mathrm{ml}$ DMEM-Komplett-Medium, $5 \times 10^{-5} \mathrm{M}$ ß-Mercaptoethanol, 20 $\mathrm{ng} / \mathrm{ml}$ murines IL-2 und $1 \mathrm{~nm}$ SIINFEKL. In dieses Medium wurden die präparierten Lymphozyten von OT-I-Mäusen aufgenommen und je $200 \mu \mathrm{l}$ in jedes Loch einer 96-Loch-Mikrotiterplatte gegeben. Aus einer Milz konnten normalerweise zwei 96-Loch-Mikrotiterplatten angesetzt werden, die anschließend im Brutschank inkubiert wurden. Dies führte innerhalb von 4 - 5 Tagen zur antigenspezifischen Aktivierung der SIINFEKL-spezifischen CD8 ${ }^{+} \mathrm{T}$ Lymphozyten. Diese Effektorzellen wurden dann in ${ }^{51}$ Chrom-Freisetzungs-Tests eingesetzt oder für eine spätere Verwendung noch einmal stimuliert (siehe 2.2.1.9).

\subsubsection{Restimulation zytotoxischer T-Lymphozyten}

Nicht benötigte CTL aus einer Kultur zur antigenspezifischen Stimulierung (siehe 2.2.1.8) wurden teilweise nach 4-5 Tagen erneut kultiviert, um sie später als Effektorzellen einzusetzen. Die Zellen wurden in einem Röhrchen 5 Minuten bei $300 \times \mathrm{g}$ zentrifugiert, der Überstand wurde verworfen. Dann wurden die Zellen behandelt wie bei der Stimulation, nur wurden dem Ansatz noch pro 70$100 \times 10^{6} \mathrm{CTL} 50-100 \times 10^{6}$ Stimulatorzellen hinzu gegeben. Bei den Stimulatorzellen handelte es sich um bestrahlte Zellen (15 Minuten; 30Gy) aus der Milz von C57BI/6- oder 129Sv-Mäusen, die H2K $\mathrm{K}^{\mathrm{b}}$ exprimieren, welches das SIINFEKL-Peptid bindet und es so den CTL präsentiert wird. Die restimulierten Zellen konnten dann am 4. oder 5. Tag als Effektorzellen eingesetzt werden. 


\subsubsection{Zytotoxizitätstest}

\subsubsection{Allgemeines zu der Arbeit mit radioaktiven Stoffen}

Alle Arbeiten mit radioaktiven Stoffen wurden im Isotopenlabor durchgeführt. Die Arbeit erforderte keine absolute Sterilität, weil die jeweiligen Versuche nur 4 Stunden dauerten. Die Werkbank war mit einer bleiernen Schutzmauer versehen, hinter der die Arbeit mit den radioaktiven Stoffen erfolgte. Flüssiger und fester radioaktiver Abfall wurden getrennt in dafür vorgesehene Behältnisse entleert. Alle verwendeten Materialien und Geräte wurden nur im Isotopenlabor eingesetzt.

\subsubsection{Der ${ }^{51}$ Chrom-Freisetzungs-Test}

Der Chromfreisetzungstest ist ein In-vitro-Test zur Bestimmung der zytolytischen Aktivität von CTL. Zielzellen, deren MHC-Klasse-I-Komplex ein spezifisches Antigen präsentiert, aktivieren antigenspezifische CTL und werden von diesen lysiert. Die Zielzellen wurden zuvor mit dem radioaktiven Isotop

${ }^{51}$ Chrom in Form von Natriumchromat inkubiert. Das Chrom wird in die Zellen aufgenommen und dort an zelluläre Proteine gebunden. Wenn es zu einer antigenspezifischen Aktivierung der CTL kommt, schütten diese ihre zytotoxischen Granula aus und dann wird durch Perforin-abhängige Lyse der Zielzellen das Chrom in den Überstand freigesetzt.

\subsubsection{Durchführung des ${ }^{51}$ Chrom-Freisetzungs-Tests}

Der Chromtest wurde am 4. oder 5. Tag nach der Stimulation der CTL durchgeführt. Als Effektorzellen dienten aktivierte CTL aus OT-I- Mäusen. Als Zielzellen dienten RMA-Zellen oder embryonale Fibroblastenlinien aus Mäusen (MEF). 
Die Zielzellen wurden geerntet, in ein steriles Röhrchen überführt und 5 Minuten bei 300 x g zentrifugiert. Anschließend wurden die Zellen in $10 \mathrm{ml}$ Hepes-gepuffertem DMEM-Medium mit 10\% FCS resuspendiert und gezählt. Die benötigte Menge an Zellen ( $1 \times 10^{6}$ Zellen pro Mikrotiterplatte für ein Killer-/ Zielzellverhältnis von 10:1) wurde entnommen und wieder zentrifugiert. Der Überstand wurde verworfen. Anschließend wurden die Zielzellen für eine Stunde bei $37^{\circ} \mathrm{C}$ chromiert. Dazu wurden die Zellen in eine Lösung mit $200 \mu \mathrm{l}$ Hepes-gepuffertem DMEM-Medium, $100 \mu \mathrm{l}$ FCS und 25-50 $\mu \mathrm{l}$ (je nach Alter und Aktivität der verwendeten Charge) des radioaktiven Chrom-Isotops $\mathrm{Na}_{2}{ }^{51} \mathrm{CrO}_{4}$ gebracht.

Die Zielzellen wurden nach einer Stunde dreimal mit $10 \mathrm{ml}$ Hepes-gepuffertem DMEM-Medium für 10 Minuten bei 300 x g gewaschen und der Überstand wurde jeweils verworfen. Dadurch wurde das freie Chrom entfernt. Die Zellen wurden in Hepes-gepuffertem DMEM-Medium aufgenommen, so dass eine Konzentration von 100.000 Zellen/ml erreicht wurde.

Die Effektorzellen (OT-I) wurden in ihrem Medium resuspendiert, in ein 50-mlRöhrchen mit $30 \mathrm{ml}$ Hepes-gepuffertem DMEM-Medium überführt und 5 Minuten bei $300 \times \mathrm{g}$ zentrifugiert. Der Überstand wurde verworfen und die Zellen in $5 \mathrm{ml}$ Hepes-gepuffertem DMEM-Medium aufgenommen und gezählt. Die benötigte Menge an Effektorzellen ( $2 \times 10^{5}$ Zellen/Verdünnungsreihe) wurde entnommen, 5 Minuten bei $300 \times \mathrm{g}$ zentrifugiert und danach in der benötigten Menge von Hepes-gepuffertem DMEM-Medium mit 10\% FCS aufgenommen (50 $\mu \mathrm{l} /$ Verdünnungsreihe). In eine 96-Loch-Mikrotiterplatte wurden in jedes Loch $50 \mu$ l Hepes-gepuffertes DMEM mit 10\% FCS vorgelegt. In das erste Loch der Verdünnungsreihe wurden je $50 \mu \mathrm{l}$ der Effektorzellen gegeben und dann fünfmal resuspendiert. Davon wurden dann wieder $50 \mu$ in das nächste Loch geben. So wurde eine Verdünnungsreihe erstellt. Um die spontane Chromfreisetzung aus den Zielzellen (Spontanrelease) zu bestimmen, wurden in die letzte Reihe der Platte nur Zielzellen und keine Effektorzellen gegeben. 
Um die Peptidspezifität zu zeigen, wurde zu der Negativkontrolle kein Peptid (SIINFEKL (Ovalbumin aa 257-264)) hinzu gegeben, sondern nur $50 \mu \mathrm{l}$ Hepesgepuffertes DMEM-Medium. Allen anderen Testreihen wurden sowohl $50 \mu \mathrm{l}$ Hepes-gepuffertes DMEM-Medium, als auch $0.25 \mu \mathrm{g} / \mathrm{ml}$ des Peptids zugesetzt. Als Nachweis, dass die Lyse über den Granula-Exozytose-Weg vermittelt wird und daher calciumabhängig ist, wurde zu einem Triplett außerdem 2 mM EGTA und $4 \mathrm{mM} \mathrm{MgCl}_{2}$ gegeben. Die Zugabe weiterer Reagenzien erfolgte je nach Fragestellung.

Anschließend wurden $100 \mu \mathrm{l}$ der chromierten Zielzellen in den Konzentrationsverhältnissen von 10:1 bis 0.16:1 zu den Effektorzellen hinzu gegeben. Das Gesamtvolumen betrug $200 \mu / / L o c h$. Jede Versuchsreihe wurde als Triplett angesetzt. Die spontane Chromfreisetzung (Spontanrelease) wurde durch Inkubation der Zielzellen ohne Zugabe von Effektorzellen ermittelt. 


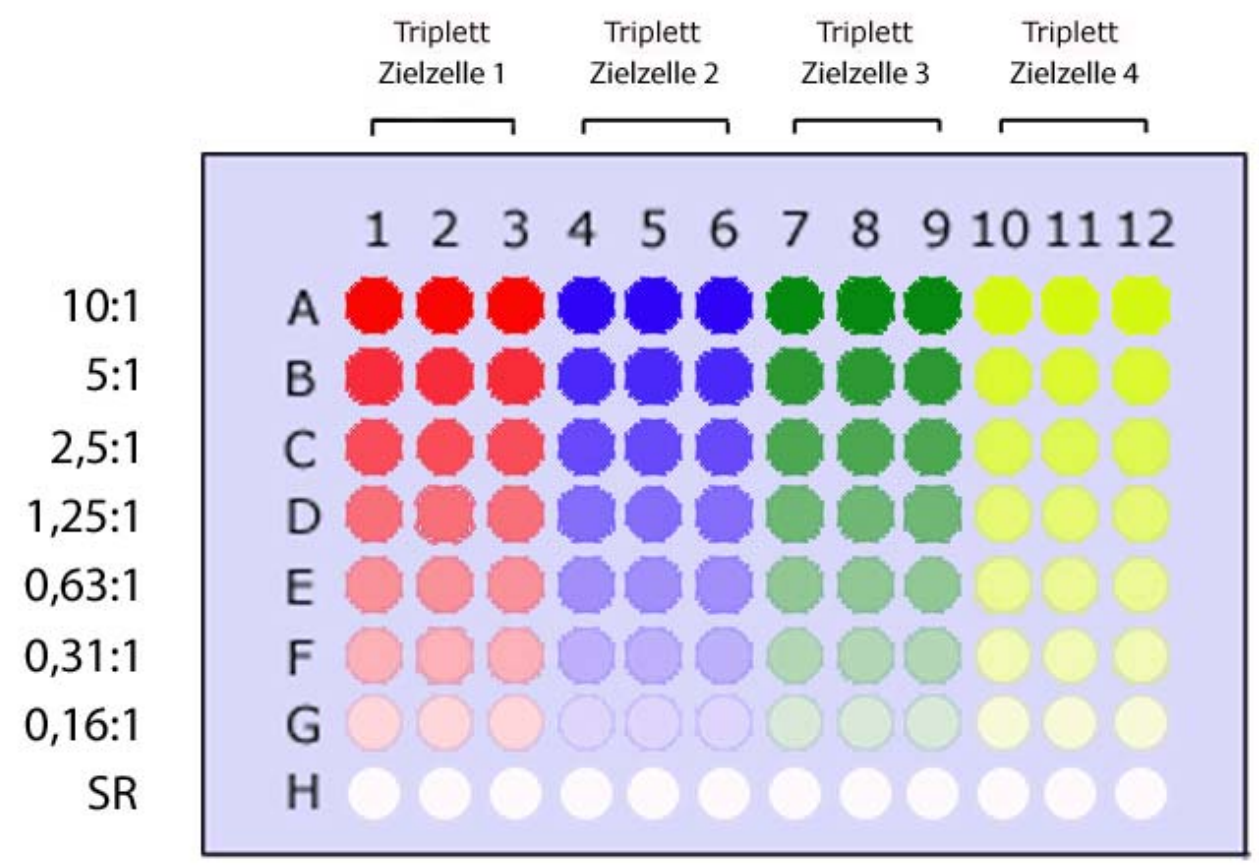

\section{Abbildung 1: Darstellung des Pipettierschemas eines Chromtests in einer 96-Loch- Mikrotiterplatte}

Es wird beispielhaft das Pipettierschema eines Chromtests dargestellt. In jedes Loch der 96Loch-Mikrotiterplatte wurden $50 \mu \mathrm{l}$ Hepes-gepuffertes DMEM-Medium mit 10\% FCS gegeben. In Reihe A wurde in jedes Loch $50 \mu \mathrm{l}\left(2 \times 10^{5}\right.$ Zellen) der Effektorzellsuspension gegeben. Dann wurde eine Verdünnungsreihe (z.B. von 10:1 bis 0,16:1) erstellt. In die Reihe H wurden keine Effektorzellen gegeben, da hier der Spontanrelease (SR) bestimmt wurde. Danach wurde in jedes Loch $50 \mu$ eines Ansatzes gegeben, der Hepes-gepuffertes DMEM-Medium enthielt und das Peptid. Weitere Zusätze, wie EGTA oder der Cathepsin-B-Inhibitor, wurden in Abhängigkeit von der Fragestellung hinzu gegeben. Nur in die Negativkontrolle wurde kein Peptid gegeben. Alle Ansätze erfolgten als Triplett. Dann wurden in jedes Loch $100 \mu \mathrm{l}$ der Zielzellsuspension

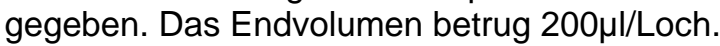

Nach Zusammengabe der Effektor- und Zielzellen wurde die 96-LochMikrotiterplatte eine Minute bei 20 x g zentrifugiert, um den Kontakt der Zellen herzustellen. Anschließend erfolgte die Inkubation für 4 Stunden bei $37^{\circ} \mathrm{C}$ in einer feuchten Kammer. Nach 4 Stunden wurde die 96-Loch-Mikrotiterplatte wieder für 1 Minute bei 20 x g zentrifugiert, um die Zellen vom Überstand zu trennen, der das freigesetzte ${ }^{51}$ Chrom enthielt. Je $50 \mu$ des Überstandes wurden abgenommen und in einen 96-Loch-Wallac-Messplatte überführt. Um die Gesamtmenge des Chroms in den Zellen bestimmen zu können, musste man den Gehalt des Chroms in den Sedimenten messen. Da das Chrom erst 
nach der Zerstörung der Zellmembran freigesetzt wird (Brunner et al. 1968), wurden vor Abnahme des Sediments in jedes Loch $5 \mu$ l 10\% Triton X-100Lösung zur Zerstörung der noch intakten Zellen gegeben. Die Sedimente wurden mit dem verbliebenen Überstand (150 $\mu \mathrm{l})$ vermischt. Anschließend wurden je $50 \mu$ dieses Gemisches (das sog. Sediment) in eine Messplatte überführt. Um die Radioaktivität messen zu können, wurde in jedes Loch der 96-Loch-Wallac-Messplatte $200 \mu$ l Szintillator (Optiphase "Supermix") gegeben. Die Messplatten wurden mit einer Klebefolie verschlossen und kurz auf einem Schüttler geschüttelt. Die Messung des ${ }^{51}$ Chrom erfolgte mit Hilfe des WallacMicroBeta-Trilux-Zählers. Ermittelt wurden die counts per minute (cpm) in jedem Loch der Messplatte. Die Lyse wurde mit der folgenden Formel berechnet:

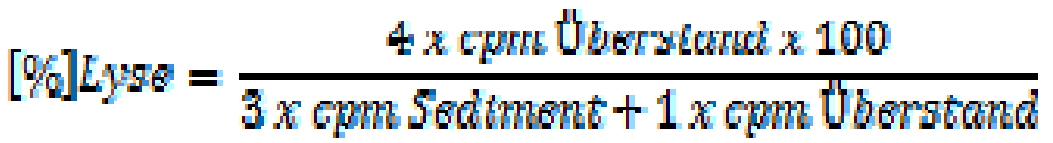

Zur Ermittlung der spezifischen Lyse, welche die Aktivität der CTL wiedergibt, musste man von der prozentualen Lyse den Spontanrelease abziehen. Der Spontanrelease entspricht der Freisetzung von ${ }^{51}$ Chrom aus den Zellen unabhängig von den CTL.

\subsubsection{4 ${ }^{51}$ Chrom-Freisetzungs-Test mit Inhibitor}

Im Rahmen der Untersuchung zur Funktion des extrazellulären Cathepsin B wurden Testreihen mit dem spezifischen zellmembranimpermeablen irreversiblen Cathepsin-B-Inhibitor CA-074 durchgeführt. Zur Detektion einer konzentrationsabhängigen Beeinflussung der CTL-Induzierten Lyse durch den Inhibitor wurde er in den Konzentrationen von $20 \mu \mathrm{M}, 10 \mu \mathrm{M}$ oder $5 \mu \mathrm{M}$ eingesetzt. Um die intrazelluläre Funktion des Cathepsin B zu untersuchen, wurde der spezifische zellmembranpermeable irreversible Cathepsin-B-Inhibitor CA-074 Me verwendet. Dieser wurde in Konzentrationen von $20 \mu \mathrm{M}$ und $5 \mu \mathrm{M}$ 
eingesetzt. Weiterhin wurde in einer zusätzlichen Testreihe der Effekt des Lösungsmittels DMSO auf die Zellen ermittelt. Dazu wurde DMSO in demselben Volumen hinzu gegeben, wie der Inhibitor in der Konzentration von $20 \mu \mathrm{M}$.

\subsubsection{5 ${ }^{51}$ Chrom-Freisetzungs-Test mit Zugabe von Cathepsin-B-Inhibitoren zu den Zielzellen}

Um den Einfluss der Cathepsin-B-Inhibitoren auf die CTL zu vermeiden, wurden in einigen Versuchen die Cathepsin-B-Inhibitoren und das DMSO nicht in den Testansatz gegeben, sondern vor Beginn des Chrom-Freisetzungs-Tests nur zu den Zielzellen. Der Versuchsablauf war wie unter 2.2.2.3 beschrieben. Die Zielzellen wurden nach dem Chromieren jedoch nur zweimal mit Hepes-gepuffertem DMEM-Medium gewaschen. Dann wurden die Cathepsin-B-Inhibitoren jeweils in der Konzentration von $20 \mu \mathrm{M}$ oder $5 \mu \mathrm{M}$ zu den Zielzellen gegeben und für eine halbe Stunde bei $37^{\circ} \mathrm{C}$ inkubiert. Danach wurden die Zellen erneut zweimal in Hepes-gepuffertem DMEM-Medium gewaschen. In gleicher Weise wurde auch eine Kontrolle mit DMSO behandelt. Die Menge des DMSO entsprach der Menge des Cathepsin-B-Inhibitors in der Konzentration von 20 $\mu \mathrm{M}$.

\subsubsection{6 ${ }^{51}$ Chrom-Freisetzungs-Test mit Zugabe von Inhibitor zu den Effektorzellen}

Der Einfluss der Cathepsin-B-Inhibition der Effektorzellen auf die Lyse von RMA-Tumorzellen wurde untersucht, indem in einem Teil der Versuche der Cathepsin-B-Inhibitor nur zu den Effektorzellen gegeben wurde. Es wurde der zellmembranpermeable Cathepsin-B-Inhibitor CA-074 Me eingesetzt. Der Inhibitor wurde in der Konzentration von $20 \mu \mathrm{M}$ oder $5 \mu \mathrm{M}$ zu den Effektorzellen gegeben und eine Stunde bei $37^{\circ} \mathrm{C}$ inkubiert. Anschließend wurden die Zellen zweimal mit Hepes-gepuffertem DMEM-Medium gewaschen, bevor sie zum 
${ }^{51}$ Chrom-Freisetzungs-Test hinzu gegeben wurden. Es wurde auch wieder eine Kontrolle mit DMSO durchgeführt. Das DMSO wurde in derselben Menge wie der Inhibitor in der höheren Konzentration zu den OT-1-Zellen gegeben, bevor sie für eine Stunde bei $37^{\circ} \mathrm{C}$ inkubiert und zweimal mit Hepes-gepuffertem DMEM-Medium gewaschen wurden.

\subsubsection{7 ${ }^{51}$ Chrom-Freisetzungs-Test mit MEF}

Neben den RMA-Zellen wurden auch embryonale Mäusefibroblasten (MEF) als Zielzellen eingesetzt. Diese Fibroblasten stammten zum einen aus CathepsinB-knock-out-Mäusen (CathB -/-). Als Vergleichskontrolle dienten Fibroblasten von Cathepsin-B-Wildtyp-Mäusen (CathB Wt). Um die Expression der MHCKlasse-I-Moleküle ( $\mathrm{H} 2 \mathrm{~K}^{\mathrm{b}}$, das Restriktionselement für das SIINFEKL-Peptid) auf den MEF zu erhöhen, wurden diese Zellen 48 Stunden vor Testbeginn mit 1000 $\mathrm{U} / \mathrm{ml}$ IFN- $\gamma$ stimuliert. Die MHC-Klasse-I-Expression wurde mittels Durchflusszytometrie bestimmt. Der Versuchablauf entsprach dem unter 2.2.2.3 beschriebenen ${ }^{51}$ Chrom-Freisetzungs-Test.

\subsubsection{Durchflusszytometrie}

\subsubsection{Allgemeines zur Durchflusszytometrie}

Durch die Durchflusszytometrie kann die Expression von Oberflächenmolekülen und intrazellulären Proteinen bestimmt werden und so können Zellen hinsichtlich der Expression dieser Moleküle oder Proteine verglichen werden. Als Grundlage dient häufig eine Antigen-Antikörper-Reaktion mit fluoreszenzmarkierten monoklonalen Antikörpern. Diese Antikörper sind spezifisch für Strukturen auf der Zelloberfläche oder im Zellinneren. Diese Markierung kann direkt oder indirekt geschehen. Zur Ermittlung unspezifischer Bindungen wird ein Teil der Zellen mit einem Antikörper des gleichen Isotyps inkubiert, dieser richtet sich aber gegen Strukturen, die auf den zu analysierenden Zellen nicht 
vorkommen. Die Isotypenkontrolle wird dann bei der Auswertung von der Fluoreszenz der untersuchten Zellen abgezogen. Die Zellen werden in Einzelsuspension in die Messkammer angesaugt und so einzeln in einem laminären Strom aus Spülflüssigkeit an einem Laserstrahl geeigneter Wellenlänge vorbei geleitet. Die Zellen emittieren Licht proportional zu der Menge ihrer gebundenen Antikörper.

\subsubsection{Bestimmung der MHC-Klasse-I-Expression auf MEF-Zellen mittels Durchflusszytometrie}

Parallel zu jedem Chromtest, bei dem die MEF als Zielzellen eingesetzt wurden, wurde die MHC-Klasse-I-Expression auf den Zielzellen gemessen. Diese Messung erfolgte durch eine Färbung mit einem direkt markierten Antikörper. Die MHC-Klasse-I-Expression der RMA-Zellen wurde als Positivkontrolle zusätzlich bestimmt. Von den MEF wurden sowohl Zellen, die mit IFN- $\gamma$ stimuliert wurden, gemessen als auch nicht stimulierte Zellen. Dadurch wurde überprüft, ob die Stimulation erfolgreich war.

Die zu messenden Zellen wurden auf je 3 FACS-Röhrchen verteilt, mit PBS aufgefüllt und 5 Minuten bei $300 \times \mathrm{g}$ zentrifugiert. Der Überstand wurde verworfen. Im ersten Röhrchen wurden die Zellen nicht gefärbt. Im zweiten Röhrchen wurden die Zellen mit $1 \mu$ der Isotypenkontrolle (mlgG ${ }_{2 a}$, RPEkonjugiert) inkubiert. Im dritten Röhrchen wurden die Zellen mit $1 \mu$ l eines RPEkonjugierten Antikörpers gegen $\mathrm{H} 2 \mathrm{~K}^{\mathrm{b}}$ gefärbt. Die Zellen wurden 30-45 Minuten im Kühlschrank inkubiert, dann mit PBS aufgefüllt und 5 Minuten bei $300 \times \mathrm{g}$ gewaschen. Der Überstand wurde verworfen. Danach wurde in jedes FACSRöhrchen $300 \mu \mathrm{l}$ PBS gegeben und die Fluoreszenzintensität wurde im FACScan gemessen und mit dem Programm Cell Quest ausgewertet. 


\subsubsection{Westernblot-Analyse}

\subsubsection{Allgemeines zur Westernblot-Analyse}

Der Westernblot ist ein Verfahren zum Nachweis spezifischer Proteine aus einem komplexen Proteingemisch mit Hilfe von Antikörpern. Nach Auftrennung der Proteine (abhängig von ihrer Größe) durch Gelelektrophorese werden diese durch ein senkrecht zum Gel angelegtes elektrisches Feld aus der Polyacrylamidmatrix auf eine Membran aus Nitrocellulose transferiert. Dabei bleibt das Muster der elektrophoretischen Auftrennung erhalten. Anschließend werden sie mittels spezifischen Antikörpern detektiert. Der gebundene erste Antikörper wird durch einen zweiten Antikörper, der an ein Enzym gebunden ist, detektiert und so sichtbar gemacht.

\subsubsection{Erstellen von Zell-Lysaten für den Westernblot}

1-2 × $10^{6}$ Zellen wurden in ein Röhrchen überführt und mit PBS aufgefüllt. Anschließend wurden die Zellen bei 300 x g 5 Minuten zentrifugiert, der Überstand wurde verworfen. Die Zellen wurden in $1 \mathrm{ml}$ PBS aufgenommen und in ein Eppendorf-Cup überführt und in diesem wieder 5 Minuten bei $300 \times \mathrm{g}$ zentrifugiert. Der Überstand wurde verworfen und die restliche Flüssigkeit von dem Zellpellet mit einer Pipette abgesaugt. Anschließend wurde das Zellpellet bei $-20^{\circ} \mathrm{C}$ eingefroren.

Um die Zellpellets im Westernblot auftrennen zu können, wurden pro $2 \times 10^{5}$ Zellen $30 \mu \mathrm{l}$ reduzierender Probenpuffer hinzugegeben. Dann wurden die Proben 5 Minuten bei $95^{\circ} \mathrm{C}$ gekocht, kurz gevortext und für 5 Minuten bei 10.000 x g zentrifugiert. Jetzt konnten die Lysate in einer SDS-PolyacrylamidGelelekrophorese aufgetrennt werden. 


\subsubsection{SDS-Polyacrylamid-Gelelktrophorese}

Zum Aufbau der Gelkammer wurden 2 Glasplatten $(19 \times 19,5 \mathrm{~cm}$ und $16 \times 16,5$ $\mathrm{cm})$ mit Isopropanol gereinigt, die Spacer wurden bündig auf 3 Seiten der größeren Platte gelegt und die kleinere Platte wurde darauf mit je 3 Klammern an jeder Seite befestigt. Das Trenngel wurde zwischen die beiden Platten gegossen bis ca. $3 \mathrm{~cm}$ unter den Rand der kleineren Platte und sofort mit ca. $0,5 \mathrm{ml}$ Isopropanol überschichtet. Dann musste das Trenngel ca. 30 Minuten aushärten. Das Isopropanol wurde mit destilliertem Wasser ausgespült, das Sammelgel über das Trenngel geschichtet und sofort ein Kamm mit Kammern gesteckt. Nach ca. 1 Stunde war das Gel ausgehärtet. Wenn das Gel nicht sofort benötigt wurde, wurde es in feuchte Tücher und Frischhaltefolie gewickelt und im Kühlschrank aufbewahrt.

Das Gel wurde nach Entfernen der Klammern, des unteren Spacers und des Kamms mit Klammern an der Elektrophoreseapperatur befestigt und in die obere und untere Kammer wurde 1 x SDS-Laufpuffer gegeben. Die Blasen am unteren Rand der Gelkammer wurden mit einer Spritze mit Laufpuffer entfernt. Dann wurde in die erste Tasche zunächst ein Proteinmarker als Längenstandard gegeben. Dieser enthält eine Mischung von Proteinen bekannter Größe. In die folgenden Kammern wurden $30 \mu$ oder $50 \mu$ der Zelllysate gegeben. Dann wurde eine Spannung von $20 \mathrm{~mA}$ angelegt, bis die Proben das Trenngel erreicht hatten. Anschließend wurde eine Spannung von $40 \mathrm{~mA}$ eingestellt, solange bis die Proben am unteren Rand angelangt waren. Dann wurde die Elektrophorese gestoppt, die Platten aus der Apparatur genommen und vorsichtig getrennt. Das Gel wurde vorsichtig von der Platte gelöst und zurechtgeschnitten. Das Gel wurde in Transferpuffer gegeben und 10 Minuten auf dem Schüttler äquibriliert. 


\subsubsection{Der Westernblot}

Der Transfer der Proteine auf die Nitrocellulosemembran erfolgte auf elektrophoretischem Weg. Beim Zusammenstellen des Blots war darauf zu achten, dass alle Teile mit Transferpuffer befeuchtet waren und keine Luftblasen zwischen Gel und Nitrozellulose vorhanden waren. Zu beachten war auch, dass das Filterpapier und die Nitrozellulose nicht wesentlich größer sein sollten, als das Gel.

Aufbau des Blots:

1. Kathode,

2. Schwamm (angefeuchtet mit Transferpuffer),

3. Wathman Filterpapier (angefeuchtet mit Transferpuffer),

4. Gel,

5. Nitrozellulose,

6. Wathman Filterpapier (angefeuchtet mit Transferpuffer),

7. Schwamm (angefeuchtet mit Transferpuffer),

8. Anode.

Dann wurde die Transferapparatur in eine vertikale Blotkammer mit Transferpuffer gegeben und über Nacht bei $4^{\circ} \mathrm{C}$ mit 16 Volt geblottet. Hierfür wird senkrecht zu dem Gel ein elektrisches Feld angelegt, so dass die negativ geladenen Proteine auf die Nitrozellulose-Membran übertragen werden. Deswegen war es wichtig, beim Aufbau der Transferapperatur Blasen zwischen dem Gel und der Nitrozellulose-Membran zu vermeiden.

\subsubsection{Immunfärbung der transferierten Proteine}

Am nächsten Tag erfolgte die Immunfärbung des Blots. Die Inkubationsschritte wurden auf einem Schüttler durchgeführt. Die Nitrocellulose wurde eine Stunde in PBS/Tween gewaschen. Dann wurde die Nitrozellulose in einer Ponceau-SLösung (1:10 in PBS verdünnt) gegeben und so die Proteine angefärbt. Die 
Marker wurden eingezeichnet und die Membran in Streifen geschnitten. Danach wurden sie zweimal kurz in PBS/Tween gewaschen.

Eine Hälfte der Nitrozellulose wurde nur mit einem sekundären Antikörper inkubiert. Dieser Streifen wurde in eine Petrischale mit $5 \mathrm{ml}$ PBS/Tween gegeben. Der andere Teil Streifen wurde mit primärem und sekundärem Antikörper inkubiert. Dieser wurde in eine Petrischale mit $5 \mathrm{ml}$ PBS/Tween, 10

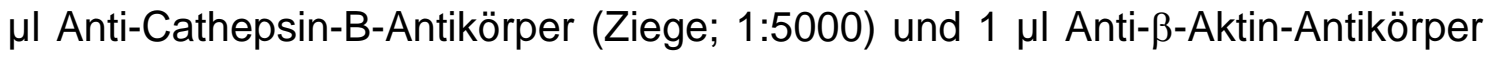
(Maus; 1:5000) gegeben. $\beta$-Aktin färbt ein Strukturprotein an, das immer vorhanden ist und als Ladekontrolle und zur Quantifizierung diente.

Die Inkubation erfolgte für 2 Stunden auf dem Schüttler, danach wurde die Nitrozellulose 3 × 5 Minuten mit PBS/Tween gewaschen. Anschließend erfolgte die Inkubation mit dem sekundären Antikörper. Hierfür wurden beide Hälften der Nitrozellulose in einer Petrischale mit $10 \mathrm{ml}$ PBS, $5 \mu \mathrm{l}$ Meerrettichperoxidasekonjugiertem Kaninchen anti-Ziege IgG (1:2000) bzw. $5 \mu l$ Meerrettichperoxidase-konjugiertem Ziege anti-Maus IgG (1:2000) und für 1,5 Stunden inkubiert. Danach wurden sie viermal für 5 Minuten gründlich in PBS/Tween gewaschen.

Die Substratreaktion erfolgte, indem die Nitrozellulose kurz in einen Ansatz mit $50 \mathrm{mg}$ DAB, $50 \mathrm{ml}$ PBS/Tween und $50 \mu \mathrm{H} \mathrm{H}_{2} \mathrm{O}_{2}$ getaucht wurde. Im Anschluss wurde die Nitrozellulose 2 x für 10 Minuten in PBS/Tween gewaschen und danach ließ man sie zwischen zwei Whatman-Filterpapieren trocknen.

\subsubsection{Statistische Analyse}

Die Signifikanzprüfung erfolgte im Fall der Überprüfung der Expression der MHC-Klasse-I-Moleküle auf MEF mit einem nichtparametrischen Test für zwei unabhängige Stichproben, dem Mann-Whitney-U-Test. Als Signifikanzniveau wurde $\alpha=0,05$ angenommen.

Die Varianzanalyse (ANOVA) zur Evaluierung der ${ }^{51}$ Chrom-Freisetzungs-Tests wurde in der Abteilung Genetische Epidemiologie des Zentrums für Informatik, Statistik und Epidemiologie der Georg-August-Universität Göttingen 
durchgeführt. Für alle Experimente wurde ein Signifikanzniveau von $\alpha=0,05$ angenommen. Behandlung, Effektor-Zielzell-Verhältnis, Testfaktoren und deren Interaktionen wurden in das statistische Modell mit einbezogen. Aufgrund einer begrenzten Probengröße zweier Experimente wurde in diesen Fällen ein reduziertes Modell mit weniger Interaktionsgrößen gewählt. Anpassungen für Mehrfachvergleiche wurden mit Hilfe des Tukey-Kramer Verfahrens durchgeführt. 


\section{Ergebnisse}

3.1 Einfluss des zellmembranimpermeablen Cathepsin-B-Inhibitors CA-074 auf die Lyse von Tumorzellen durch CTL

Es wurde in früheren Studien gezeigt, dass CTL sich mittels Cathepsin B, das an der Zelloberfläche exprimiert wird, vor den von innen ausgeschütteten Perforinen schützen (Balaji et al. 2002). Im Rahmen einer Bachelor-Arbeit wurden in unserem Labor präliminäre Experimente durchgeführt, bei denen sich für RMA-Tumorzellen der Hinweis ergab, dass diese sich mittels Cathepsin B vor der Lyse durch CTL schützen (Ribarska and Dressel, 2005). In diesen Experimenten war der Cathepsin-B-Inhibitor CA-074 verwendet worden, um extrazelluläres Cathepsin B zu inhibieren.

In den folgenden Experimenten wurde daher der Einfluss des Cathepsin-BInhibitors CA-074 auf die CTL-induzierte Apoptose systematisch untersucht.

3.1.1 Signifikante Verbesserung der durch CTL induzierten Lyse von Tumorzellen durch den zellmembranimpermeablen Cathepsin-B-Inhibitor CA-074

Als Methode zur Bestimmung der durch CTL induzierten spezifischen Lyse von Tumorzellen wurde der ${ }^{51} \mathrm{Chrom}$-Freisetzungs-Test eingesetzt. Die CTL wurden aus der Milz von OT-I-Mäusen gewonnen, die transgen für einen bestimmten Vo2ß5-T-Zell-Rezeptor sind (Hogquist et al. 1994). Dieser ist spezifisch für das aus dem Ovalbumin abgeleitete Peptid SIINFEKL (Ovalbumin aa 257-264), das durch das MHC-Klasse-I-Molekül $\mathrm{H}_{2} \mathrm{~K}^{\mathrm{b}}$ präsentiert wird. Als Zielzellen wurden RMA-Zellen eingesetzt. Dies sind Zellen einer T-Zell-Lymphom-Linie einer Maus, die $\mathrm{H} 2 \mathrm{~K}^{\mathrm{b}}$-Moleküle exprimieren und daher nach Zugabe des SIINFEKLPeptids durch aktivierte CTL aus OT-I-Mäusen lysiert werden können.

Die Peptidspezifität des CTL-vermittelten Killings wurde jeweils durch eine Kontrolle ohne Beigabe des Peptids SIINFEKL gezeigt. Als Positivkontrolle 
diente ein Ansatz, zu dem das Peptid, aber kein Cathepsin-B-Inhibitor gegeben wurde. Um identische Bedingungen zu schaffen, wurde zu diesem Ansatz auch DMSO hinzu gegeben, da der Inhibitor in DMSO gelöst war. Die verwendete Menge an DMSO entsprach immer der größten eingesetzten Menge an Inhibitor. Der Cathepsin-B-Inhibitor wurde in der Konzentration von $20 \mu \mathrm{M}, 10$ $\mu \mathrm{M}$ und $5 \mu \mathrm{M}$ verwendet. Als Nachweis, dass die Lyse über den GranulaExozytose-Weg vermittelt wird und daher calciumabhängig ist, wurde zu einem Ansatz der Calciumbinder EGTA gegeben.

Die Ergebnisse der Versuche sind in Abbildung 2 dargestellt. Es zeigte sich eine signifikante Verbesserung der CTL-induzierten Lyse von RMA-Zellen in Anwesenheit des Cathepsin-B-Inhibitors CA-074 in der Konzentration von $5 \mu \mathrm{M}$ gegenüber der Vergleichskontrolle mit DMSO ( $p=0,0039$, ANOVA). Auch wenn der Inhibitor in der Konzentration von $10 \mu \mathrm{M}$ eingesetzt wurde, war die Lyse leicht erhöht. Eine Verbesserung der Lyse zeigte sich dagegen nicht bei Einsatz des Inhibitors CA-074 in einer Konzentration von $20 \mu \mathrm{M}$.

In Abbildung 2A ist gezeigt, dass in Anwesenheit des Calziumbinders EGTA keine Lyse von RMA durch peptidspezifische CTL stattfindet. Die Lyse von RMA-Zellen bei einem Effektor:Zielzell-Verhältnis von 5:1 und 2,5:1 in der Negativkontrolle in dem in Abbildung 2A gezeigten Experiment ist wahrscheinlich durch eine Verschleppung des Peptids in diesen Ansatz zu erklären. 
A:

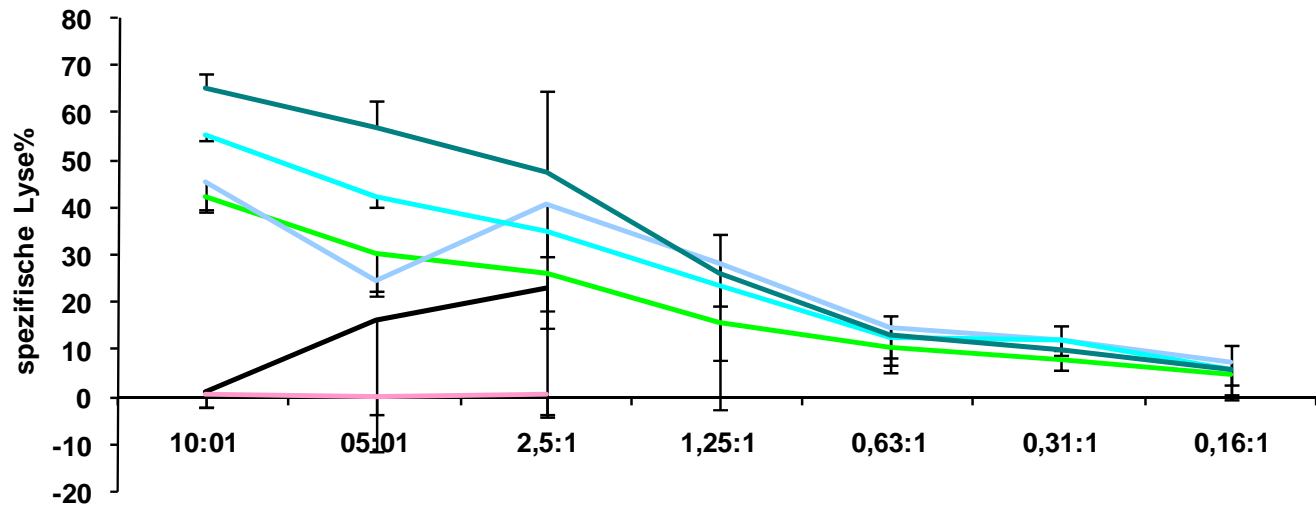

Killer:Zielzell Verhältnis

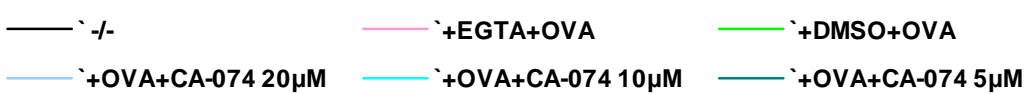

B:

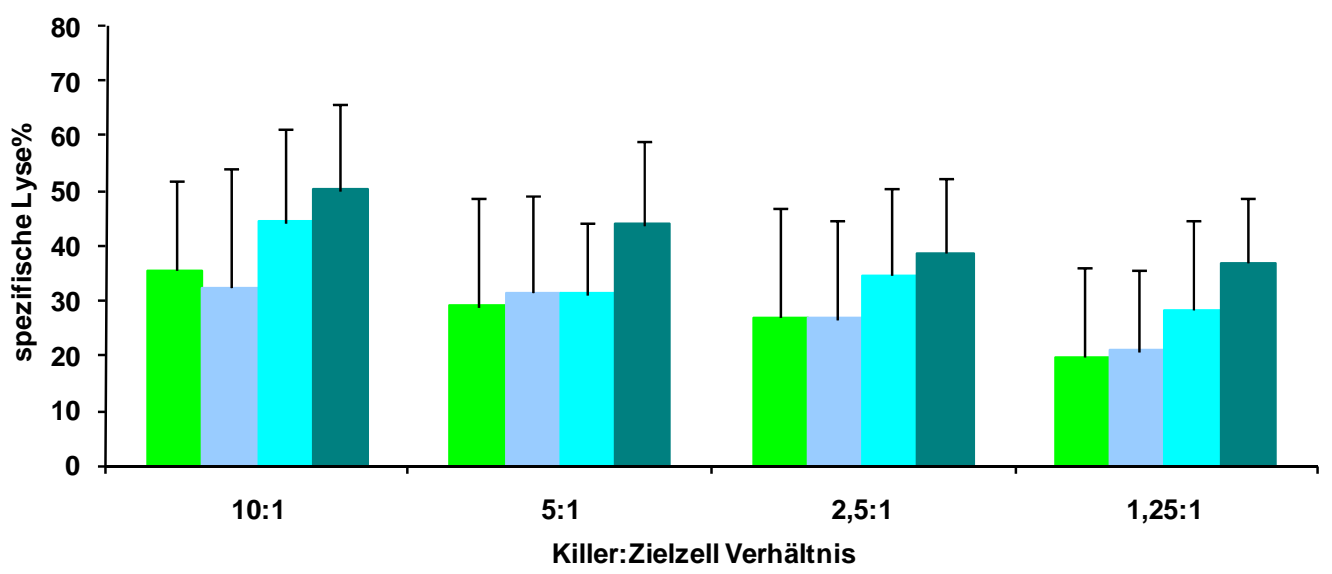

-OOVA+DMSO (n=11)

- $+O V A+C A-07420 \mu \mathrm{M}(\mathrm{n}=9)$

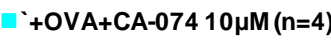

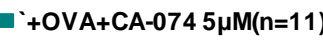

Abbildung 2: Spezifische Lyse von RMA-Zellen durch CTL in Abhängigkeit von der Konzentration des zellmembranimpermeablen Cathepsin-B-Inhibitors CA-074

Zur Bestimmung der spezifischen Lyse wurde der ${ }^{51}$ Chrom-Freisetzungs-Test eingesetzt. Als Zielzellen dienten RMA-Zellen, Effektorzellen waren peptidspezifische CTL.

A Ein einzelnes Experiment ist exemplarisch dargestellt. Zu den Kontrollen gehört eine Negativkontrolle ohne SIINFEKL (-/-) und eine Kontrolle der Calciumabhängigkeit der Lyse (+EGTA+OVA), zu der EGTA/MgCl 2 und das SIINFEKL-Peptid gegeben wurde. Zu einem weiteren Ansatz wurde das SIINFEKL-Peptid und das Lösungsmittel DMSO (+OVA+DMSO) oder der in DMSO gelöste Cathepsin-B-Inhibitor CA-074 in der jeweiligen Konzentration gegeben (+OVA+CA-074 20 $\mu \mathrm{M} / 10 \mu \mathrm{M} / 5 \mu \mathrm{M}$ ). Alle Ansätze erfolgten als Tripletts. Es sind jeweils die mittlere Lyse und die Standardabweichung dargestellt. B zeigt die Zusammenfassung der Mittelwerte der einzelnen Experimente und deren Standardabweichung. 


\subsubsection{Bestimmung der relativen Lyse}

Um eine bessere Vergleichbarkeit der Tests herzustellen, wurde für jedes Experiment nicht nur die spezifische Lyse in Prozent bestimmt, sondern auch die relative Lyse im Vergleich zur Kontrolle mit DMSO. Dazu wurde in jedem einzelnen Test der Wert der spezifischen Lyse des Ansatzes mit SIINFEKL und DMSO mit dem Killer:Zielzell-Verhältnis von 10:1 als $100 \%$ festgelegt und die relative Lyse bei allen anderen experimentellen Bedingungen berechnet.

Die Ergebnisse dieser Berechnungen sind in Abbildung 3 dargestellt. Auch hier zeigte sich, dass die Lyse von RMA-Zellen durch peptidspezifische CTL in Anwesenheit des Cathepsin-B-Inhibitors CA-074 in der Konzentration von $5 \mu \mathrm{M}$ verbessert wird. Eine geringere Verbesserung zeigte sich in Anwesenheit des Cathepsin-B-Inhibitors in der Konzentration von $10 \mu \mathrm{M}$, jedoch nicht in der Konzentration von $20 \mu \mathrm{M}$. 


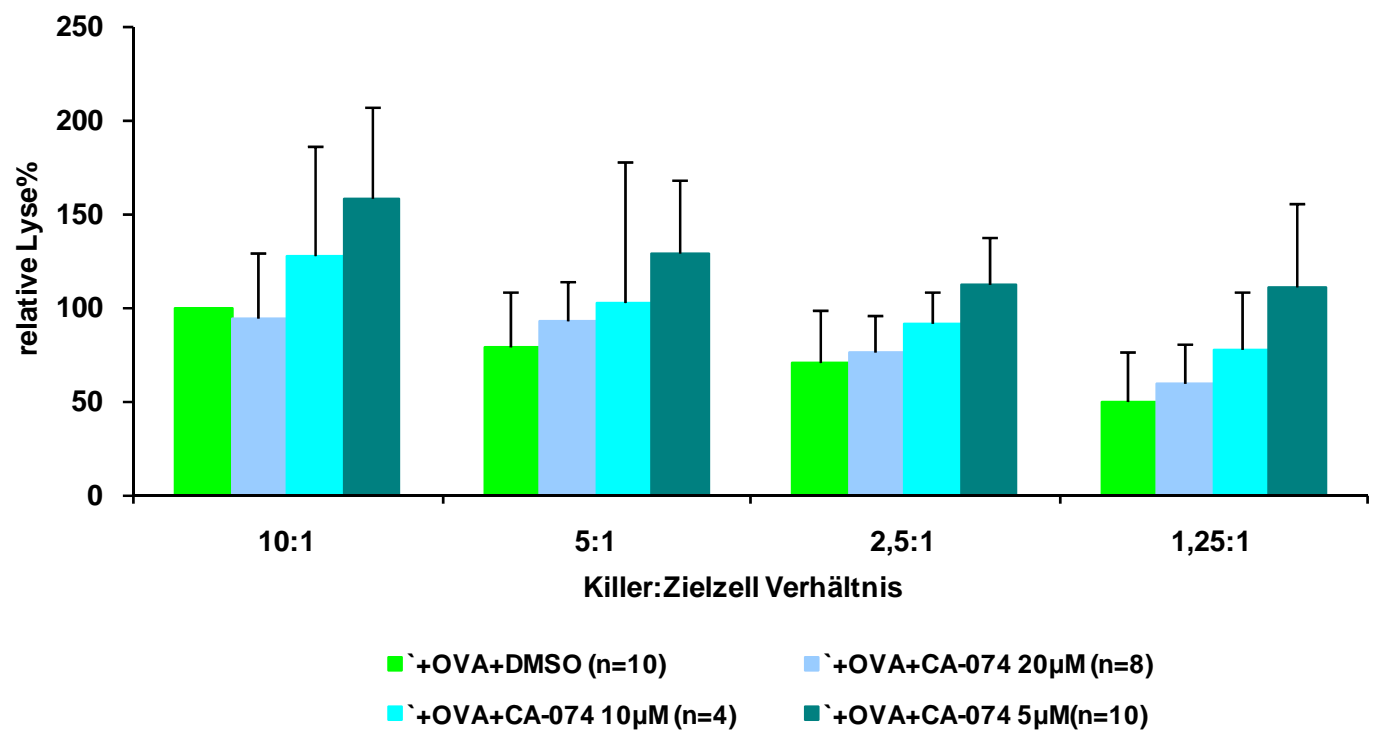

Abbildung 3: Relative Lyse von RMA-Zellen durch CTL in Abhängigkeit von der Konzentration des Cathepsin-B-Inhibitors CA-074

Zur Bestimmung der relativen Lyse wurde der Wert der spezifischen Lyse der Kontrolle +OVA+DMSO 10:1 als 100\% festgesetzt.

Die Abbildung zeigt die Zusammenfassung der Mittelwerte der relativen Lyse und deren Standarabweichung. Zu einem Ansatz wurde das SIINFEKL-Peptid und das Lösungsmittel DMSO (+OVA+DMSO) oder der in DMSO gelöste Cathepsin-B-Inhibitor CA-074 in der jeweiligen Konzentration gegeben (+OVA+CA-074 20 $\mu \mathrm{M} / 10 \mu \mathrm{M} / 5 \mu \mathrm{M})$. Alle Ansätze erfolgten als Tripletts.

3.2 Einfluss des zellmembranpermeablen Cathepsin-B-Inhibitors CA-074 Me auf die Lyse von Tumorzellen durch CTL

Bei Verwendung des zellmembranimpermeablen Cathepsin-B-Inhibitors CA-074 hatte sich eine konzentrationsabhängige Beeinflussung der Lyse von Tumorzellen durch peptidspezifische CTL gezeigt. Da eine andere Studie jedoch Anhaltspunkte dafür lieferte, dass der zellmembranimpermeable Cathepsin-B-Inhibitor CA-074 ab einer Konzentration von $10 \mu \mathrm{M}$ auch intrazelluläres Cathepsin B hemmen kann (Szpaderska and Frankfater 2001), haben wir, um den Einfluss der Inhibition des intrazellulären Cathepsin B auf die Lyse von Tumorzellen durch CTL zu untersuchen, im nächsten Schritt den zellmembranpermeablen Cathepsin-B-Inhibitor CA-074 Me eingesetzt. 
3.2.1 Tendenziell verbesserte Lyse von RMA-Tumorzellen durch den zellmembranpermeablen Cathepsin-B-Inhibitor CA-074 Me

Zur Bestimmung der spezifischen Lyse diente wieder der unter 2.2.2.3 beschriebene ${ }^{51}$ Chrom-Freisetzungs-Test. Diesmal wurde der zellmembranpermeable Cathepsin-B-Inhibitor CA-074 Me in der Konzentration von $5 \mu \mathrm{M}$ und $20 \mu \mathrm{M}$ eingesetzt. Die Ergebnisse der Versuche sind in Abbildung 4 dargestellt. Die Anwesenheit des zellmembranpermeablen Cathepsin-B-Inhibitors CA-074 Me in der Konzentration von $5 \mu \mathrm{M}$ verbesserte tendenziell die Lyse der RMA-Zellen durch CTL gegenüber der Kontrolle mit DMSO, jedoch war diese Verbesserung nicht signifikant ( $p=0,2062$, ANOVA). Die Anwesenheit des Inhibitors CA-074 Me in der Konzentration von $20 \mu \mathrm{M}$ führte zu keiner wesentlichen Verbesserung der Lyse. In Abbildung 4A sieht man, dass die Lyse der RMA-Zellen peptidabhängig erfolgte. In Anwesenheit des Calciumbinders EGTA fand keine Lyse von RMA durch CTL statt. 
A:

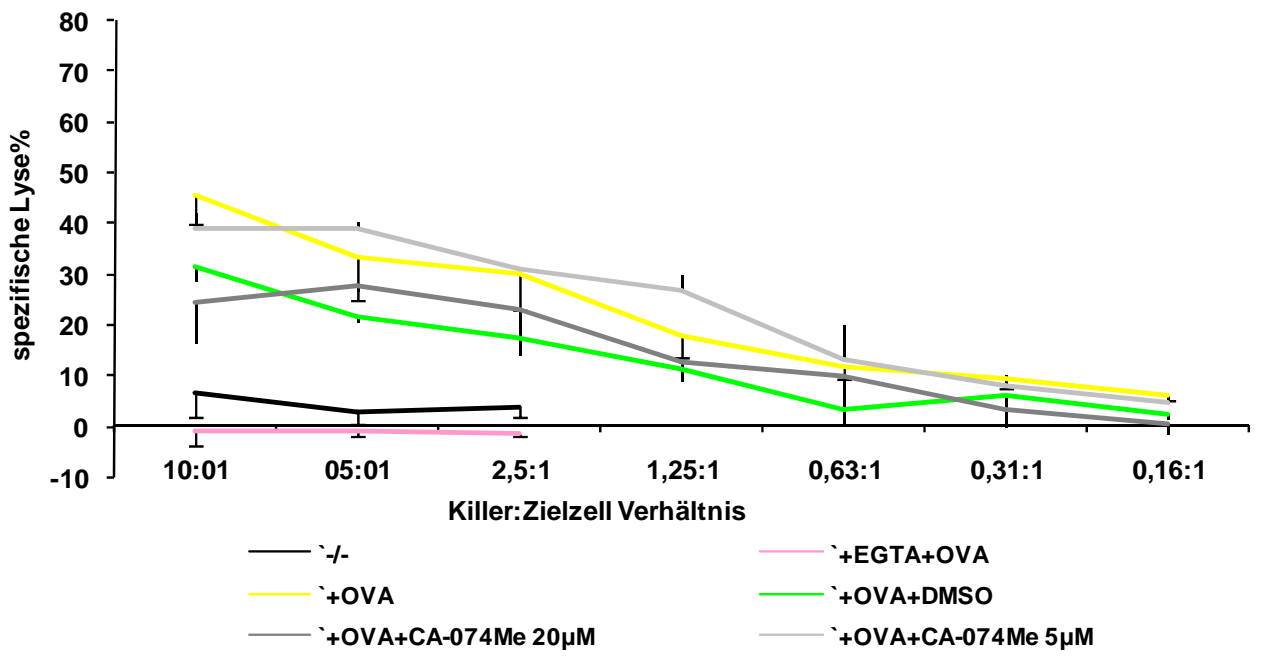

B:

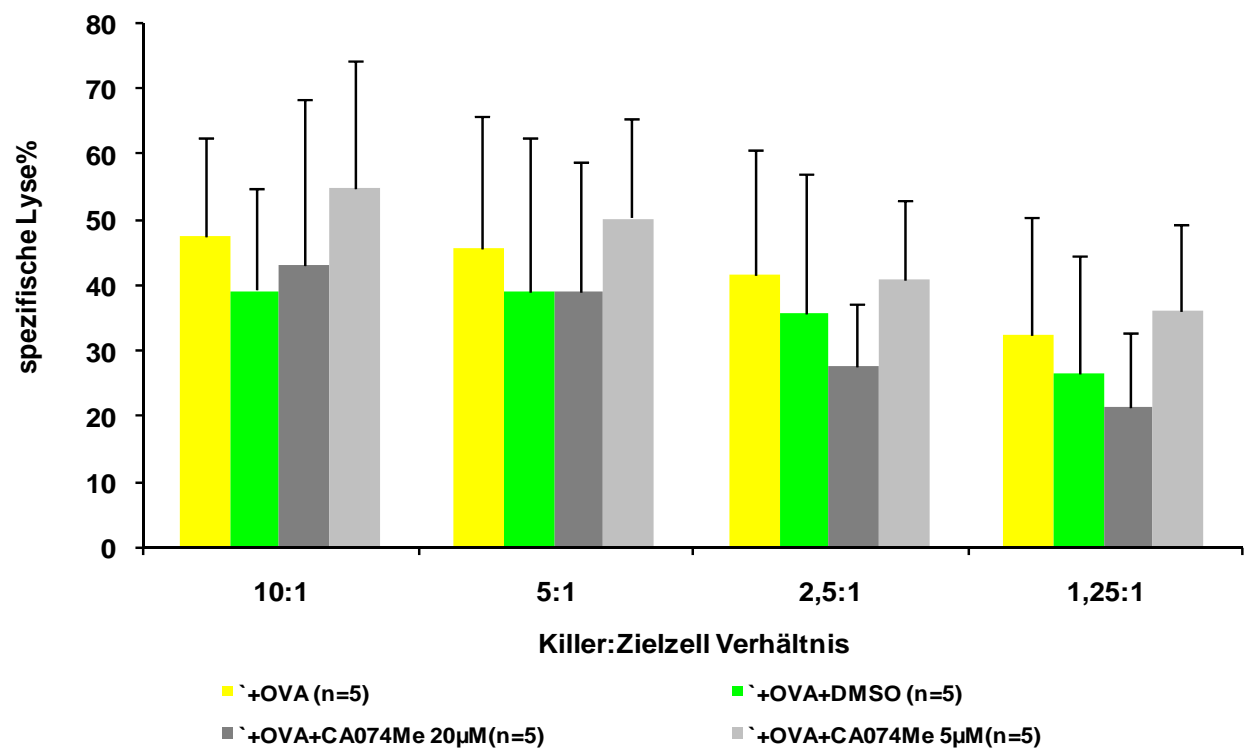

Abbildung 4: Einfluss des zellmembranpermeablen Cathepsin-B-Inhibitors CA-074 Me auf die spezifische Lyse von RMA durch peptidspezifische OT-I-CTL

Die spezifische Lyse wurde durch den ${ }^{51} \mathrm{Chrom}$-Freisetzungs-Test bestimmt. Als Zielzellen wurden RMA-Zellen eingesetzt. Effektorzellen waren peptidspezifische CTL.

A Ein einzelnes Experiment ist exemplarisch dargestellt. Zu den Kontrollen gehört eine Negativkontrolle ohne SIINFEKL (-/-) und eine Kontrolle der Calciumabhängigkeit der Lyse (+EGTA+OVA), zu der EGTA/MgCl ${ }_{2}$ und das SIINFEKL-Peptid gegeben wurde. Zu einem weiteren Ansatz wurde nur das SIINFEKL-Peptid (+OVA) oder zusätzlich das Lösungsmittel DMSO (+OVA+DMSO) oder der in DMSO gelöste Cathepsin-B-Inhibitor CA-074 Me in der jeweiligen Konzentration gegeben (+OVA+CA-074Me $20 \mu \mathrm{M} / 5 \mu \mathrm{M}$ ). Alle Ansätze erfolgten als Tripletts. Es sind jeweils die mittlere Lyse und die Standardabweichung dargestellt. B zeigt die Zusammenfassung der Mittelwerte der einzelnen Experimente und deren Standardabweichung. 


\subsubsection{Bestimmung der relativen Lyse}

Um eine bessere Vergleichbarkeit der Tests herzustellen, wurde auch diesmal für jedes Experiment nicht nur die spezifische Lyse errechnet, sondern auch die relative Lyse im Vergleich zur DMSO-Kontrolle. Die Ergebnisse dieser Berechnungen sind in Abbildung 5 dargestellt. Durch Anwesenheit des zellmembranpermeablen Cathepsin-B-Inhibitors in der Konzentration von $5 \mu \mathrm{M}$ zeigte sich eine tendenzielle Verbesserung der Lyse der RMA-Tumorzellen durch CTL gegenüber der Kontrolle mit DMSO. Wurde der Inhibitor in der Konzentration von $20 \mu \mathrm{M}$ eingesetzt, zeigte sich keine wesentliche Verbesserung der Lyse. Es zeigte sich, dass die Lyse in Anwesenheit des DMSO geringer war, als bei der Kontrolle, die nur das Peptid enthielt.

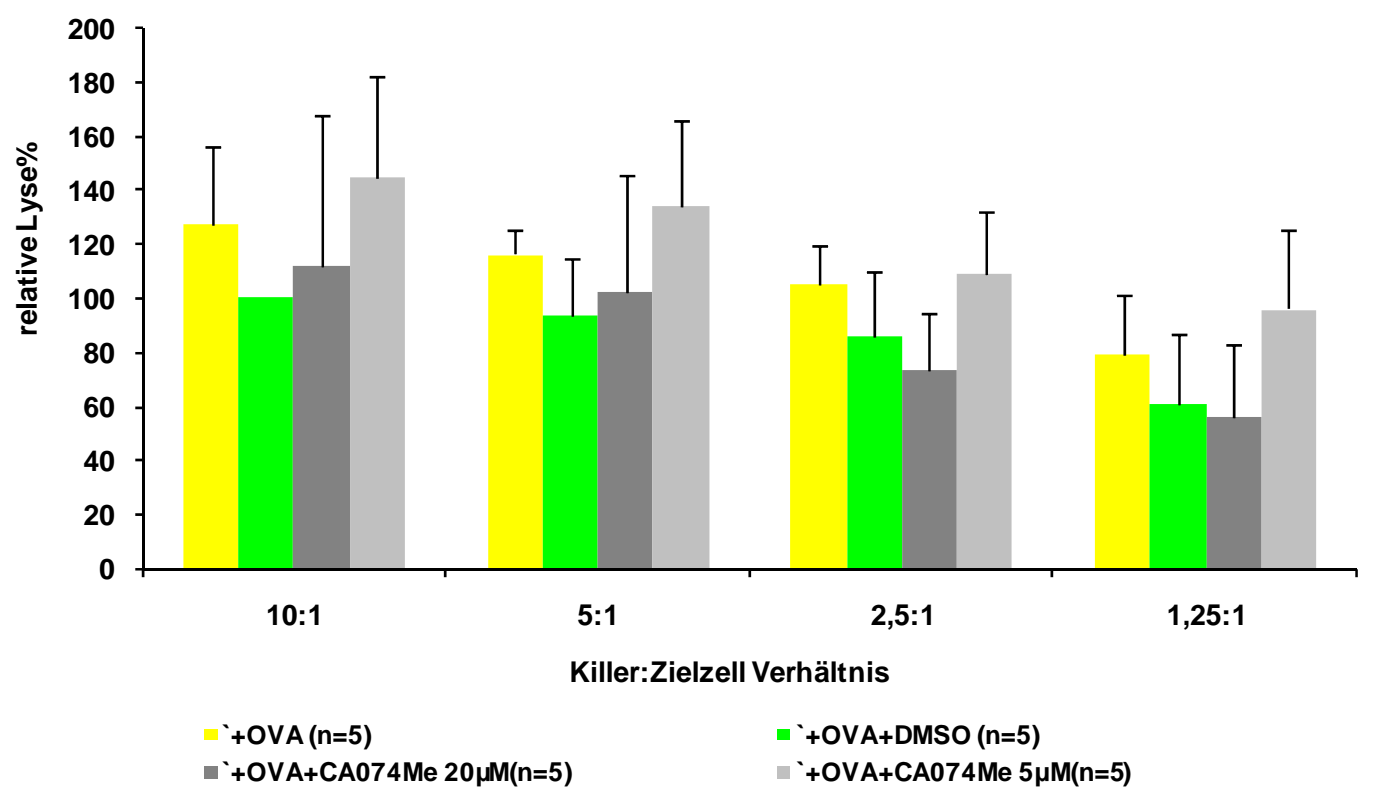

Abbildung 5: Relative Lyse von RMA-Zellen durch CTL in Abhängigkeit von der Konzentration des Cathepsin-B-Inhibitors CA-074 Me

Zur Bestimmung der relativen Lyse wurde der Wert der spezifischen Lyse der Kontrolle +OVA+DMS0 10:1 als 100\% festgesetzt.

Die Abbildung zeigt die Zusammenfassung der Mittelwerte der relativen Lyse und deren Standardabweichung. Zu einem Ansatz wurde nur das SIINFEKL-Peptid (+OVA) oder zusätzlich das Lösungsmittel DMSO (+OVA+DMSO) oder der in DMSO gelöste Cathepsin-BInhibitor CA-074 Me in der jeweiligen Konzentration gegeben (+OVA+CA-074Me 20 $\mu \mathrm{M} / 5 \mu \mathrm{M}$ ). Alle Ansätze erfolgten als Tripletts. 
3.3 Einfluss der ausschließlichen Inhibition des Tumorzell-assoziierten Cathepsin B auf die Lyse durch CTL

Da Cathepsin B von CTL nach der Degranulation auf der Zelloberfläche exprimiert wird, um diese vor dem ausgeschütteten Perforin zu schützen (Balaji et al. 2002), sollte im nächsten Teil der Versuche verhindert werden, dass die Cathepsin-B-Inhibitoren auch das Cathepsin B auf der Oberfläche der CTL beeinflussen.

3.3.1 Bei ausschließlicher Inhibition des Tumorzell-assoziierten Cathepsin B wird die Lysibilität durch CTL nicht wesentlich verbessert

Der Versuchsaufbau war ähnlich wie in Abschnitt 3.1 und 3.2. Als Methode zur Bestimmung der durch peptidspezifische CTL induzierten Lyse von RMA-Zellen wurde der ${ }^{51}$ Chrom-Freisetzungs-Test verwendet.

Die Zielzellen wurden eine Stunde mit dem Isotop ${ }^{51} \mathrm{Chrom}\left(\mathrm{Na}_{2}{ }^{51} \mathrm{CrO}_{4}\right)$ inkubiert, danach wurden sie zweimal gewaschen. Im Anschluss wurden die Zielzellen mit dem Cathepsin-B-Inhibitor CA-074 oder CA-074 Me in der Konzentration von $5 \mu \mathrm{M}$ oder $20 \mu \mathrm{M}$ für eine Stunde bei $37^{\circ} \mathrm{C}$ inkubiert. Nach einer Stunde wurden die Zielzellen wieder zweimal gewaschen. Erst danach wurden sie für vier Stunden mit den Effektorzellen inkubiert.

Im Verlauf der Versuche gab es das Problem, dass die spontane ChromFreisetzung (Spontanrelease) der Zielzellen bei diesem Versuchsaufbau oft sehr hoch war. Der Spontanrelease gibt an, wie viele Zellen ohne Einfluss der CTL ${ }^{51}$ Chrom freisetzen. Deswegen wurden alle Versuchsreihen mit einem Spontanrelease höher als $25 \%$ nicht in die abschließende Auswertung mit einbezogen.

Sowohl in dem Einzelexperiment als auch in der vergleichenden Auswertung wird ersichtlich, dass die spezifische Lyse der Ansätze mit Inhibitor sich nicht deutlich von der spezifischen Lyse der Vergleichskontrolle mit DMSO unterscheidet (Abbildung 6). 
Im gezeigten Einzelexperiment zeigte sich, dass das Killing in Anwesenheit des Kalziumbinders EGTA gänzlich unterdrückt wurde. Die geringe Lyse der Zielzellen durch peptidspezifische CTL in Abwesenheit des Peptids (Abbildung 6A) lässt sich wahrscheinlich durch eine Verschleppung des Peptids in den Ansatz erklären. 
A:

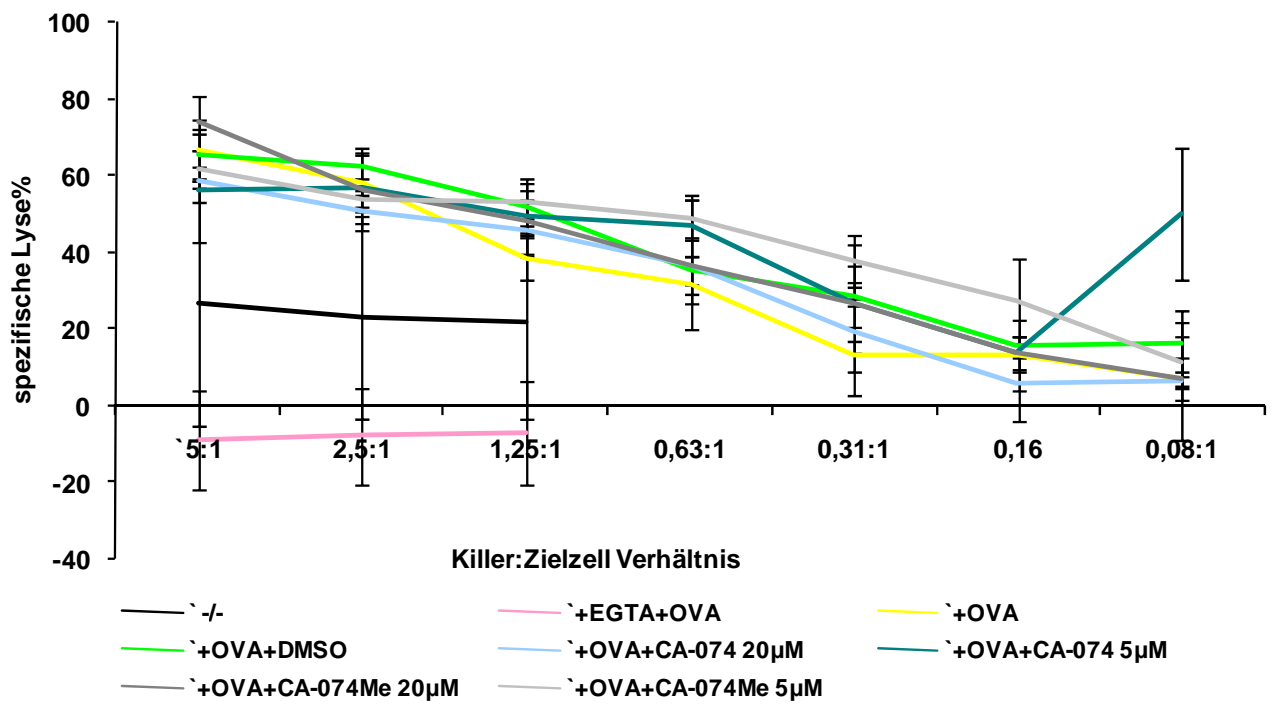

B:

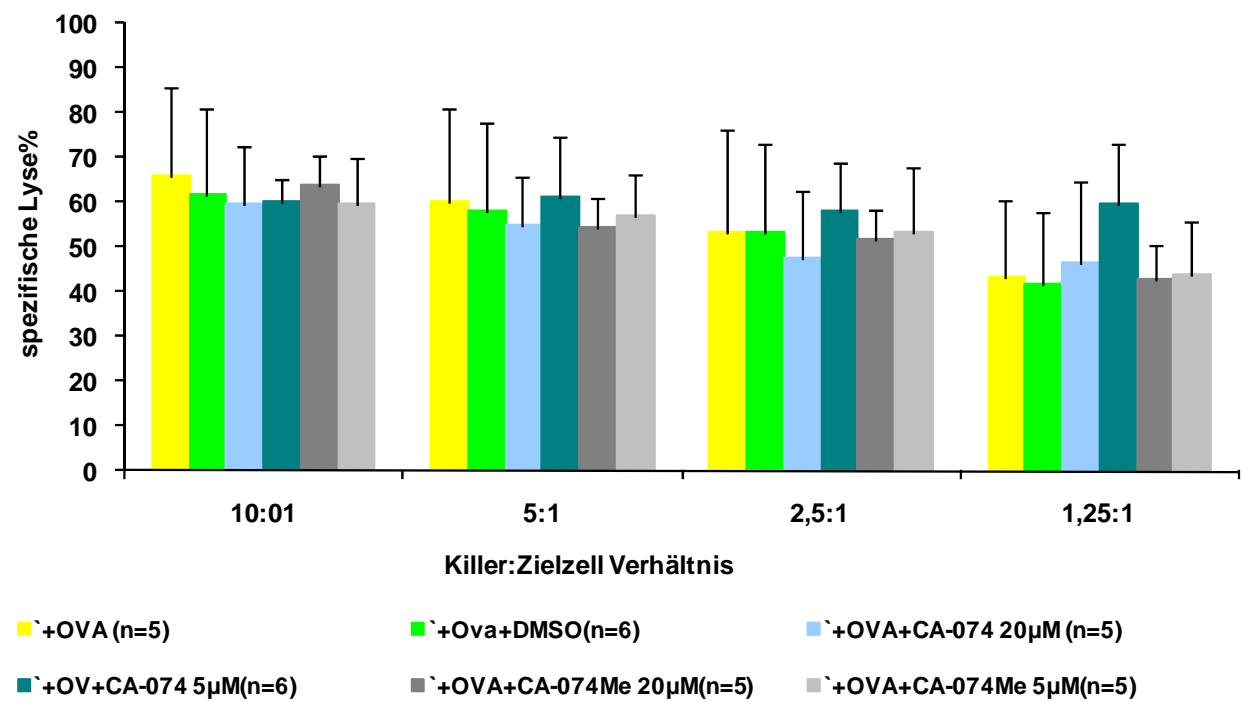

\section{Abbildung 6: Einfluss der Inhibition des Cathepsin B von RMA-Tumorzellen auf die Lyse durch peptidspezifische OT-I-CTL}

Die spezifische Lyse wurde durch den ${ }^{51}$ Chrom-Freisetzungs-Test bestimmt. Als Zielzellen wurden RMA-Zellen eingesetzt. Effektorzellen waren peptidspezifische CTL. Die Cathepsin-BInhibitoren wirkten nur auf die Zielzellen, um einen Einfluss auf das Cathepsin B der CTL zu vermeiden.

A. Ein einzelnes Experiment ist exemplarisch dargestellt. Zu den Kontrollen gehört eine Negativkontrolle ohne SIINFEKL (-/-) und eine Kontrolle der Calciumabhängigkeit der Lyse (+EGTA+ OVA), zu der EGTA/MgCl 2 und das SIINFEKL-Peptid gegeben wurde. Zu einem weiteren Ansatz wurde nur das SIINFEKL-Peptid (+OVA) oder zusätzlich das Lösungsmittel DMSO (+OVA+DMSO) oder der in DMSO gelöste Cathepsin-B-Inhibitor CA-074 in der jeweiligen Konzentration (+OVA+CA-074 20 $\mu \mathrm{M} / 5 \mu \mathrm{M}$ ) oder der in DMSO gelöste Cathepsin-BInhibitor CA-074 Me in der jeweiligen Konzentration gegeben (+OVA+CA-074Me 20 $\mu \mathrm{M} / 5 \mu \mathrm{M}$ ). Alle Ansätze erfolgten als Tripletts. Es sind jeweils die mittlere Lyse und die Standardabweichung dargestellt. B zeigt die Zusammenfassung der Mittelwerte der einzelnen Experimente und deren Standardabweichung. 


\subsubsection{Bestimmung der relativen Lyse}

Um eine bessere Vergleichbarkeit der Tests herzustellen, wurde auch diesmal für jedes Experiment nicht nur die spezifische Lyse in \% errechnet, sondern auch die spezifische Lyse der einzelnen Reihen in prozentualem Anteil zu der Vergleichsreihe mit DMSO bezogen. Dazu wurde der Wert der spezifische Lyse des Ansatzes mit +OVA+DMSO mit dem Killer:Zielzell-Verhältnis von 10:1 als $100 \%$ festgesetzt und der Werte der spezifischen Lyse der anderen Reihen prozentual auf diesen Wert bezogen. Die Ergebnisse sind in Abbildung 7 dargestellt. Auch hier zeigte sich, dass die spezifische Lyse von RMA-Zellen durch peptidspezifische CTL weder durch Präinkubation mit dem Cathepsin-BInhibitor CA-074 noch durch Präinkubation mit dem Inhibitor CA-074 Me verändert wird.

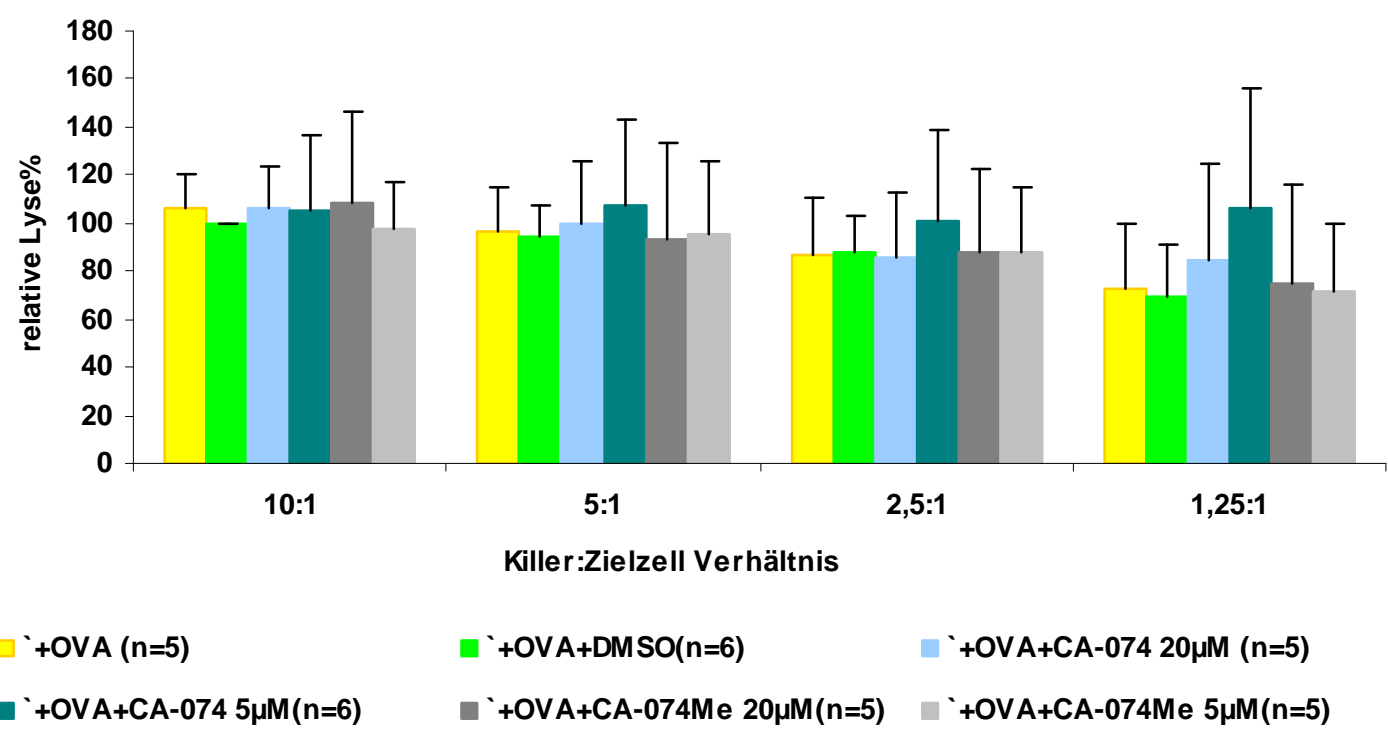

Abbildung 7: Spezifische Lyse in Relation zu dem Wert +OVA+DMSO in der Killer:Zielzell-Konzentration von10:1 als 100\%

Zur Bestimmung der relativen Lyse wurde der Wert der spezifischen Lyse der Kontrolle +OVA+DMS0 10:1 als 100\% festgesetzt.

Die Abbildung zeigt die Zusammenfassung der Mittelwerte der relativen Lyse und deren Standardabweichung. $\mathrm{Zu}$ einem Ansatz wurde nur das SIINFEKL-Peptid (+OVA) oder zusätzlich das Lösungsmittel DMSO (+OVA+DMSO) oder der in DMSO gelöste Cathepsin-BInhibitor CA-074 in der jeweiligen Konzentration (+OVA+CA-074 20 $\mu \mathrm{M} / 5 \mu \mathrm{M}$ ) oder der in DMSO gelöste Cathepsin-B-Inhibitor CA-074 Me in der jeweiligen Konzentration gegeben (+OVA+CA074Me $20 \mu \mathrm{M} / 5 \mu \mathrm{M})$. 
3.4 Vergleich der Lyse von Cathepsin-B-defizienten und Wildtyp-Zielzellen durch CTL

Da man beim Einsatz von Inhibitoren, besonders in höheren Konzentrationen, nie sicher sein kann, dass neben dem Zielmolekül nicht auch andere Moleküle beeinflusst werden, haben wir im folgenden Cathepsin-B-defiziente Zielzellen analysiert, die aus Cathepsin-B-knock-out-Mäusen gewonnen worden waren.

\subsubsection{Cathepsin-B-knock-out- und Cathepsin-B-Wildtyp-MEF}

Im folgenden Versuchsabschnitt wurden Fibroblasten aus Mäuseembryonen (MEF) eingesetzt. Diese Fibroblasten stammten zum einen aus Cathepsin-Bknock-out-Mäusen (CathB -/-). Als Kontrolle dienten Fibroblasten von WildtypMäuseembryonen (CathB Wt). Diese Zellen wurden freundlicherweise von Prof. C. Peters, Institut für Molekulare Medizin und Zellforschung, Universität Freiburg, zur Verfügung gestellt.

\subsubsection{Nachweis von Cathepsin B mittels Westernblot}

Zur Bestätigung, dass die MEF der Cathepsin-B-knock-out-Mäuse tatsächlich kein Cathepsin B exprimieren, wurde ein Westernblot durchgeführt, der das erwartete Ergebnis zeigte (Abbildung 8). 


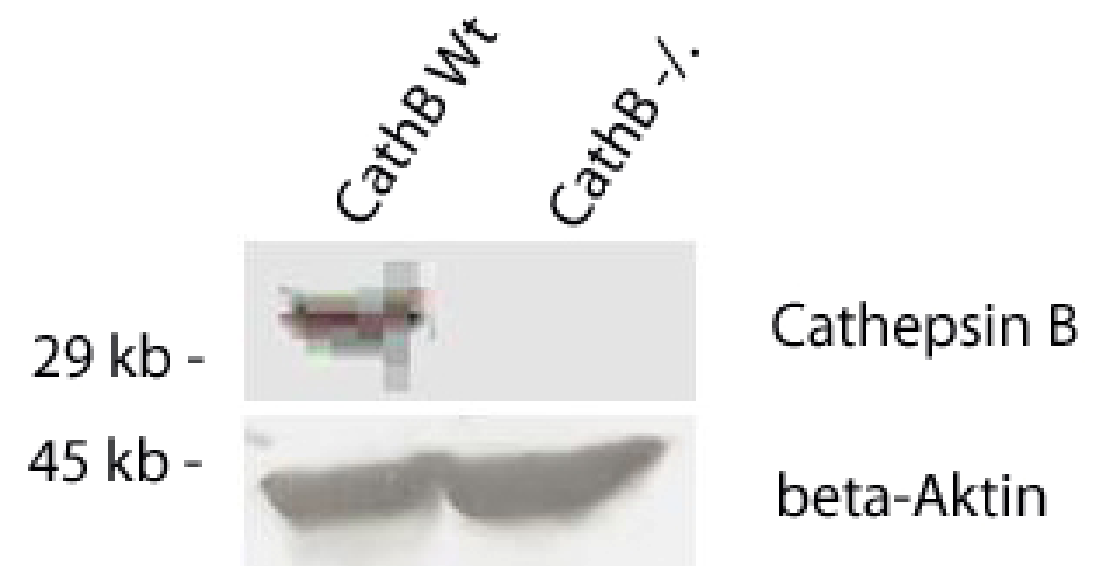

\begin{abstract}
Abbildung 8: Westernblot
Westernblot-Analyse der Cathepsin-B-Expression in Fibroblasten aus Cathepsin-B-knock-outMäuseembryonen (CathB -/-) und als Vergleichskontrolle Wildtyp-Mäuseembryonen (CathB $\mathrm{Wt}$ ). Auf der linken Seite ist der Molekulargewichtsstandard dargestellt. Die Bande in der oberen Abbildung zeigt die Cathepsin-B-Expression in den Wildtyp-Mäuseembryonen an. Die Fibroblasten der Cathepsin-B-knock-out-Mäuse exprimieren kein Cathepsin B. Die beiden Banden im unteren Bild zeigen beta-Aktin, ein Strukturprotein, welches als Ladekontrolle diente.
\end{abstract}

3.4.3 Erhöhung der MHC-Klasse-I-Expression auf MEF nach Stimulation mit Interferon- $\gamma$

Nach den ersten ${ }^{51}$ Chrom-Freisetzungs-Tests zeigte sich, dass sich die MEF kaum durch CTL aus OT-I-Mäusen lysieren ließen. Daher wurde die MHCKlasse-I-Expression auf den MEF untersucht. Diese war tatsächlich so gering, dass die Lyse beeinträchtigt sein könnte. Deswegen wurden im Folgenden 48h vor jedem Test die MEF mit 5000 U/ml IFN- $\gamma$ stimuliert. Dies führte dazu, dass die MEF mehr MHC-Klasse-I-Moleküle auf der Oberfläche exprimierten.

Bei jedem Test wurde durch eine FACS-Messung geprüft, ob die Stimulation mit IFN- $\gamma$ erfolgreich war. Dazu wurde ein Teil der eingesetzten Zellen mit Antikörpern gegen $\mathrm{H} 2 \mathrm{~K}^{\mathrm{b}}$-Moleküle markiert, so dass mittels eines Durchflusszytometers die Menge an MHC-Klasse-I-Molekülen auf der Oberfläche der Zellen gemessen und verglichen werden konnte. 
Abbildung 9 und 10 zeigen die MHC-Klasse-I-Expression der MEF mit und ohne Stimulation durch IFN- $\gamma$. Abbildung 9 zeigt die Auswertung einer FACSMessung einer beispielhaften Stimulation.
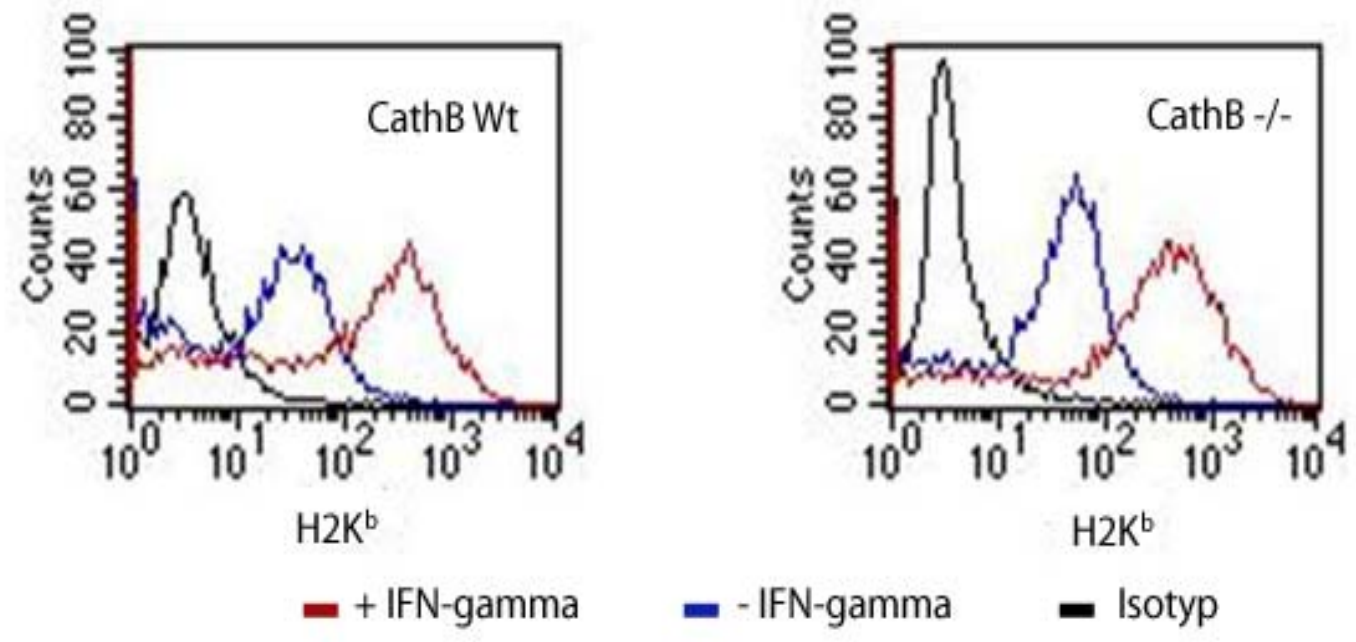

\section{Abbildung 9: Erhöhte MHC-Klasse-I-Expression auf den Zielzellen nach Stimulation mit IFN- $\gamma$}

Die Zielzellen wurden mit einem Antikörper gegen $\mathrm{H} 2 \mathrm{~K}^{\mathrm{b}}$ gefärbt und mittels Durchflusszytometrie analysiert.

Eine einzelne Stimulation ist exemplarisch dargestellt. Gemessen wurde die $\mathrm{H}_{2} \mathrm{~K}^{\mathrm{b}}$-Expression auf Fibroblasten aus Wildtyp-Mäuseembryonen (CathB Wt) und auf Fibroblasten aus Cathepsin-B-knock-out-Mäuseembryonen (CathB -/-). Die schwarze Kurve zeigt die Isotypenkontrolle (Isotyp), die blaue Kurve zeigt die $\mathrm{H} 2 \mathrm{~K}^{\mathrm{b}}$-Expression ohne vorherige Stimulation mit Interferon- $\gamma$ (- IFN-gamma), die rote Kurve zeigt die $\mathrm{H}_{2} \mathrm{~K}^{\mathrm{b}}$-Expression nach vorheriger Stimulation mit $5000 \mathrm{U} / \mathrm{ml}$ IFN- $\gamma$ (+ IFN-gamma) für 48h. Es zeigt sich eine deutliche Erhöhung der $\mathrm{H}_{2} \mathrm{~K}^{\mathrm{b}}$-Expression nach Stimulation mit IFN- $\gamma$.

Abbildung 10 zeigt die Ergebnisse der Stimulationen als Balkendiagramm. Die RMA-Zellen dienten als Positivkontrolle. Abbildung 10A zeigt die Stimulation eines einzelnen Experiments. Abbildung $10 \mathrm{~B}$ zeigt das Mittel der $\mathrm{H}_{2} \mathrm{~K}^{\mathrm{b}}$ Expression der verschiedenen Tests. Es zeigt sich, dass die MHC-Klasse-IExpression durch Stimulation mit IFN- $\gamma$ deutlich erhöht wurde. Das Mittel der $H 2 K^{b}$-Expression zeigte keinen signifikanten Unterschied ( $p=0,5136$, MannWhitney-U-Test). 
A:

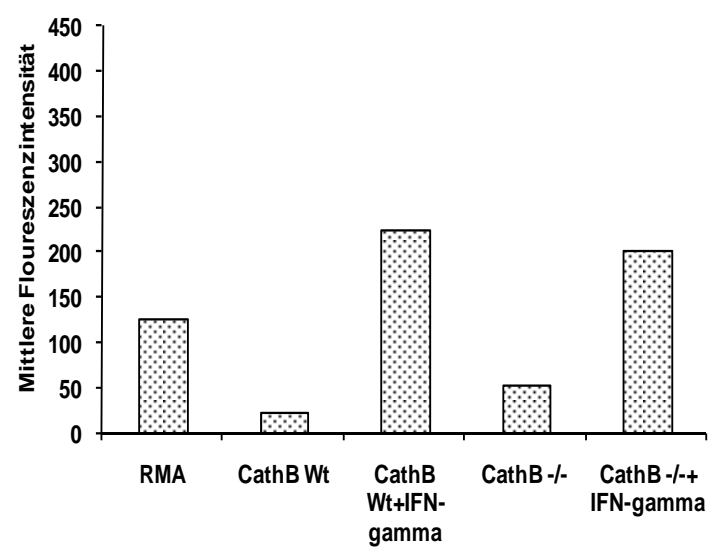

B:

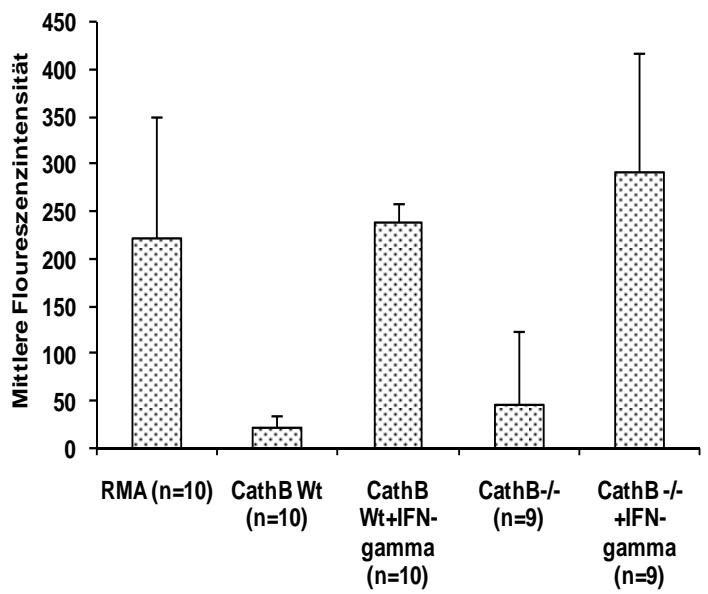

Abbildung 10: MHC-Klasse-I-Expression auf den Zielzellen mit und ohne Stimulation mit IFN- $\gamma$

Die Zielzellen wurden mit einem Anti-H2 $\mathrm{K}^{\mathrm{b}}$-Antikörper gefärbt und mittels Durchflusszytometrie analysiert.

A zeigt beispielhaft anhand eines Experiments, dass die $\mathrm{H} 2 \mathrm{~K}^{\mathrm{b}}$-Expression auf den Zielzellen durch das IFN- $\gamma$ erhöht wird. (RMA) sind Zellen einer Maus-T-Zell-Lymphom-Linie; CathB Wt sind Zellen von Wildtyp-Mäuseembryonenfibroblasten, die Cathepsin B exprimieren; (CathB Wt+IFN-gamma) bedeutet, dass die CathB Wt Zellen 48h zuvor mit $5000 \mathrm{U} / \mathrm{ml}$ IFN- $\gamma$ stimuliert wurden; (CathB-/-) sind Zellen von Cathepsin-B-defizienten Mäuseembryonenfibroblasten; (CathB-/-+IFN-gamma) meint die Stimulation der CathB -/- Zellen mit $5000 \mathrm{U} / \mathrm{ml}$ IFN- $\gamma$ 48h vor Testbeginn. B zeigt das Mittel der H2 $\mathrm{K}^{\mathrm{b}}$-Expression der verschiedenen Tests. Die Balken geben die Standardabweichung an.

3.4.4 Signifikant verbesserte Lyse von Cathepsin-B-defizienten Zellen im Vergleich zu Wildtyp-Zellen

Im folgenden Versuchsabschnitt wurde nun die Lyse von Fibroblasten (MEF) aus Cathepsin-B-knock-out-Mäusen (CathB -/-) und Wildtyp-MEF (CathB Wt) verglichen. Als Positivkontrolle wurden zusätzlich RMA-Zellen als Zielzellen eingesetzt.

Die Ergebnisse dieser Versuche sind in Abbildung 11 dargestellt. Es zeigte sich eine signifikante Verbesserung der Lyse der Zellen, die defizient für Cathepsin B sind, gegenüber den Zellen, die Cathepsin B exprimieren $(p=0,0203$, ANOVA). 
A:

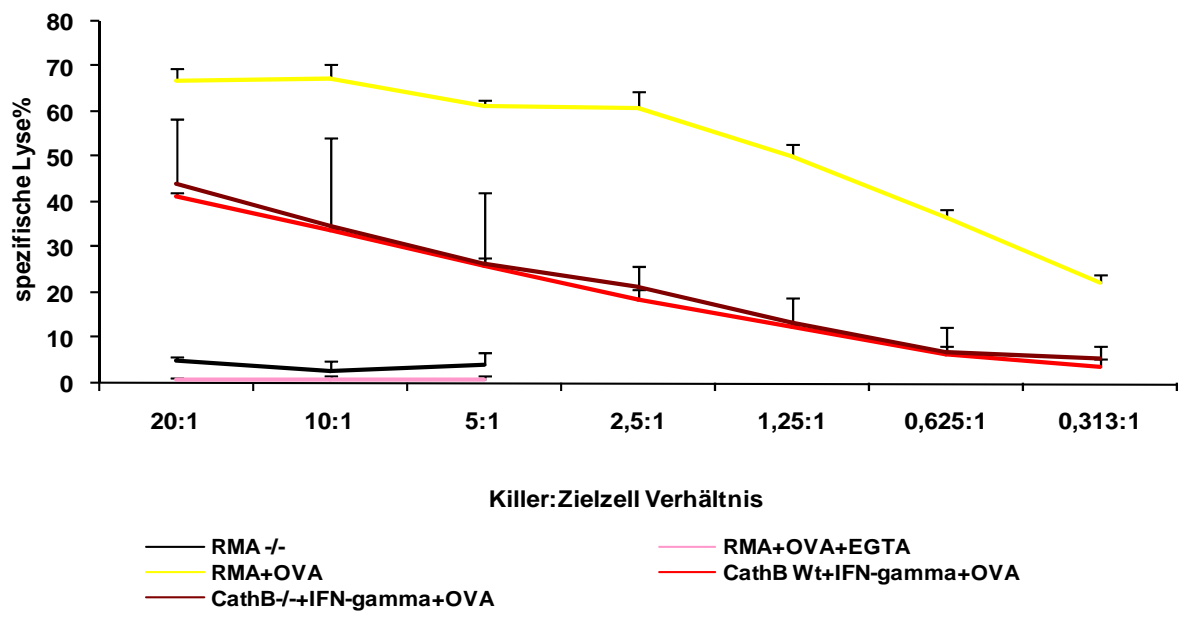

B:

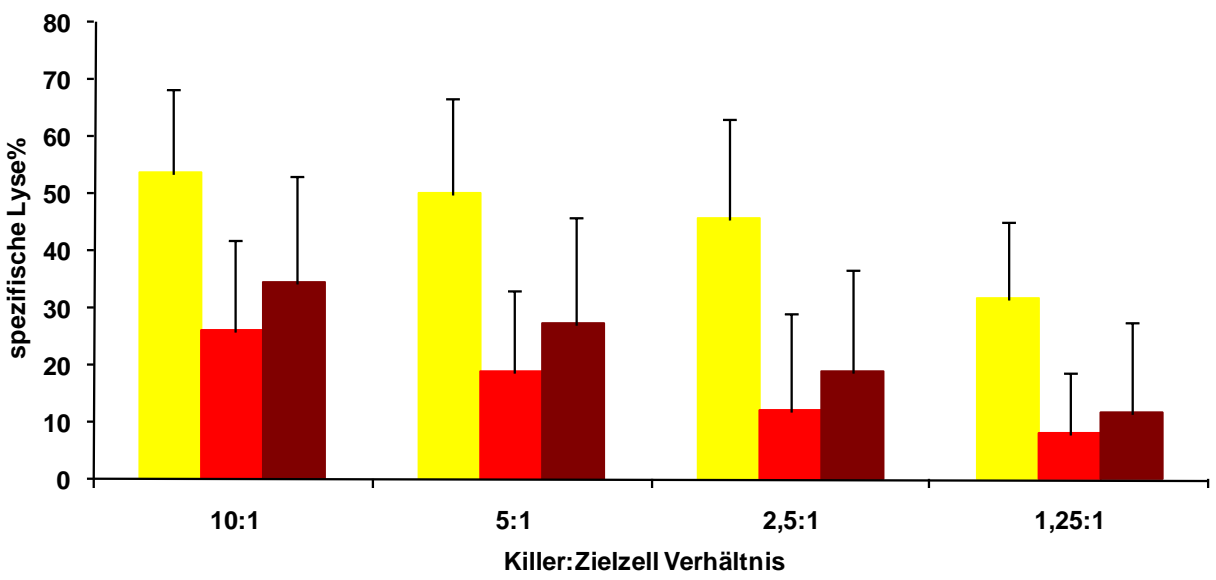

RMA+OVA(n=11) CathB Wt+IFN-gamma+OVA $(n=11)$ CathB-I-IFN-gamma+OVA $(n=11)$

Abbildung 11: Vergleich der Lysibilität von MEF aus Cathepsin-B-knock-out-Mäusen gegenüber MEF aus Wildtyp-Mäuseembryonen durch peptidspezifische CTL

Zur Bestimmung der spezifischen Lyse von Zielzellen durch CTL wurde der ${ }^{51}$ ChromFreisetzungs-Test eingesetzt. Als Zielzellen dienten MEF und RMA-Zellen. Als Effektorzellen peptidspezifische CTL von OT-I-Mäusen. Die MEF wurden 48h vor Testbeginn mit $5000 \mathrm{U} / \mathrm{ml}$ IFN- $\gamma$ stimuliert.

A Ein einzelnes Experiment ist exemplarisch dargestellt. Zu den Kontrollen gehört eine Negativkontrolle ohne SIINFEKL (RMA -/-) und eine Kontrolle der Calciumabhängigkeit der Lyse (RMA+OVA+EGTA), zu der EGTA/MgCl 2 und das SIINFEKL Peptid gegeben wurden. RMA-Zellen dienten jeweils als Zielzellen. Weitere Ansätze erfolgten mit RMA-Zellen als Zielzellen (RMA+OVA), mit IFN- $\gamma$ stimulierten Cathepsin-B-Wildtyp-MEF (CathB Wt+IFNgamma+OVA) oder mit IFN- $\gamma$ stimulierten Cathepsin-B-knock-out-MEF (CathB-/-+IFNgamma+OVA), jeweils unter der Zugabe des Peptids SIINFEKL. Alle Ansätze erfolgten als Tripletts. Es sind jeweils die mittlere Lyse und die Standardabweichung dargestellt. Abbildung B zeigt die Zusammenfassung der Mittelwerte der einzelnen Experimente und deren Standardabweichnug. 
3.5 Einfluss der Cathepsin-B-Inhibition in CTL auf die Lyse von Tumorzellen

Wie von Balaji et al. (2002) gezeigt, exprimieren CTL nach der Degranulation Cathepsin B auf ihrer Oberfläche, um sich vor den von ihnen ausgeschütteten Perforinen zu schützen. Im ersten und zweiten Versuchsabschnitt waren die Cathepsin-B-Inhibitoren CA-074 und CA-074 Me während des ganzen Tests anwesend und haben so auch auf das Cathepsin B der CTL und der Zielzellen eingewirkt. Deswegen haben wir im nächsten Versuchsabschnitt untersucht, ob die selektive Inhibition des Cathepsin B der CTL auch Einfluss auf die Lyse von Tumorzellen hat.

3.5.1 Inhibition des Cathepsin B von CTL beeinflusst die Lyse von Tumorzellen nicht

Um den Einfluss der Cathepsin-B-Inhibition von den CTL zu untersuchen, haben wir im folgenden Versuchsabschnitt den ${ }^{51}$ Chrom-Freisetzungs-Test so abgewandelt, dass der Inhibitor nur auf die Effektorzellen einwirken konnte.

Die Effektorzellen wurden, bevor sie zum Test gegeben wurden, eine Stunde mit dem zellmembranpermeablen Cathepsin-B-Inhibitor CA-074 Me in der Konzentration von $20 \mu \mathrm{M}$ oder $5 \mu \mathrm{M}$ inkubiert. Als Vergleichskontrolle wurde ein Teil der Zellen mit dem Lösungsmittel DMSO für eine Stunde bei $37^{\circ} \mathrm{C} \mathrm{im}$ Wärmeschrank inkubiert, da der Inhibitor in DMSO gelöst war. DMSO wurde in derselben Menge hinzu gegeben, in der der Inhibitor in der höheren Konzentration verwendet wurde. Danach wurden die Zellen dreimal mit Hepesgepuffertem DMEM-Medium gewaschen.

Die Ergebnisse dieser Tests sind in Abbildung 12 dargestellt. Eine Beeinflussung der CTL-induzierten Lyse von RMA-Tumorzellen durch Inhibition des Cathepsin B der CTL konnte nicht festgestellt werden. 
In Abbildung 12A sieht man, dass in Anwesenheit des Calziumbinders EGTA das Killing nahezu komplett unterdrückt wird. In Abwesenheit des Peptids SIINFEKL findet ebenfalls keine Lyse der Zielzellen durch die peptidspezifischen CTL statt. 
A:

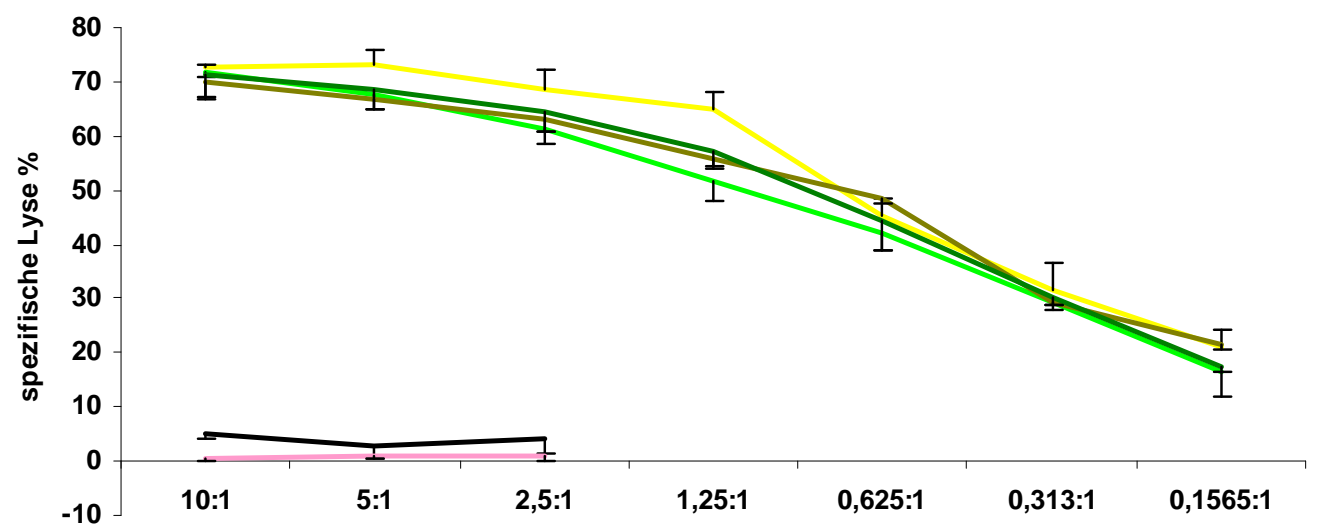

Killer:Zielzell Verhältnis

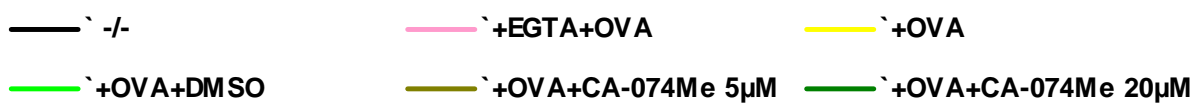

B:

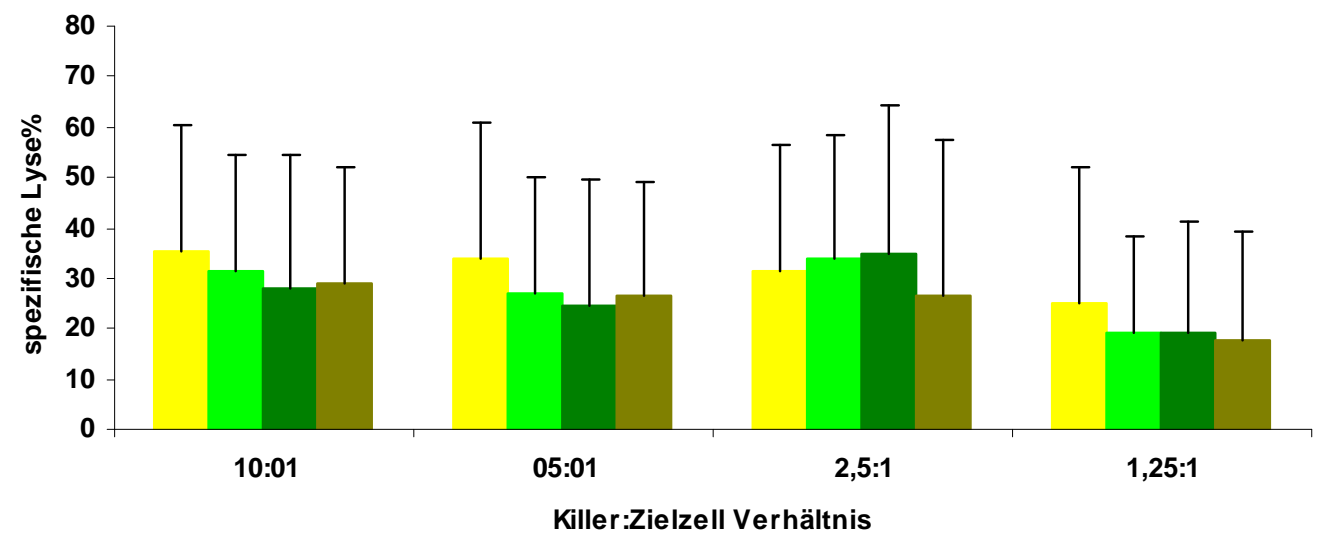

$`+O V A(n=5) \square+O V A+D M S O(n=5) \square$-OVA+CA-074Me $20 \mu M(n=5) \backsim+O V A+C A-074 M e 5 \mu M(n=5)$

\section{Abbildung 12: Einfluss der Cathepsin-B-Inhibition von CTL auf die Lyse von RMA- Tumorzellen}

Zur Bestimmung der spezifischen Lyse wurde der ${ }^{51} \mathrm{Chrom}$-Freisetzungs-Test eingesetzt. Als Zielzellen dienten RMA-Zellen. Als Effektorzellen wurden peptidspezifische CTL eingesetzt. Der Inhibitor beeinflusste nur das Cathepsin B der CTL, da diese vor Testbeginn eine Stunde mit dem Inhibitor inkubiert wurden. Danach wurden die Zellen zweimal gewaschen.

A Ein einzelnes Experiment ist exemplarisch dargestellt. Zu den Kontrollen gehört eine Negativkontrolle ohne SIINFEKL (-/-) und eine Kontrolle der Calciumabhängigkeit der Lyse (+EGTA+OVA), zu der EGTA/MgCl2 und das SIINFEKL-Peptid gegeben wurde. Zu einem Ansatz wurde nur das SIINFEKL-Peptid (+OVA), zu einem anderen Ansatz das SIINFEKLPeptid und das Lösungsmittel DMSO (+OVA+DMSO) oder der in DMSO gelöste Cathepsin-BInhibitor CA-074 Me in der jeweiligen Konzentration (+OVA+CA-074Me $20 \mu \mathrm{M} / 5 \mu \mathrm{M}$ ) gegeben. Alle Ansätze erfolgten als Tripletts. Es sind jeweils die mittlere Lyse und die Standardabweichung dargestellt. B zeigt die Zusammenfassung der Mittelwerte der einzelnen Experimente und deren Standardabweichung. 


\section{Diskussion}

In den letzten Jahren wurde eine Reihe von "Immune escape"-Mechanismen für Tumorzellen beschrieben, durch die diese der Antwort durch das Immunsystem entgehen. Dies erreichen sie zum einen dadurch, dass sie sich für das Immunsystem unsichtbar machen, aber auch, indem sie das Immunsystem aktiv unterdrücken (Ochsenbein 2005; Pawelec 2004). In dieser Studie haben wir untersucht, ob Tumorzellen Cathepsin B als einen Schutzmechanismus vor der Immunantwort durch zytotoxische T-Lymphozyten nutzen. Für CTL wurde gezeigt, dass diese nach der Sekretion ihrer zytotoxischen Granula aktives Cathepsin B auf ihrer Zelloberfläche exprimieren und sich mittels des Cathepsin B vor der Lyse durch ihr eigenes Perforin schützen, indem sie es spalten, bevor es zu einer Porenbildung in der Zellmembran der CTL kommt (Balaji et al. 2002). Perforin bindet nach der Freisetzung zunächst an die Zielzellmembran. In diesem Status ist es hoch empfindlich gegenüber Proteolyse, bevor es in einen stabilen, porenbildenden Komplex übergeht (Young et al. 1987). Unsere Fragestellung war es, ob auch Tumorzellen Cathepsin B nutzen, um sich vor dem Perforin der CTL zu schützen.

Wie auch Balaji et al. (2002), nutzten wir den ${ }^{51}$ Chrom-Freisetzungs-Test als Hauptmethode zur Untersuchung der Rolle des Cathepsin B bei der CTLinduzierten Lyse von RMA-Tumorzellen. Dabei wurde die Lyse der Tumorzellen durch antigenspezifische CTL in An- oder Abwesenheit von Cathepsin-BInhibitoren in verschiedenen Konzentrationen bestimmt.

Die CTL in diesem Versuchsmodell, die aus TCR-transgenen Mäusen gewonnen wurden, nutzen vornehmlich den Granula-Exozytose-Weg zur Lyse ihrer Zielzellen. Die Lyse konnte durch Anwesenheit des Calciumbinders EGTA inhibiert werden, da freies Calcium zur Exozytose der Granula benötigt wird.

Wenn Cathepsin B auch Tumorzellen vor der Lyse durch antigenspezifische CTL schützt, dann wäre zu erwarten, dass die Inhibition dieser Protease zu einer erhöhten Lyse und somit einer erhöhten Chrom-Freisetzung aus den Tumorzellen führt. 
Es hat sich in unseren Untersuchungen gezeigt, dass der zellmembranimpermeable Cathepsin-B-Inhibitor CA-074 in der Konzentration von $5 \mu \mathrm{M}$ tatsächlich die Lyse der RMA-Zellen durch antigenspezifische CTL signifikant verbessert. Die Anwesenheit dieses Inhibitors in der Konzentration von $10 \mu \mathrm{M}$ führte zu einer leichten Verbesserung der Lyse, jedoch wurde in der Konzentration von $20 \mu \mathrm{M}$ keine Verbesserung der Lyse erreicht (siehe Abbildung 2 und 3). Dies zeigt, dass die Inhibition des Cathepsin B tatsächlich zu einer Verbesserung der CTL-induzierten Lyse von Tumorzellen beitragen kann.

Das Ergebnis, dass die Zugabe des Inhibitors in einer geringen Konzentration zu einer Verbesserung der Lyse führt, in einer höheren Konzentration jedoch nicht, war unerwartet. Eine mögliche Erklärung könnte sein, dass der Cathepsin-B-Inhibitor in höheren Konzentrationen nicht nur Cathepsin B hemmt, sondern auch andere Enzyme, deren Inhibition die Lyse der Tumorzellen nicht verbessert, sondern verschlechtert. Dies würde dann dazu führen, dass sich diese Effekte gegenseitig aufheben und es so zu keiner Veränderung der Lyse der Tumorzellen käme.

Eine andere mögliche Erklärung wäre, dass der Inhibitor in der Konzentration von $20 \mu \mathrm{M}$ nicht nur extrazelluläres, sondern auch intrazelluläres Cathepsin B hemmt, welches eventuell eine andere Funktion in der CTL-induzierten Apoptose hat. Der Inhibitor CA-074 ist als zellmembranimpermeabel beschrieben worden (Balaji et al. 2002). Szpaderska und Frankfater (2001) haben in einer anderen Studie jedoch gezeigt, dass der Cathepsin-B-Inhibitor CA-074 in der Konzentration von $10 \mu \mathrm{M}$ in einer zeitabhängigen Weise doch die Zellemembran durchdringt und so intrazelluläres Cathepsin B hemmen kann. Zwar wurde der Inhibitor in diesen Versuchen für 12 bzw. 24 h zu den Zellen gegeben, aber es wurde auch die zeitabhängige Inhibition von intrazellulärem Cathepsin B untersucht und diese zeigte, dass auch schon nach 4 Stunden ca. 45 \% des intrazellulären Cathepsin B gehemmt wurde, wenn der Inhibitor in der Konzentration von $10 \mu \mathrm{M}$ eingesetzt wurde. In unseren Versuchen war der Inhibitor während der Testzeit von 4 Stunden anwesend, 
jedoch in der Konzentration von maximal $20 \mu \mathrm{M}$, so dass man vermuten kann, dass auch intrazelluläres Cathepsin B gehemmt wurde.

Die Annahme, dass CA-074 auch intrazelluläres Cathepsin B hemmt, steht in Kontrast zu der Aussage von Bogyo et al. (2000), die postulieren, dass CA-074 nicht in die Zellen aufgenommen wird, auch nicht, wenn man es in der Konzentration von $100 \mu \mathrm{M}$ einsetzt. Allerdings wurde zu diesem Experiment nicht angegeben, über welchen Zeitraum der Inhibitor zu den untersuchten Zellen hinzu gegeben wurde. Die Inkubationszeit war vielleicht so kurz, dass das intrazelluläre Cathepsin B nicht beeinflusst wurde.

Auch in einem anderen Zusammenhang wurde gezeigt, dass es unterschiedliche Auswirkungen hat, wenn Cathepsin B nur extrazellulär oder auch intrazellulär gehemmt wird. Bei einer Studie über die Rolle des Cathepsin $B$ bei der Invasivität von Tumorzellen zeigte sich, dass die Inhibition des extrazelluären Cathepsin B durch Einsatz von CA-074 in der Konzentration von $1 \mu \mathrm{M}$ die Invasivität von Tumorzellen in einem Matrigel nicht vermindert. Wenn aber das intrazelluläre Cathepsin B gehemmt wurde, dann wurde die Invasivität der Tumorzellen vermindert (Szpaderska and Frankfater 2001).

Dieses Ergebnis lässt vermuten, dass es einen Unterschied macht, ob das Tumorzell-assoziierte Cathepsin B nur extrazellulär oder auch intrazellulär gehemmt wird.

Um die Bedeutung des intrazellulären Cathepsin B genauer zu untersuchen, haben wir den zellmembranpermeablen Cathepsin-B-Inhibitor CA-074 Me eingesetzt. Dieser ist in seiner Form als Methylesther (Me) zunächst ein inaktiver Proinhibitor. Er wird erst nach Aufnahme in die Zelle durch endogene Esterasen aktiviert und so intrazellulär $z u$ seiner aktiven Form CA-074 konvertiert (Buttle et al. 1992).

Eine Wirkung dieses Inhibitors auf das extrazelluläre Cathepsin B ist sehr unwahrscheinlich, da der Inhibitor zunächst in die Zelle aufgenommen werden muss, um dort durch Abspaltung seines Methylesters aktiviert zu werden. Vor Abspaltung des Methyesthers hat CA-074 Me keinen inhibierenden Effekt auf Cathepsin B (Buttle et al. 1992). 
Die Anwesenheit dieses Inhibitors im ${ }^{51}$ Chrom-Freisetzungs-Test führte zu einer tendenziellen Verbesserung der Lyse der RMA-Tumorzellen, wenn er in der Konzentration von $5 \mu \mathrm{M}$ eingesetzt wurde. Dieser Effekt war jedoch nicht signifikant. In der Konzentration von $20 \mu \mathrm{M}$ beeinflusste er die Lyse der RMATumorzellen nicht (Abbildung 4 und 5).

Das Ergebnis, dass der zellmembranpermeable Cathepsin-B-Inhibitor in der Konzentration von $5 \mu \mathrm{M}$ die Lyse der RMA-Tumorzellen zwar tendenziell, jedoch nicht signifikant verbessert, unterstützt die Annahme, dass vor allem das extrazelluläre Cathepsin B zur Protektion der Tumorzellen vor den Perforinen der CTL beiträgt. Eine mögliche Erklärung für die tendenzielle Verbesserung der Lyse wäre, dass CA-074 Me in der geringeren Konzentration das Cathepsin B hemmt, welches anschließend zur Zelloberfläche transportiert wird, dort aber aufgrund der Inhibition nicht aktiv sein kann.

Das Ergebnis, dass auch der zellmembranpermeable Cathepsin-B-Inhibitor die Lyse von Tumorzellen nicht verbessert, wenn er in einer höheren Konzentration eingesetzt wird, stützt die Vermutung, dass der Cathepsin-B-Inhibitor in einer höheren Konzentration möglicherweise auch andere Enzyme inhibiert, die den protektiven Effekt der spezifischen Cathepsin-B-Inhibition wieder aufheben.

Es ist ein generelles Problem bei der Arbeit mit Inhibitoren, dass nie ausgeschlossen werden kann, dass neben der Hauptzielstruktur noch weitere Strukturen und Prozesse beeinflusst werden. Es wurde gezeigt, dass insbesondere CA-074 Me auch zusätzlich noch andere Enzyme, wie zum Beispiel Cathepsin L, beeinflusst (Montaser et al. 2002). Cathepsin L wird ebenfalls von Tumorzellen sezerniert und inm wird auch eine Rolle bei der Invasion und Metastasierung von Tumorzellen zugesprochen (Colella and Casey 2003).

In den vorher beschriebenen Versuchen waren die eingesetzten Inhibitoren während der gesamten Testzeit von 4 Stunden anwesend. Somit wäre es auch möglich, dass der Inhibitor die CTL für ihre eigenen Perforine suszeptibel gemacht hat, so dass weniger CTL zur Zielzellyse zur Verfügung standen. 
Es wäre somit denkbar, dass die beobachtete Verbesserung der Tumorzelllyse durch Cathepsin-B-Inhibition noch deutlicher gewesen wäre, wenn nicht CTL durch ihre eigenen zytotoxischen Granula lysiert worden wären.

Um die mögliche Beeinflussung der CTL durch die Anwesenheit der CathepsinB-Inhibitoren zu untersuchen, haben wir Versuche durchgeführt, bei denen nur RMA-Zellen mit dem Inhibitor in Kontakt kamen. Dies wurde dadurch erreicht, dass die RMA-Zellen nach der Chromierung mit dem Inhibitor inkubiert wurden. Vor Testbeginn wurde der Inhibitor ausgewaschen, so dass die CTL nicht mehr mit dem Inhibitor in Kontakt kamen. So sollte das Cathepsin B der CTL nicht beeinflusst werden, da die Inhibitoren während des Zytotoxizitätstests nicht anwesend waren. Bei der Durchführung dieser Versuche gab es das Problem, dass durch die längeren Inkubationszeiten und die häufigeren Wasch- und Pipettierschritte die RMA-Zellen geschädigt wurden und sich so die spontane Lyse erhöhte, da mehr RMA-Zellen auf eine CTL-unabhängige Weise beschädigt wurden und Chrom freisetzten. Durch sehr vorsichtiges Resuspendieren der Zellen und Verringerung der Anzahl der Waschschritte von 6 auf insgesamt 4 ließ sich dies zwar verbessern, jedoch leider nicht ganz optimieren. Jedoch erklärt dies die Schwankungen und die erhöhten Standardabweichungen in diesen Experimenten. Es zeigte sich, dass die Präinkubation der RMA-Zellen weder mit dem zellemembranpermeablen noch mit dem zellmembranimpermeablen Cathepsin-B-Inhibitor zu einer Veränderung der Lysibilität der RMA-Tumorzellen durch CTL führte (siehe Abbildung 6 und 7).

Eine mögliche Erklärung hierfür könnte sein, dass das Cathepsin B während des Tests neu synthetisiert wurde. Linebaugh et al. (1999) haben eine Methode entwickelt, um die perizelluläre Cathepsin-B-Aktivität kontinuierlich zu messen. Damit konnten sie zeigen, dass die Cathepsin-B-Aktivität stark reduziert wurde, wenn die Zellen zuvor für eine halbe Stunde mit dem Cathepsin-B-Inhibitor inkubiert wurden. Die Präinkubation der Zellen mit dem Inhibitor für eine Stunde führte zu einem kompletten Wegfall der anschließend gemessenen CathepsinB-Aktivität. Allerdings wurde die Cathepsin-B-Aktivität nur für 15 Minuten gemessen, der Zytotoxizitätstest dauerte jedoch 4 Stunden. Es ist also möglich, 
dass die Präinkubation mit dem Inhibitor nur zu einer kurzfristigen Abnahme der Cathepsin-B-Aktivität führte, die dann im Verlauf des Tests wieder zunahm.

In den folgenden Experimenten wurde versucht, den Effekt der Cathepsin-BInhibition auf die CTL zu bestimmen. Von anderen Autoren war beschrieben worden, dass die Inhibition des Cathepsin B der CTL dazu führt, dass diese vermehrt durch ihre eigenen Granula lysiert wurden, da sie sich nicht mehr mit Hilfe ihres Cathepsin B schützen konnten (Catalfamo and Henkart 2003). Wenn eine beträchtliche Anzahl von CTL für ihre eigenen toxischen Granula durch Inhibition des Cathepsin B empfindlich gemacht würden, dann stünden weniger CTL zur Verfügung, um die Zielzellen zu lysieren.

Um diesen möglichen Störfaktor genauer zu untersuchen, haben wir wieder ${ }^{51}$ Chrom-Freisetzungs-Tests durchgeführt. Diesmal wurden die CTL mit dem Inhibitor präinkubiert und vor Testbeginn ausgewaschen, so dass nur das Cathepsin B der CTL inhibiert wurde. Die Versuche wurden mit dem zellmembranpermeablen Cathepsin-B-Inhibitor CA-074 Me durchgeführt, da die CTL vor der Aktivierung kaum Cathepsin B auf ihrer Zelloberfläche exprimieren (Balaji et al. 2002). Die Lyse der Tumorzellen wurde durch die Präinkubation mit dem Inhibitor nicht wesentlich beeinflusst (siehe Abbildung 12).

Dieser Befund entspricht den Ergebnissen von Balaji et al. (2002), die zeigten, dass in einem 4-Stunden-Test der Inhibitor CA-074 in der Konzentration von 10 $\mu \mathrm{M}$ die Lyse der Zielzellen nicht verändert. Erst bei längerer Dauer des Tests (16 h) zeigte sich der Effekt der Inhibition des Zelloberflächen-Cathepsin-B auf das Überleben der CTL.

Eine aktuelle Studie zeigt, dass CTL von Cathepsin-B-knock-out-Mäusen während der Lyse von Zielzellen in vitro und in vivo normal überleben (Baran et al. 2006). Die Rolle des Cathepsin B als Protektionsmechanismus für CTL könnte daher initial auch überschätzt worden sein (Balaji et al. 2002) und sollte daher noch genauer untersucht werden.

Zusammenfassend kann man sagen, dass vermutlich die spezifische Inhibition des extrazellulären Cathepsin B der RMA-Zellen die Lyse verbessert hat. Eine 
Beeinflussung dieses Ergebnisses durch die Inhibition des Cathepsin B der CTL war nicht nachweisbar.

Ein bereits erwähntes Problem bei der Arbeit mit den Inhibitoren bestand jedoch darin, dass es Unsicherheiten bezüglich ihrer Spezifität und der Kinetik ihrer Wirkung gab. Wir können nicht ausschließen, dass die Inhibitoren, besonders in höheren Konzentrationen, auch andere Enzyme beeinflusst haben oder dass es während des Zytotoxizitätstests zu einer Neusynthese des Cathepsin B kam, wenn der Inhibitor nicht während des Tests anwesend war.

Um diese Störfaktoren auszuschließen, wurden Versuche mit Fibroblasten aus Mäuseembryonen (MEF) durchgeführt, bei denen das Cathepsin-B-Gen deaktiviert (CathB -/-) worden war. Verglichen wurde die CTL-induzierte Lyse dieser Zellen mit der Lyse von MEF aus Wildtyp (CathB Wt)-Mäuseembryonen. Als Positivkontrolle wurde die Lyse von RMA-Tumorzellen mit bestimmt. Mittels eines Westernblots haben wir bestätigt, dass die MEF der CathB -/- Mäuse kein Cathepsin B exprimieren. Die 31-kD-Einkettenform des Cathepsin B konnte in den CathB Wt nachgewiesen werden (siehe Abbildung 8).

Anfangs ließen sich die MEF durch die CTL nicht genügend lysieren. Die Ursache hierfür war wahrscheinlich, dass die MEF relativ wenige MHC-KlasseI-Moleküle auf ihrer Oberfläche exprimierten. Die MHC-Klasse-I-Moleküle sind notwenig, damit den CTL das SIINFEKL-Peptid, welches als Antigen dient, präsentiert werden kann. Durch vorherige Stimulation der MEF mit IFN- $\gamma$ erreichten wir eine Steigerung der MHC-Klasse-I-Moleküle auf den MEF (siehe Abbildung 9 und 10) und somit eine Verbesserung der Lyse. Bei jedem Test wurde mittels Durchflusszytometrie überprüft, ob die Stimulation mit IFN- $\gamma$ zu einer erhöhten MHC-Klasse-I-Expression geführt hat. Die Lyse der CathB -/MEF und der CathB-Wt-MEF war nicht immer ganz ohne Einschränkung vergleichbar, da die Stimulation nicht immer gleich effektiv war, so dass manchmal die CathB-Wt-MEF und manchmal die CathB -/- MEF mehr MHCKlasse-I-Moleküle auf der Oberfläche exprimiert haben. Wenn man aber das Mittel der MHC-Klasse-I-Expression in den durchgeführten Experimenten betrachtet, hat sich dieser Unterschied gut ausgeglichen (siehe Abbildung 10B). 
Wenn Cathepsin B in diesen Zellen eine protektive Funktion hat, dann sollten sich die CathB -/- MEF besser lysieren lassen, als die Cathepsin-B-WildtypMEF.

In den durchgeführten Zytotoxizitätstests ließ sich eine signifikante Verbesserung der Lyse der CathB -/- MEF gegenüber den CathB-Wt-MEF erkennen (siehe Abbildung 11). Dieses Ergebnis bestätigt unsere Vermutung, dass Zellen Cathepsin B nutzen, um sich vor der Perforin-abhängigen Lyse durch CTL zu schützen. Es ist jedoch möglich, dass vor allem von Tumorzellen dieser Weg genutzt wird, so dass MEF nicht das ideale Modell sind. Hierfür spricht, dass die Cathepsin-B-Expression in vielen Tumorzellen stark erhöht ist, wenn man diese mit nicht transformierten Zellen vergleicht. Die Transformation des Onkogens c-Ha-ras in normalen Brustepithelzellen führte zu einer erhöhten Expression von Cathepsin B und der Assoziation mit der Zellmembran (Sloane et al. 1994). Auch ist die Lokalisation des Cathepsin B in den Tumorzellen gegenüber den nicht entarteten Zellen verändert. In nicht entarteten Zellen ist das Cathepisn B in perinukleären Vesikeln lokalisiert, in Tumorzellen findet man Cathepsin B sowohl in den perinukleären Vesikeln, als auch in Vesikeln in der Zellperipherie und an der Zelloberfläche (Roshy et al. 2003). Eventuell waren die MEF auch nicht ausreichend in der Lage, ihr Cathepsin B auf die Zelloberfläche zu bringen oder zu sezernieren und konnten sich daher nicht deutlicher vor den Perforinen der CTL schützen.

Weiterhin zu bedenken ist, dass Cathepsin B generell zwei weitere kontroverse Bedeutungen zugesprochen werden. Zum einen soll es die Invasivität und das Metastasierungspotenzial der Tumorzellen erhöhen (Berquin and Sloane 1996; Podgorski and Sloane 2003; Yan et al. 1998). Andererseits wird Cathepsin B auch eine entscheidende Rolle während der Apoptose von Zellen zugeschrieben (Guicciardi et al. 2000; Lotem and Sachs 1996; Roberts et al. 1997). Defekte in der Regulierung der Apoptose spielen eine zentrale Rolle bei der Tumorpathogenese und Tumorprogression (Wyllie 1997). Die Apoptose kann über verschiedene Wege in den Zellen eingeleitet werden. Es gibt zum einen den extrinsischen Weg, bei dem es durch Aktivation von extrazellulären Todesrezeptoren zur Aktivation der Caspase 8 kommt. Zum anderen gibt es 
den intrinsischen Weg, welcher durch Zellstress induziert werden kann. Dabei kommt es zu einer Freisetzung von Cytochrom c aus den Mitochondrien und so zur Aktivierung der Pro-Caspase 9 (Danial and Korsmeyer 2004). CTL können noch über einen dritten Mechanismus Apoptose in Zellen induzieren, und zwar durch die Sekretion von zytotoxischen Granula, die unter anderem Granzyme und Perforin enthalten. Dieser scheint der entscheidende Weg bei der Eliminierung von Virus-infizierten und entarteten Zellen zu sein. Granzym B aktiviert die Caspase-abhängige Apoptose vor allem durch Spaltung von Caspase 3. CTL können aber auch in Anwesenheit von Caspase-Inhibitoren Apoptose in den Zellen induzieren. Dies gibt Anhalt dafür, dass sie auch durch einen von Caspasen unabhängigen Mechanismus Apoptose induzieren können. Ein bekannter Mechanismus ist, dass Granzym B BID spaltet, welches dann die Mitochondrien angreift und zur Freisetzung des Apoptose-induzierenden Cytochrom c führt. Granzym B kann aber auch direkt die Durchlässigkeit der Mitochondrienmembran verändern und so Apoptose induzieren (Lieberman 2003). Die Rolle des Perforins hierbei ist immer noch nicht ganz klar.

Cathepsin B ist zum Beispiel an der durch Gallensalze verursachten Apoptose von Leberzellen beteiligt. Die Exposition der Leberzellen mit einer schädlichen Konzentration Gallensalze führte zu einer erhöhten Cathepsin-B-Aktivität in den apoptotischen Zellen. Der Cathepsin-B-Inhibitor CA-074 Me blockierte die Apoptose (Roberts et al. 1997). Eine andere Studie zeigte, dass die Inhibition von Cathepsin B durch den Inhibitor Z-Phe-Ala-fmk zu einer Inhibition der p53abhängigen Apoptose in Leukämiezellen führt (Lotem and Sachs 1996). Besonders deutlich ist die Rolle des Cathepsin B bei der TNF- $\alpha$-induzierten Apoptose (Foghsgaard et al. 2001; Guicciardi et al. 2000; Guicciardi et al. 2001). TNF- $\alpha$ führt durch Bindung an den TNF-Rezeptor TNF-R1 zur Aktivierung des Caspase 8. Dies führt zur Initiation der Cascade der Caspasen und so zur Apoptose der Zelle (Baker and Reddy 1998).

Es scheint verschiedene Mechanismen zu geben, wie Cathepsin B an der Apoptose in den Zielzellen beteiligt ist. Eine Möglichkeit ist, dass Caspase 8, eine der Proteasen, die an der Initiation der Apoptose beteiligt ist, zu einer Freisetzung von Cathepsin B aus den Lysosomen führt. Cathepsin B wiederum 
führt in Verbindung mit einem anderen im Zytosol lokalisierten Faktor zur Freisetzung von Cytochrom c aus den Mitochondrien. Cytochrom c führt dann über die Aktivierung weiterer Caspasen zur Apoptose der Zelle (Guicciardi et al. 2000). Außerdem kann Cathepsin B BID spalten, was dann zu einer Freisetzung von Cytochrom c aus den Mitochondrien führt (Stoka et al. 2001). Cathepsin B scheint auch an der durch TNF verursachten Reduktion des Enzyms Sphingosin-Kinase-1 beteiligt zu sein (Taha et al. 2005). SphingosinKinase-1 schützt die Zelle normalerweise vor Apoptose durch Aktivierung von NF-кB (Xia et al. 2002).

Es wurde nachgewiesen, dass Cathepsin B während des apoptotischen Prozesses zum Cytosol (Guicciardi et al. 2000; Taha et al. 2005), aber auch zum Nukleus transloziert wurde. Im Nucleus konnte vor allem die 26-kDa-Form des Cathepsin B nachgewiesen werden (Roberts et al. 1997).

Die von uns durchgeführten Versuche mit den CathB -/- MEF und CathB-WtMEF geben keinen Anhalt für eine pro-apoptotische Funktion des Cathepsin B bei der Perforin-abhängigen Lyse von Zielzellen, denn sonst hätten wir eine verschlechterte Lyse der CathB -/- MEF verglichen mit den CathB-Wt-MEF beobachten müssen. Eine Erklärung hierfür könnte sein, dass Perforin und Granzym nicht zu einer Cathepsin-B-Freisetzung in der Zielzelle führen und somit Cathepsin B nicht zur Spaltung von BID oder Freisetzung von Cytochrom c führen kann.

Ein generelles Problem bei der Arbeit mit Zellen von Tieren, bei denen ein Gen ausgeschaltet wurde, ist, dass man nicht ausschließen kann, dass die Expression anderer Gene kompensatorisch heraufreguliert wird. So scheinen zum Beispiel Cathepsin B und Cathepsin $L$ teilweise füreinander zu kompensieren, denn die Tiere, die defizient für eines der beiden Cathepsine sind, haben keine verkürzte Lebensdauer (Reinheckel et al. 2001), während Tiere, die defizient für beide Cathepsine sind, eine stark verkürzte Lebensdauer aufweisen. Es wurde beobachtet, dass es in neuronalen Zellen nur bei Cathepsin-B- und Cathepsin-L-Doppel-knock-out-Mäusen zu eine Anreicherung lysosomaler Proteine in den Neuronen kommt, aber nicht bei den jeweiligen 
Einzel-knock-out-Mäusen. Außerdem ist das Cathepsin D in diesen Neuronen kompensatorisch stark erhöht (Stahl et al. 2007).

Daher können wir auch nicht ausschließen, dass unser Ergebnis dadurch beeinflusst wurde, dass die MEF der Cathepsin-B-knock-out-Mäuse nicht kompensatorisch vermehrt andere Proteasen, zum Beispiel mehr Cathepsin L oder D, exprimierten.

Interessant ist aber, dass wir in den CathB-Wt-MEF nur die 31-kDa-Form des Cathepsin B nachweisen konnten (siehe Abbildung 8). Eigentlich überwiegt in den meisten Zellen die 25- bis 26-kDa + 5-kDa zweikettige Form des Cathepsin B. Sezerniert wird von den Zellen allerdings überwiegend die 31-kDa-Form (Linebaugh et al. 1999). Es wäre möglich, dass die beiden verschiedenen Formen auch unterschiedliche Funktionen haben. Somit könnte auch dies die Erklärung dafür sein, dass die CathB -/- MEF tendenziell besser lysiert wurden als die CathB-Wt-MEF, da eventuell die 31-kDa-Form eher eine protektive Funktion hat, während die 25- bis 26-kDa-Form eher eine proapoptotische Funktion hat.

Vielleicht liefert die weitere genauere Untersuchung der verschiedenen Formen des Cathepsin B einen Hinweis für seine gegensätzliche Rolle in malignen Zellen, deren Malignität es zum einen reduziert durch seine proapoptotischen Eigenschaften (Foghsgaard et al. 2001; Nagaraj et al. 2006; Sandes et al. 2007), aber auch die Invasivität und Metastasierung durch Degradation der extrazellulären Matrix fördert (Berquin and Sloane 1996; Frosch et al. 1999; Roshy et al. 2003).

Wir konnten zeigen, dass der zellmembranimpermeable Cathepsin-B-Inhibitor die Lyse von RMA-Tumorzellen durch antigenspezifische CTL signifikant verbessert, wenn er in einer Konzentration von $5 \mu \mathrm{M}$ eingesetzt wird, während der zellmembranpermeable Cathepsin-B-Inhibitor in dieser Konzentration diese nur tendenziell, jedoch nicht signifikant verbesserte.

Diese Beobachtung spricht dafür, daß vor allem das extrazelluläre Cathepsin B zur Protektion der RMA-Tumorzellen beiträgt. 
Eine mögliche Erklärung für die beobachtete Konzentrationsabhängigkeit ist, dass nur in dieser geringen Konzentration eine spezifische Inhibition des Cathepsin B stattfindet, beim Einsatz der Inhibitoren in einer höheren Konzentration jedoch auch andere Enzyme beeinflusst werden, die diesen Effekt revidieren.

Für einen protektiven Effekt des Cathepsin B spricht auch, dass sich CathepsinB-defiziente MEF signifikant besser durch CTL lysieren lassen, als die Wildtypen-MEF.

Es sind jedoch noch weitere Studien notwendig, um diese Frage definitiv zu klären. Dies könnte geschehen durch die Entwicklung spezifischerer Inhibitoren und neuer Methoden, um das Cathepsin B selektiv in den Tumorzellen zu hemmen, damit eine Inhibition des Cathepsin B der CTL vermieden wird. 


\section{Zusammenfassung}

Cathepsin B ist eine lysosomale Cystein-Protease, die in vielen Tumoren vermehrt exprimiert, sezerniert und auf die Oberfläche gebracht wird. Für zytotoxische T-Lymphozyten (CTL) wurde gezeigt, dass diese nach der Degranulation aktives Cathepsin B auf der Zelloberfläche exprimieren und sich so während der Zielzelllyse vor ihrem eigenen Perforinen schützen. In der vorliegenden Studie haben wir untersucht, ob auch Tumorzellen Cathepsin B nutzen, um sich vor der Lyse durch CTL zu schützen.

Wir haben die Lyse von Zellen einer Maus-T-Zell-Lymphom-Linie, den RMAZellen, durch antigenspezifische CTL in An- und Abwesenheit unterschiedlicher Cathepsin-B-Inhibitoren in Zytotoxizitätstests systematisch gemessen und verglichen. Eingesetzt wurden der zellmembranimpermeable Cathepsin-BInhibitor CA-074 und der zellmembaranpermeable Cathepsin-B-Inhibitor CA$074 \mathrm{Me}$. Da es Hinweise dafür gibt, dass CA-074 in höheren Konzentrationen die Zellmembran durchdringt, wurden zur Detektion einer Konzentrationsabhängigkeit die Inhibitoren jeweils in verschiedenen Konzentrationen eingesetzt.

Es hat sich gezeigt, dass die Inhibition des extrazellulären Cathepsin B tatsächlich zu einer signifikantan Verbesserung der CTL-induzierten Lyse von Tumorzellen beitragen kann. Unerwartet war jedoch, dass dieser Effekt bei einer niedrigen Konzentration $(5 \mu \mathrm{M})$ am ausgeprägtesten war. In einer Konzentration von $20 \mu \mathrm{M}$ wurde die Lyse der Tumorzellen nicht mehr verbessert. Der Grund dafür könnte sein, dass die Inhibitoren in höheren Konzentrationen auch intrazelluläres Cathepsin B oder unspezifisch andere Enzyme beeinflussen, wodurch die Lyse von Tumorzellen nicht verbessert, sondern verschlechtert wird.

Da die eingesetzten Inhibitoren während der gesamten Testdauer anwesend waren, besteht die Möglichkeit, dass aufgrund der Cathepsin-B-Inhibition die CTL durch ihr eigenes Perforin getötet wurden und so weniger CTL für die Zielzelllyse zur Verfügung standen. In weiteren Experimenten haben wir 
untersucht, wie die ausschließliche Inhibition des Cathepsin B der Zielzellen die Lyse beeinflusst. Die Präinkubation der Zielzellen mit den Inhibitoren veränderte deren Lyse nicht. Es ist jedoch möglich, dass die Präinkubation nur zu einer kurzfristigen Abnahme der Cathepsin-B-Aktivität führte und es während des Tests durch Neusynthese zu einer Zunahme der Cathepsin-B-Aktivität kam.

Daraufhin versuchten wir, den Effekt der Cathepsin-B-Inhibition auf die CTL zu bestimmen, indem diesmal nur die CTL mit dem Inhibitor präinkubiert wurden. Die Lyse der Tumorzellen wurde nicht verändert. Es ist somit nicht davon auszugehen, dass die Inhibition des Perforin der CTL zu einer Beeinflussung der Lyse der Tumorzellen geführt hat.

Da die Selektivität von Inhibitoren immer begrenzt ist und man nicht ausschließen kann, dass es während des Zytotoxizitätstests zu einer Neusynthese des Cathepsin B kam, haben wir die Lyse von Cathepsin-Bdefizienten embryonalen Fibroblasten (MEF) mit der Lyse von MEF aus Wildtyp-Mäusen verglichen. Hier zeigte sich eine signifikante Verbesserung der Lyse der Cathepsin-B-defizienten MEF gegenüber den Fibroblasten, die Cathepsin B exprimierten. Dies stützt die Vermutung, dass Cathepsin B, möglicherweise vor allem das extrazelluläre Cathepsin B, zum Schutz der Tumorzellen vor der Perforin-abhängigen Lyse durch CTL beitragen kann. 


\section{Literaturverzeichnis}

Achkar C, Gong QM, Frankfater A, Bajkowski AS (1990): Differences in targeting and secretion of cathepsins $B$ and $L$ by BALB/3T3 fibroblasts and Moloney murine sarcoma virus-transformed BALB/3T3 fibroblasts. J Biol Chem $\underline{265}, 13650-13654$.

Ackerman AL, Cresswell P (2004): Cellular mechanisms governing crosspresentation of exogenous antigens. Nat Immunol $\underline{5}, 678-684$.

Andreola G, Rivoltini L, Castelli C, Huber V, Perego P, Deho P, Squarcina P, Accornero P, Lozupone F, Lugini L (2002): Induction of lymphocyte apoptosis by tumor cell secretion of FasL-bearing microvesicles. J Exp Med 195, 13031316.

Arkona C, Wiederanders B (1996): Expression, subcellular distribution and plasma membrane binding of cathepsin B and gelatinases in bone metastatic tissue. Biol Chem 377, 695-702.

Baker SJ, Reddy EP (1998): Modulation of life and death by the TNF receptor superfamily. Oncogene 17, 3261-3270.

Balaji KN, Schaschke N, Machleidt W, Catalfamo M, Henkart PA (2002): Surface cathepsin B protects cytotoxic lymphocytes from self-destruction after degranulation. J Exp Med 196, 493-503.

Baran K, Ciccone A, Peters C, Yagita H, Bird PI, Villadangos JA, Trapani JA (2006): Cytotoxic T lymphocytes from cathepsin B-deficient mice survive normally in vitro and in vivo after encountering and killing target cells. J Biol Chem 281, 30485-30491.

Berquin IM, Sloane BF (1996): Cathepsin B expression in human tumors. Adv Exp Med Biol 389, 281-294.

Berquin IM, Cao L, Fong D, Sloane BF (1995): Identification of two new exons and multiple transcription start points in the 5 -untranslated region of the human cathepsin-B-encoding gene. Gene 159, 143-149.

Blakely A, Gorman K, Ostergaard H, Svoboda K, Liu CC, Young JD, Clark WR (1987): Resistance of cloned cytotoxic $\mathrm{T}$ lymphocytes to cell-mediated cytotoxicity. J Exp Med 166, 1070-1083. 
Bogyo M, Verhelst S, Bellingard-Dubouchaud V, Toba S, Greenbaum D (2000): Selective targeting of lysosomal cysteine proteases with radiolabeled electrophilic substrate analogs. Chem Biol $\underline{7}$, 27-38.

Boon T, van der Bruggen $P$ (1996): Human tumor antigens recognized by $T$ lymphocytes. J Exp Med 183, 725-729.

Boon T, Cerottini JC, Van den Eynde B, van der Bruggen P, Van Pel A (1994): Tumor antigens recognized by T lymphocytes. Annu Rev Immunol 12, 337-365.

Brix K, Linke M, Tepel C, Herzog V (2001): Cysteine proteinases mediate extracellular prohormone processing in the thyroid. Biol Chem $\underline{382}, 717-725$.

Brunner KT, Mauel J, Cerottini JC, Chapuis B (1968): Quantitative assay of the lytic action of immune lymphoid cells on 51-Cr-labelled allogeneic target cells in vitro; inhibition by isoantibody and by drugs. Immunology $\underline{14}$, 181-196.

Buhling F, Waldburg N, Reisenauer A, Heimburg A, Golpon H, Welte T (2004): Lysosomal cysteine proteases in the lung: role in protein processing and immunoregulation. Eur Respir J 23, 620-628.

Burnet FM (1970): The concept of immunological surveillance. Prog Exp Tumor Res 13, 1-27.

Burnett D, Abrahamson M, Devalia JL, Sapsford RJ, Davies RJ, Buttle DJ (1995): Synthesis and secretion of procathepsin B and cystatin C by human bronchial epithelial cells in vitro: modulation of cathepsin B activity by neutrophil elastase. Arch Biochem Biophys $\underline{317}$, 305-310.

Buttle DJ, Murata M, Knight CG, Barrett AJ (1992): CA074 methyl ester: a proinhibitor for intracellular cathepsin B. Arch Biochem Biophys 299, 377-380.

Campo E, Munoz J, Miquel R, Palacin A, Cardesa A, Sloane BF, Emmert-Buck MR (1994): Cathepsin B expression in colorectal carcinomas correlates with tumor progression and shortened patient survival. Am J Pathol 145, 301-309.

Cao L, Taggart RT, Berquin IM, Moin K, Fong D, Sloane BF (1994): Human gastric adenocarcinoma cathepsin $\mathrm{B}$ : isolation and sequencing of full-length cDNAs and polymorphisms of the gene. Gene 139, 163-169.

Catalfamo M, Henkart PA (2003): Perforin and the granule exocytosis cytotoxicity pathway. Curr Opin Immunol 15, 522-527.

Cavallo-Medved D, Sloane BF (2003): Cell-surface cathepsin B: understanding its functional significance. Curr Top Dev Biol $\underline{54}$, 313-341. 
Chen Q, Daniel V, Maher DW, Hersey P (1994): Production of IL-10 by melanoma cells: examination of its role in immunosuppression mediated by melanoma. Int J Cancer $\underline{56}$, 755-760.

Colella R, Casey SF (2003): Decreased activity of cathepsins L + B and decreased invasive ability of PC3 prostate cancer cells. Biotech Histochem $\underline{78}$, 101-108.

Dancescu M, Rubio-Trujillo M, Biron G, Bron D, Delespesse G, Sarfati M (1992): Interleukin 4 protects chronic lymphocytic leukemic B cells from death by apoptosis and upregulates Bcl-2 expression. J Exp Med 176, 1319-1326.

Danial NN, Korsmeyer SJ (2004): Cell death: critical control points. Cell $\underline{116}$, 205-219.

Demchik LL, Sameni M, Nelson K, Mikkelsen T, Sloane BF (1999): Cathepsin B and glioma invasion. Int J Dev Neurosci 17, 483-494.

Dressel R, Raja SM, Honing S, Seidler T, Froelich CJ, von Figura K, Gunther E (2004): Granzyme-mediated cytotoxicity does not involve the mannose 6phosphate receptors on target cells. J Biol Chem 279, 20200-20210.

Dunn GP, Bruce AT, Ikeda H, Old LJ, Schreiber RD (2002): Cancer immunoediting: from immunosurveillance to tumor escape. Nat Immunol $\underline{3}$, 991998.

Emmert-Buck MR, Roth MJ, Zhuang Z, Campo E, Rozhin J, Sloane BF, Liotta LA, Stetler-Stevenson WG (1994): Increased gelatinase A (MMP-2) and cathepsin B activity in invasive tumor regions of human colon cancer samples. Am J Pathol 145, 1285-1290.

Foghsgaard L, Wissing D, Mauch D, Lademann U, Bastholm L, Boes M, Elling F, Leist M, Jaattela M (2001): Cathepsin B acts as a dominant execution protease in tumor cell apoptosis induced by tumor necrosis factor. J Cell Biol $\underline{153}, 999-1010$.

Fong D, Chan MM, Hsieh WT, Menninger JC, Ward DC (1992): Confirmation of the human cathepsin B gene (CTSB) assignment to chromosome 8. Hum Genet $\underline{89}, 10-12$.

Froelich CJ, Orth K, Turbov J, Seth P, Gottlieb R, Babior B, Shah GM, Bleackley RC, Dixit VM, Hanna W (1996): New paradigm for lymphocyte granule-mediated cytotoxicity. Target cells bind and internalize granzyme B, but an endosomolytic agent is necessary for cytosolic delivery and subsequent apoptosis. J Biol Chem 271, 29073-29079. 
Frohlich E, Schlagenhauff B, Mohrle M, Weber E, Klessen C, Rassner G (2001): Activity, expression, and transcription rate of the cathepsins B, D, H, and $L$ in cutaneous malignant melanoma. Cancer $\underline{91}$, 972-982.

Frosch BA, Berquin I, Emmert-Buck MR, Moin K, Sloane BF (1999): Molecular regulation, membrane association and secretion of tumor cathepsin B. APMIS 107, 28-37.

Gorelik L, Flavell RA (2001): Immune-mediated eradication of tumors through the blockade of transforming growth factor-beta signaling in T cells. Nat Med $\underline{7}$, 1118-1122.

Grakoui A, Bromley SK, Sumen C, Davis MM, Shaw AS, Allen PM, Dustin ML (1999): The immunological synapse: a molecular machine controlling $\mathrm{T}$ cell activation. Science $\underline{285}, 221-227$.

Groscurth P, Filgueira L (1998): Killing Mechanisms of Cytotoxic T Lymphocytes. News Physiol Sci 13, 17-21.

Guicciardi ME, Deussing J, Miyoshi H, Bronk SF, Svingen PA, Peters C, Kaufmann SH, Gores GJ (2000): Cathepsin B contributes to TNF-alphamediated hepatocyte apoptosis by promoting mitochondrial release of cytochrome c. J Clin Invest $\underline{106}, 1127-1137$.

Guicciardi ME, Miyoshi H, Bronk SF, Gores GJ (2001): Cathepsin B knockout mice are resistant to tumor necrosis factor-alpha-mediated hepatocyte apoptosis and liver injury: implications for therapeutic applications. Am J Pathol $\underline{159}$, 2045-2054.

Hanabuchi S, Koyanagi M, Kawasaki A, Shinohara N, Matsuzawa A, Nishimura Y, Kobayashi Y, Yonehara S, Yagita H, Okumura K (1994): Fas and its ligand in a general mechanism of T-cell-mediated cytotoxicity. Proc Natl Acad Sci U S A 91, 4930-4934.

Hanewinkel H, Glossl J, Kresse H (1987): Biosynthesis of cathepsin B in cultured normal and I-cell fibroblasts. J Biol Chem 262, 12351-12355.

Henkart PA (1994): Lymphocyte-mediated cytotoxicity: two pathways and multiple effector molecules. Immunity $\underline{1}$, 343-346.

Heuser J (1989): Changes in lysosome shape and distribution correlated with changes in cytoplasmic $\mathrm{pH}$. J Cell Biol 108, 855-864. 
Hogquist KA, Jameson SC, Heath WR, Howard JL, Bevan MJ, Carbone FR (1994): T cell receptor antagonist peptides induce positive selection. Cell $\underline{76}$, 17-27.

Hook V, Schechter I, Demuth HU, Hook G (2008): Alternative pathways for production of beta-amyloid peptides of Alzheimer's disease. Biol Chem $\underline{389}$, 993-1006.

Hughes SJ, Glover TW, Zhu XX, Kuick R, Thoraval D, Orringer MB, Beer DG, Hanash S (1998): A novel amplicon at 8p22-23 results in overexpression of cathepsin B in esophageal adenocarcinoma. Proc Natl Acad Sci U S A $\underline{95}$, 12410-12415.

Jiang SB, Ojcius DM, Persechini PM, Young JD (1990): Resistance of cytolytic lymphocytes to perforin-mediated killing. Inhibition of perforin binding activity by surface membrane proteins. J Immunol 144, 998-1003.

Jones EY, Tormo J, Reid SW, Stuart DI (1998): Recognition surfaces of MHC class I. Immunol Rev $\underline{163}$, 121-128.

Kageshita T, Hirai S, Ono T, Hicklin DJ, Ferrone S (1999): Down-regulation of HLA class I antigen-processing molecules in malignant melanoma: association with disease progression. Am J Pathol 154, 745-754.

Kagi D, Ledermann B, Burki K, Seiler P, Odermatt B, Olsen KJ, Podack ER, Zinkernagel RM, Hengartner H (1994): Cytotoxicity mediated by T cells and natural killer cells is greatly impaired in perforin-deficient mice. Nature $\underline{369}$, 3137.

Kirschke H, Barrett AJ, Rawlings ND (1995): Proteinases 1: lysosomal cysteine proteinases. Protein Profile 2, 1581-1643.

Kranz DM, Eisen HN (1987): Resistance of cytotoxic T lymphocytes to lysis by a clone of cytotoxic T lymphocytes. Proc Natl Acad Sci U S A 84, 3375-3379.

Krepela E, Vicar J, Cernoch M (1989): Cathepsin B in human breast tumor tissue and cancer cells. Neoplasma $\underline{36}$, 41-52.

Krueger S, Haeckel C, Buehling F, Roessner A (1999): Inhibitory effects of antisense cathepsin B cDNA transfection on invasion and motility in a human osteosarcoma cell line. Cancer Res 59, 6010-6014.

Kvist S, Wiman K, Claesson L, Peterson PA, Dobberstein B (1982): Membrane insertion and oligomeric assembly of HLA-DR histocompatibility antigens. Cell $\underline{29}, 61-69$. 
Lang A, Horler D, Baici A (2000): The relative importance of cysteine peptidases in osteoarthritis. J Rheumatol 27, 1970-1979.

Lemaire R, Huet G, Zerimech F, Grard G, Fontaine C, Duquesnoy B, Flipo RM (1997): Selective induction of the secretion of cathepsins $B$ and $L$ by cytokines in synovial fibroblast-like cells. $\mathrm{Br} \mathrm{J}$ Rheumatol $\underline{36}, 735-743$.

Lenschow DJ, Walunas TL, Bluestone JA (1996): CD28/B7 system of T cell costimulation. Annu Rev Immunol 14, 233-258.

Lieberman J (2003): The ABCs of granule-mediated cytotoxicity: new weapons in the arsenal. Nat Rev Immunol $\underline{3}, 361-370$.

Linebaugh BE, Sameni M, Day NA, Sloane BF, Keppler D (1999): Exocytosis of active cathepsin $\mathrm{B}$ enzyme activity at $\mathrm{pH} 7.0$, inhibition and molecular mass. Eur J Biochem 264, 100-109.

Liu CC, Jiang S, Persechini PM, Zychlinsky A, Kaufmann Y, Young JD (1989): Resistance of cytolytic lymphocytes to perforin-mediated killing. Induction of resistance correlates with increase in cytotoxicity. J Exp Med 169, 2211-2225.

Liu Y, Xiao S, Shi Y, Wang L, Ren W, Sloane BF (1998): Cathepsin B on invasion and metastasis of gastric carcinoma. Chin Med J (Engl) 111, 784-788.

Lord SJ, Rajotte RV, Korbutt GS, Bleackley RC (2003): Granzyme B: a natural born killer. Immunol Rev 193, 31-38.

Lorenzo K, Ton P, Clark JL, Coulibaly S, Mach L (2000): Invasive properties of murine squamous carcinoma cells: secretion of matrix-degrading cathepsins is attributable to a deficiency in the mannose 6-phosphate/insulin-like growth factor II receptor. Cancer Res $\underline{60}, 4070-4076$.

Lotem J, Sachs L (1996): Differential suppression by protease inhibitors and cytokines of apoptosis induced by wild-type p53 and cytotoxic agents. Proc Natl Acad Sci U S A 93, 12507-12512.

Lowin B, Hahne M, Mattmann C, Tschopp J (1994): Cytolytic T-cell cytotoxicity is mediated through perforin and Fas lytic pathways. Nature $\underline{370}, 650-652$.

Luciani MF, Brunet JF, Suzan M, Denizot F, Golstein P (1986): Self-sparing of long-term in vitro-cloned or uncloned cytotoxic T lymphocytes. J Exp Med 164, 962-967. 
Mach L, Stuwe K, Hagen A, Ballaun C, Glossl J (1992): Proteolytic processing and glycosylation of cathepsin $\mathrm{B}$. The role of the primary structure of the latent precursor and of the carbohydrate moiety for cell-type-specific molecular forms of the enzyme. Biochem J 282 (Pt 2), 577-582.

Maffei A, Papadopoulos K, Harris PE (1997): MHC class I antigen processing pathways. Hum Immunol $\underline{54}$, 91-103.

Mai J, Finley RL, Jr., Waisman DM, Sloane BF (2000): Human procathepsin B interacts with the annexin II tetramer on the surface of tumor cells. J Biol Chem $\underline{275}, 12806-12812$.

Marincola FM, Jaffee EM, Hicklin DJ, Ferrone S (2000): Escape of human solid tumors from T-cell recognition: molecular mechanisms and functional significance. Adv Immunol 74, 181-273.

Marrack P, Kappler J (1987): The T cell receptor. Science 238, 1073-1079.

McGrath ME (1999): The lysosomal cysteine proteases. Annu Rev Biophys Biomol Struct 28, 181-204.

Moin K, Day NA, Sameni M, Hasnain S, Hirama T, Sloane BF (1992): Human tumour cathepsin B. Comparison with normal liver cathepsin B. Biochem J $\underline{285}$ (Pt 2), 427-434.

Montaser M, Lalmanach G, Mach L (2002): CA-074, but not its methyl ester CA$074 \mathrm{Me}$, is a selective inhibitor of cathepsin B within living cells. Biol Chem $\underline{383}$, 1305-1308.

Morse MA, Clay TM, Mosca P, Lyerly HK (2002): Immunoregulatory T cells in cancer immunotherapy. Expert Opin Biol Ther 2, 827-834.

Mort JS, Buttle DJ (1997): Cathepsin B. Int J Biochem Cell Biol 29, 715-720.

Motyka B, Korbutt G, Pinkoski MJ, Heibein JA, Caputo A, Hobman M, Barry M, Shostak I, Sawchuk T, Holmes CF (2000): Mannose 6-phosphate/insulin-like growth factor II receptor is a death receptor for granzyme B during cytotoxic $T$ cell-induced apoptosis. Cell 103, 491-500.

Muller C, Tschopp J (1994): Resistance of CTL to perforin-mediated lysis. Evidence for a lymphocyte membrane protein interacting with perforin. J Immunol 153, 2470-2478. 
Murnane MJ, Sheahan K, Ozdemirli M, Shuja S (1991): Stage-specific increases in cathepsin B messenger RNA content in human colorectal carcinoma. Cancer Res $\underline{51}, 1137-1142$.

Nagaraj NS, Vigneswaran N, Zacharias W (2006): Cathepsin B mediates TRAIL-induced apoptosis in oral cancer cells. J Cancer Res Clin Oncol 132, 171-183.

Nagata S, Golstein P (1995): The Fas death factor. Science 267, 1449-1456.

Nishimura $\mathrm{Y}$, Kawabata $\mathrm{T}$, Kato K (1988): Identification of latent procathepsins $B$ and $L$ in microsomal lumen: characterization of enzymatic activation and proteolytic processing in vitro. Arch Biochem Biophys 261, 64-71.

Ochsenbein AF (2005): Immunological ignorance of solid tumors. Springer Semin Immunopathol 27, 19-35.

Pawelec G (2004): Tumour escape from the immune response. Cancer Immunol Immunother $\underline{53}, 843$.

Podgorski I, Sloane BF (2003): Cathepsin B and its role(s) in cancer progression. Biochem Soc Symp 므, 263-276.

Poole AR, Tiltman KJ, Recklies AD, Stoker TA (1978): Differences in secretion of the proteinase cathepsin $B$ at the edges of human breast carcinomas and fibroadenomas. Nature $273,545-547$.

Qian F, Bajkowski AS, Steiner DF, Chan SJ, Frankfater A (1989): Expression of five cathepsins in murine melanomas of varying metastatic potential and normal tissues. Cancer Res 노, 4870-4875.

Recklies AD, Poole AR, Mort JS (1982): A cysteine proteinase secreted from human breast tumours is immunologically related to cathepsin B. Biochem $\mathrm{J}$ 207, 633-636.

Reinheckel T, Deussing J, Roth W, Peters C (2001): Towards specific functions of lysosomal cysteine peptidases: phenotypes of mice deficient for cathepsin $B$ or cathepsin L. Biol Chem $\underline{382}$, 735-741.

Rempel SA, Rosenblum ML, Mikkelsen T, Yan PS, Ellis KD, Golembieski WA, Sameni M, Rozhin J, Ziegler G, Sloane BF (1994): Cathepsin B expression and localization in glioma progression and invasion. Cancer Res $\underline{54}$, 6027-6031.

Ribarska T, Dressel R, Göttingen:persönliche Mitteilung 2005 
Roberts LR, Kurosawa H, Bronk SF, Fesmier PJ, Agellon LB, Leung WY, Mao F, Gores GJ (1997): Cathepsin B contributes to bile salt-induced apoptosis of rat hepatocytes. Gastroenterology $\underline{113}, 1714-1726$.

Roshy S, Sloane BF, Moin K (2003): Pericellular cathepsin B and malignant progression. Cancer Metastasis Rev 22, 271-286.

Rowan AD, Mason P, Mach L, Mort JS (1992): Rat procathepsin B. Proteolytic processing to the mature form in vitro. J Biol Chem 267, 15993-15999.

Rozhin J, Sameni M, Ziegler G, Sloane BF (1994): Pericellular pH affects distribution and secretion of cathepsin B in malignant cells. Cancer Res $\underline{54}$, 6517-6525.

Russell JH, Ley TJ (2002): Lymphocyte-mediated cytotoxicity. Annu Rev Immunol 20, 323-370.

Sakaguchi S, Sakaguchi N, Shimizu J, Yamazaki S, Sakihama T, Itoh M, Kuniyasu Y, Nomura T, Toda M, Takahashi T (2001): Immunologic tolerance maintained by CD25+ CD4+ regulatory T cells: their common role in controlling autoimmunity, tumor immunity, and transplantation tolerance. Immunol Rev 182, 18-32.

Sandes E, Lodillinsky C, Cwirenbaum R, Arguelles C, Casabe A, Eijan AM (2007): Cathepsin B is involved in the apoptosis intrinsic pathway induced by Bacillus Calmette-Guerin in transitional cancer cell lines. Int J Mol Med 20, 823828.

Sarin A, Williams MS, Alexander-Miller MA, Berzofsky JA, Zacharchuk CM, Henkart PA (1997): Target cell lysis by CTL granule exocytosis is independent of ICE/Ced-3 family proteases. Immunity $\underline{6}$, 209-215.

Schirrmacher V, Schild HJ, Guckel B, von Hoegen P (1993): Tumour-specific $C T L$ response requiring interactions of four different cell types and recognition of $\mathrm{MHC}$ class I and class II restricted tumour antigens. Immunol Cell Biol $\underline{71(\mathrm{Pt}}$ 4), 311-326.

Scorilas A, Fotiou S, Tsiambas E, Yotis J, Kotsiandri F, Sameni M, Sloane BF, Talieri M (2002): Determination of cathepsin B expression may offer additional prognostic information for ovarian cancer patients. Biol Chem $\underline{383}, 1297-1303$.

Shankaran V, Ikeda H, Bruce AT, White JM, Swanson PE, Old LJ, Schreiber RD (2001): IFNgamma and lymphocytes prevent primary tumour development and shape tumour immunogenicity. Nature $\underline{410}, 1107-1111$. 
Sinha AA, Gleason DF, Deleon OF, Wilson MJ, Sloane BF (1993): Localization of a biotinylated cathepsin $B$ oligonucleotide probe in human prostate including invasive cells and invasive edges by in situ hybridization. Anat Rec $\underline{235}$, 233240.

Sivaparvathi M, Sawaya R, Wang SW, Rayford A, Yamamoto M, Liotta LA, Nicolson GL, Rao JS (1995): Overexpression and localization of cathepsin B during the progression of human gliomas. Clin Exp Metastasis 13, 49-56.

Sloane BF, Dunn JR, Honn KV (1981): Lysosomal cathepsin B: correlation with metastatic potential. Science 212, 1151-1153.

Sloane BF, Moin K, Sameni M, Tait LR, Rozhin J, Ziegler G (1994): Membrane association of cathepsin $B$ can be induced by transfection of human breast epithelial cells with c-Ha-ras oncogene. J Cell Sci 107 (Pt 2), 373-384.

Smyth MJ, Thia KY, Street SE, MacGregor D, Godfrey DI, Trapani JA (2000): Perforin-mediated cytotoxicity is critical for surveillance of spontaneous lymphoma. J Exp Med 192, 755-760.

Stahl S, Reinders Y, Asan E, Mothes W, Conzelmann E, Sickmann A, Felbor U (2007): Proteomic analysis of cathepsin B- and L-deficient mouse brain lysosomes. Biochim Biophys Acta 1774, 1237-1246.

Stoka V, Turk B, Schendel SL, Kim TH, Cirman T, Snipas SJ, Ellerby LM, Bredesen D, Freeze H, Abrahamson M (2001): Lysosomal protease pathways to apoptosis. Cleavage of bid, not pro-caspases, is the most likely route. J Biol Chem 276, 3149-3157.

Szpaderska AM, Frankfater A (2001): An intracellular form of cathepsin B contributes to invasiveness in cancer. Cancer Res $\underline{61}$, 3493-3500.

Taha TA, Kitatani K, Bielawski J, Cho W, Hannun YA, Obeid LM (2005): Tumor necrosis factor induces the loss of sphingosine kinase-1 by a cathepsin Bdependent mechanism. J Biol Chem 280, 17196-17202.

Thomas L (1982): On immunosurveillance in human cancer. Yale J Biol Med 55, 329-333.

Trabandt A, Gay RE, Fassbender HG, Gay S (1991): Cathepsin B in synovial cells at the site of joint destruction in rheumatoid arthritis. Arthritis Rheum $\underline{34}$, 1444-1451.

Trapani JA (1998): Dual mechanisms of apoptosis induction by cytotoxic lymphocytes. Int Rev Cytol 182, 111-192. 
Turk BE, Huang LL, Piro ET, Cantley LC (2001): Determination of protease cleavage site motifs using mixture-based oriented peptide libraries. Nat Biotechnol 19, 661-667.

Turk V, Bode W (1991): The cystatins: protein inhibitors of cysteine proteinases. FEBS Lett 285, 213-219.

Verret CR, Firmenich AA, Kranz DM, Eisen HN (1987): Resistance of cytotoxic T lymphocytes to the lytic effects of their toxic granules. J Exp Med 166, 15361547.

Werle B, Ebert W, Klein W, Spiess E (1994): Cathepsin B in tumors, normal tissue and isolated cells from the human lung. Anticancer Res $\underline{14}, 1169-1176$.

Wyllie AH (1997): Apoptosis: an overview. Br Med Bull 53, 451-465.

Xia P, Wang L, Moretti PA, Albanese N, Chai F, Pitson SM, D'Andrea RJ, Gamble JR, Vadas MA (2002): Sphingosine kinase interacts with TRAF2 and dissects tumor necrosis factor-alpha signaling. J Biol Chem 277, 7996-8003.

Yan S, Sameni M, Sloane BF (1998): Cathepsin B and human tumor progression. Biol Chem $\underline{379}, 113-123$.

Young JD, Hengartner H, Podack ER, Cohn ZA (1986): Purification and characterization of a cytolytic pore-forming protein from granules of cloned lymphocytes with natural killer activity. Cell $\underline{44}$, 849-859.

Young JD, Damiano A, DiNome MA, Leong LG, Cohn ZA (1987): Dissociation of membrane binding and lytic activities of the lymphocyte pore-forming protein (perforin). J Exp Med 165, 1371-1382.

Yue FY, Dummer R, Geertsen R, Hofbauer G, Laine E, Manolio S, Burg G (1997): Interleukin-10 is a growth factor for human melanoma cells and downregulates HLA class-I, HLA class-II and ICAM-1 molecules. Int J Cancer $\underline{71}$, 630-637. 


\section{Danksagung}

Mein Dank gilt PD Dr. med. R. Dressel für die Überlassung des interessanten Themas, die gute Betreuung, die Freundlichkeit und die stete Diskussionsbereitschaft.

Bei Dr. rer. nat. T. Reinheckel und Prof. Dr. med. C. Peters, Institut für Molekulare Medizin und Zellforschung der Universität Freiburg, bedanke ich mich für die Bereitstellung der Fibroblasten, ohne die ein Teil der Experimente nicht möglich gewesen wäre.

Sehr herzlich danke ich auch Leslie Elsner. Als LTA in unserem Labor brachte sie mir vieles über die grundlegenden Arbeitstechniken bei und war mir mit ihrer Erfahrung eine große Unterstützung. Trotz aller Arbeit hatte sie stets ein offenes Ohr für die kleinen und großen Probleme der Doktoranden.

Bei Frau Jingky Lozano aus der Abteilung Genetische Epidemiologie der Universität Göttingen bedanke ich mich sehr herzlich für die Hilfe bei der statistischen Analyse.

Auch bedanken möchte ich mich bei allen Mitarbeitern der Arbeitsgruppe, vor allem bei Frau Sara Demiroglu, für die stetige Hilfsbereitschaft, die nette Arbeitsatmosphäre und die anregenden Diskussionen.

Außerdem gilt mein Dank Jens Scholz für seine unermütliche Hilfe bei allen Fragen und Problemen rund um den Computer.

Schließlich gilt mein großer Dank meiner Mutter. Sie ermöglichte mir das Medizinstudium und gab mir den nötigen Rückhalt und die Kraft, mein Studium und diese Dissertation abzuschließen. 


\section{Lebenslauf}

Am 15.02.1981 wurde ich, Miriam Ensslen, als Tochter der Eheleute Carola Ensslen und Hugo Ensslen in Offenbach am Main geboren.

Von 1987 - 1991 besuchte ich die Grundschule „Kerschensteiner“ in Frankfurt am Main. Im Jahr 1991 kam ich auf das „Heinrich-von-Gagern-Gymnasium“ in Frankfurt am Main, welches ich bis 1995 besuchte. Von 1995 bis 2000 besuchte ich das „Kaiserin-Friedrich-Gymnasium“ in Bad Homburg vor der Höhe. Im Mai 2000 erlangte ich die Allgemeine Hochschulreife. Von Juni 2000 bis Juli 2002 war ich als Verkaufsberaterin bei der E-Plus Service GmbH tätig. Im August und September 2002 besuchte ich einen RettungssanitäterLehrgang.

Im Oktober 2002 nahm ich das Studium der Humanmedizin an der GeorgAugust-Universität in Göttingen auf und bestand im September 2004 die Ärztliche Vorprüfung. Das Studium schloss ich im November 2008 mit bestandener 2. Ärztlicher Prüfung ab. Seit November 2008 arbeite ich an der Fertigstellung der vorliegenden Dissertation. 